Florida International University FIU Digital Commons

6-11-2014

\title{
Cognitive behavior therapy for anxiety disorders in youth: Treatment specificity and mediation effects
}

Ileana Hernandez

Florida International University, ihern003@fiu.edu

DOI: $10.25148 /$ etd.FI14071132

Follow this and additional works at: https://digitalcommons.fiu.edu/etd

Part of the Child Psychology Commons, Clinical Psychology Commons, and the Developmental Psychology Commons

\section{Recommended Citation}

Hernandez, Ileana, "Cognitive behavior therapy for anxiety disorders in youth: Treatment specificity and mediation effects" (2014). FIU Electronic Theses and Dissertations. 1423.

https://digitalcommons.fiu.edu/etd/1423 


\section{FLORIDA INTERNATIONAL UNIVERSITY \\ Miami, Florida}

\section{COGNITIVE BEHAVIOR THERAPY FOR ANXIETY DISORDERS IN YOUTH:}

TREATMENT SPECIFICITY AND MEDIATION EFFECTS

A dissertation submitted in partial fulfillment of the

requirements for the degree of

DOCTOR OF PHILOSOPHY

in

PSYCHOLOGY

by

Ileana Hernandez 
To: Dean Kenneth G. Furton

College of Arts and Sciences

This dissertation, written by Ileana Hernandez, and entitled Cognitive Behavior Therapy for Anxiety Disorders in Youth: Treatment Specificity and Mediation Effects, having been approved in respect to style and intellectual content, is referred to you for judgment.

We have read this dissertation and recommend that it be approved.

Maureen C. Kenny

Mary J. Levitt

Wendy K. Silverman, Co-Major Professor

Jeremy Pettit, Co-Major Professor

Date of Defense: June 11, 2014

The thesis of Ileana Hernandez is approved.

$\begin{array}{r}\text { Dean Michael R. Heithaus } \\ \text { Interim Dean, College of Arts and Sciences } \\ \hline \begin{array}{r}\text { Dean Lakshmi N. Reddi } \\ \text { University Graduate School }\end{array}\end{array}$

Florida International University, 2014 


\section{ABSTRACT OF THE DISSERTATION \\ COGNITIVE BEHAVIOR THERAPY FOR ANXIETY DISORDERS IN YOUTH: TREATMENT SPECIFICITY AND MEDIATION EFFECTS \\ by}

Ileana Hernandez

Florida International University, 2014

Miami, Florida

Professor Jeremy Pettit, Co-Major Professor

Professor Wendy K. Silverman, Co-Major Professor

The present study investigated the efficacies of Individual CBT (ICBT), Parent Relationship Skill Training (RLST, which targets increasing parental acceptance of youth and increasing autonomy granting) and Parent Reinforcement Skills Training (RLST, which targets increasing parental positive reinforcement and decreasing negative reinforcement). The specific aims were to examine treatment specificity and mediation effects of parenting variables. ICBT was used as a baseline comparison condition.

The sample consisted of 253 youth (ages 5-16 years; $M=9.38 ; S D=2.42$ ) and their parents. To examine treatment outcome and specificity, the data were analyzed using analysis of variance within a structural equation modeling framework. Mediation was analyzed via structural equation modeling using MPlus.

Results indicated that ICBT, RLST, and RFST produced positive treatment outcomes across all indices of change (i.e., clinically significant improvement, anxiety symptom reduction) and across all informants (i.e., youths and parents). RLST was associated with incremental reduction in youth anxiety symptoms beyond ICBT, as per 
youth report. Treatment specificity effects were found for participants in RFST in terms of parental reinforcement, as per parent report only. Treatment mediation was not found for any of the hypothesized parenting variables (i.e., parental acceptance, parental autonomy granting, parental reinforcement). The results support the use of CBT involving only the youth and the parent and youth together for treating youth anxiety. The findings' implications are further discussed in terms of the need to conduct further meditational treatment outcome designs in order to continue to advance theory and research in youth anxiety treatment. 


\section{TABLE OF CONTENTS}

CHAPTER

PAGE

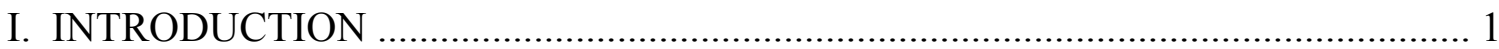

Psychosocial Interventions for Anxiety Disorders in Youth ................... 1

II. LITERATURE REVIEW ................................................. 8

Parenting Variables Associated with Youth Anxiety ........................ 9

Parental Involvement in Youth Anxiety Treatment ........................... 14

Treatment Mediation ................................................ 26

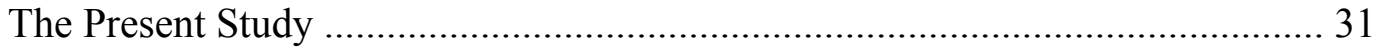

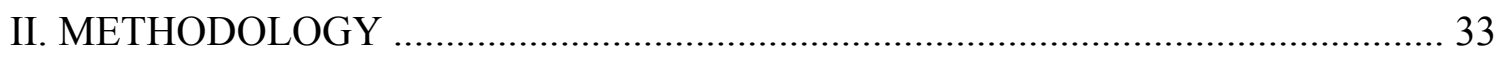

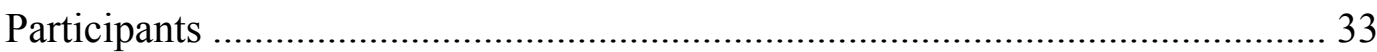

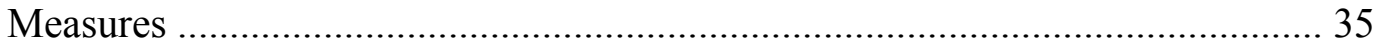

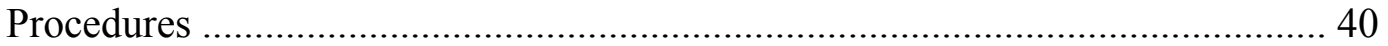

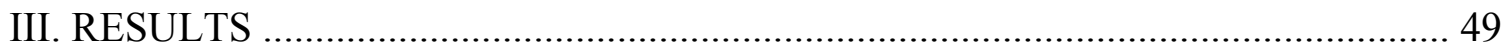

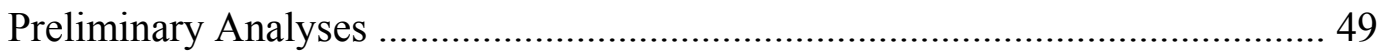

Treatment Outcome ...................................................... 50

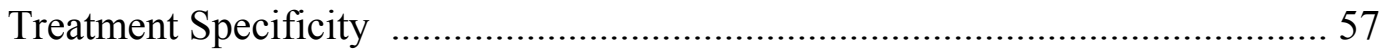

Treatment Mediation Analyses........................................ 64

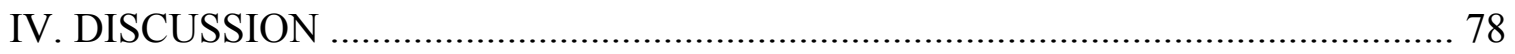

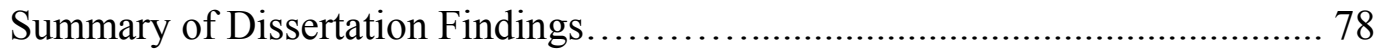

Contribution of the Present Study and Implications........................ 80

Limitations and Future Research Directions ............................. 84

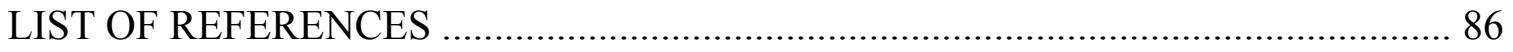

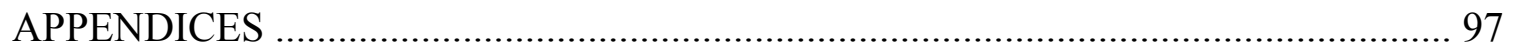

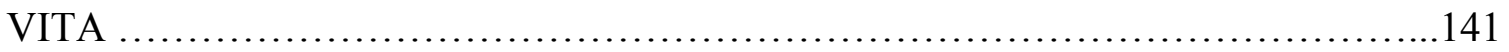




\section{LIST OF TABLES}

TABLE

PAGE

1. Demographic and Diagnostic Information by Treatment Condition................ 98

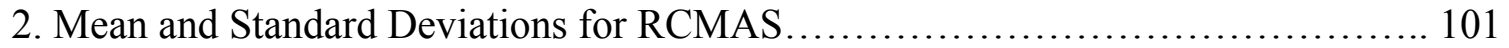

3. Single Degree of Freedom Contrasts: Treatment Outcome, RCMAS.............. 102

4. Mean and Standard Deviations for MASC ................................... 103

5. Single Degree of Freedom Contrasts: Treatment Outcome, MASC ................. 104

6. Mean and Standard Deviations for RCMAS-P ............................... 105

7. Single Degree of Freedom Contrasts: Treatment Outcome, RCMAS-P..............106

8. Single Degree of Freedom Contrasts: Treatment Specificity, CDQ-C-PR/NR ...... 107

9. Single Degree of Freedom Contrasts: Treatment Specificity, CRPBI-A/PC.........108

10. Single Degree of Freedom Contrasts: Treatment Specificity, CDQ-PR/NR ....... 109

11. Single Degree of Freedom Contrasts: Treatment Specificity, PRPBI-A/PC ....... 110

12. Mean (Standard Deviations) for Youth Completed Mediator Measures..............111

13. Mean (Standard Deviations) for Parent Completed Mediator Measures............ 112 


\section{LIST OF FIGURES}

FIGURE

PAGE

1. Conceptual Model for Parental Positive Reinforcement........................ 113

2. Conceptual Model for Parental Negative Reinforcement........................114

3. Conceptual Model for Parental Acceptance....................................115

4. Conceptual Model for Parental Psychological Control...........................116

5a. CDQ-C-PR RCMAS Model with ICBT as Reference Group......................117

5b. CDQ-C-PR RCMAS Model with RLST as Reference Group.....................118

6a. CDQ-C-NR RCMAS Model with ICBT as Reference Group.......................119

6b. CDQ-C-NR RCMAS Model with RLST as Reference Group....................120

7a. CRPBI-A RCMAS Model with ICBT as Reference Group....................... 121

7b. CPRBI-A RCMAS Model with RLST as Reference Group.................... 122

8a. CRPBI-PC RCMAS Model with ICBT as Reference Group.....................123

8b. CRPBI-PC RCMAS Model with RLST as Reference Group.................... 124

9a. CDQ-C-PR MASC Model with ICBT as Reference Group......................125

9b. CDQ-C-PR MASC Model with RLST as Reference Group......................126

10a. CDQ-C-NR MASC Model with ICBT as Reference Group.....................127

10b. CDQ-C-NR MASC Model with RLST as Reference Group......................128

11a. CRPBI-A MASC Model with ICBT as Reference Group......................129 
11b. CPRBI-A MASC Model with RLST as Reference Group........................130

12a. CRPBI-PC MASC Model with ICBT as Reference Group .......................131

12b. CRPBI-PC MASC Model with RLST as Reference Group......................132

13a. CDQ-PR RCMAS-P Model with ICBT as Reference Group.......................133

13b. CDQ-PR RCMAS-P Model with RLST as Reference Group.....................134

14a. CDQ-NR RCMAS-P Model with ICBT as Reference Group......................135

14b. CDQ-NR RCMAS-P Model with RLST as Reference Group.....................136

15a. PRPBI-A RCMAS-P Model with ICBT as Reference Group......................137

15b. PPRBI-A RCMAS-P Model with RLST as Reference Group....................138

16a. PRPBI-PC RCMAS-P Model with ICBT as Reference Group.....................139

16b. PRPBI-PC RCMAS-P Model with RLST as Reference Group....................140 


\section{CHAPTER I. \\ INTRODUCTION}

Anxiety disorders are among the most common psychological problems reported in children and adolescents (e.g., Copeland, Shanahan, Costello, \& Angold 2009; Costello, Egger, Copeland, Erkanli, \& Angold, 2011; Mattison, 1992). (Hereafter, children and adolescents are referred to as youth, unless when referring to a specific developmental stage.) Although experiencing fear and anxiety occurs as part of most youths' normative development, for some this fear and anxiety may develop into a clinically diagnosable disorder when it intensifies, interferes with functioning, and persists over time (Last, Perrin, Hersen, \& Kazdin, 1996).

The reported prevalence rates of anxiety disorders in youth vary widely in both community and clinical samples, largely as a function of whether impairment in functioning is evaluated. When functional impairment is evaluated, prevalence rates tend to be lower and more consistent across studies, with reported mean estimates of $11 \%$ for any anxiety disorder for children 6 to 12 years of age and $10.2 \%$ for adolescents 13 and 18 years of age (Costello et al., 2011). If left untreated, anxiety disorders can have a negative impact on later adjustment, leading to the development of other anxiety disorders, depressive disorders, substance use disorders, and suicide-related behaviors (e.g., Cole, Peeke, Martin, Truglio, \& Serocynski, 1998; Hill, Castellanos, \& Pettit, 2011; Saavedra, Silverman, Morgan-Lopez, \& Kurtines, 2010).

\section{Psychosocial Interventions for Anxiety Disorders in Youth}

Randomized clinical trials (RCT) have provided evidence for the efficacy of cognitive behavioral therapy (CBT) in reducing anxiety disorders in youth (see review by 
Silverman, Pina, and Viswesvaran, 2008). CBTs have been found to be efficacious when delivered in formats involving only the youth (e.g., Compton et al., 2014; Hollen \& Beck, 2013; Kendall, 1994; Kendall, Flannery-Schroeder, Panichelli-Mindel, Southam-Gerow, Henin, \& Warman, 1997) and the parent and youth together (e.g., Barrett, Dadds, \& Rapee, 1996; Silverman, Kurtines, Jaccard, \& Pina, 2009).

Although the evidence for $\mathrm{CBT}$ delivered to youths and $\mathrm{CBT}$ delivered to parents and youths together has generally been positive, there exists room for improvement. Early studies evaluating the effects of parent involvement in CBTs demonstrated enhanced effects on some outcome measures (Barret et al., 1996a; Cobham, Dadds, \& Spence, 1998). However, findings of differential treatment benefits of parent involvement relative to individual youth treatment have been inconsistent across informants and measures in most studies (e.g., Mendlowitz, Manassis, Bradley, Scapillato, Miezitis, \& Shaw, 1999; Nauta, Scholing, Emmelkamp, \& Minderas, 2003; Spence et al., 2000; Wood, Piancentini, Southam-Gerow, Chu, \& Sigman, 2006).

Given the equivocal results of past research on the benefits of parent involvement in CBT for youth anxiety disorders and the etiologic evidence implicating familial/parent influences on anxiety disorders in youth (e.g., Barrett, 2000), calls have been made for additional research into whether parent involvement improves treatment outcome (e.g., Barmish \& Kendall, 2005; Hudson \& Rapee, 2005; Silverman \& Berman 2001). This dissertation study reports the results of a randomized controlled trial comparing an individual cognitive behavioral intervention (ICBT) and two parent-child CBT interventions. The following section of the Introduction provides a summary of research on the use of CBT in the reduction of anxiety and its disorders in youth. This is followed 
by a brief summary of the present study's main research questions with respect to treatment specificity and treatment mediation.

Comparative trials on ICBT and parent-involvement CBT. As noted, research regarding the treatment benefits of parent involvement over ICBT in youth anxiety treatment has produced inconsistent findings (Silverman et al., 2008). The CBT studies in youth anxiety treatment research that included parent involvement contained different components targeting a variety of parenting variables/skills. Although there is some variation in the specific skills that have been taught to parents, there are two parenting skills typically involved in most treatment studies (see reviews by Barmish et al., 2005; Wood, McLeod, Sigman, Hwang, \& Chu, 2003). The first is a parent reinforcement skills training aimed at teaching parents reinforcement strategies in response to the youth's avoidant behaviors (e.g., Barrett, 1998; Barrett et al., 1996a). The second is a parent relationship skills training aimed at improving parenting behaviors and the parent-youth relationship (e.g., Barrett, 1998; Barrett et el., 1996a; Silverman, Kurtines, Ginsburg, Weems, Lumpkin, \& Hicks-Carmichael, 1999). These parenting skills have been hypothesized to meditate positive child treatment outcome (e.g., Bogels \& Sigueland, 2006; Silverman \& Kurtines, 1996; Wood et al., 2006).

The present dissertation study evaluated treatment enhancement effects of parent involvement relative to individual treatment by targeting specific parenting variables. The two parent conditions were designed to dismantle key components representative of parent treatment prototypes as mediators of treatment response in the youth anxiety treatment research literature. The two parent involvement conditions are: 1) Parent Relationship Skills Training (RLST) (i.e., increasing parental autonomy granting and 
increasing parental acceptance of youth) and 2) Parent Reinforcement Skills Training (RFST) (i.e., increasing parental use of positive reinforcement and decreasing parental use of negative reinforcement).

Treatment specificity and treatment mediation. Although there is evidence for positive treatment outcome in youth anxiety CBTs that train parents in particular skills, there has been little research evaluating whether targeting particular parenting skills produces specific intended effects on parents' skills in those domains. Documenting a positive treatment outcome is not enough to support the conclusion that the positive treatment outcome was in fact due to the specific training of parents in these skills and not on another set of skills that was not trained (Wood et al., 2003). That is, if parents receive training in the use of reinforcement skills, does that training produce changes in parents' use of reinforcement and not in another parenting skill/variable such as autonomy granting, which was not targeted in the treatment? The treatment research literature refers to this question as "treatment specificity" (Brent \& Kolko, 1998; Kolko et al., 2000).

Evaluating treatment specificity is valuable in the field as it provides empirical evidence regarding the claims that including (or not including) the training of parents in certain parenting skills/variables improves treatment outcome in youth. More specifically, the analysis of treatment specificity in the area of youth anxiety has the potential to establish interventions that are not only efficacious in the reduction of youth anxiety but also in the improvement of a youth's context (i.e., the parent-youth relationship). 
In addition to a lack of empirical data on treatment specificity in CBT for youth anxiety disorders, there also has been very little research on whether it was the specific targeting of these parenting variables/skills that resulted in (i.e., mediated) treatment response (Barmish et al., 2005; Wood et al., 2003). Only two studies (Settipani, O'Neil, Podell, Beidas, \& Kendall, 2013; Silverman et al., 2009) have evaluated whether changes produced on parent variables mediated treatment response. These studies and their findings are described further in Chapter II. The present study, thus, examined treatment specificity and treatment mediation in the context of a randomized clinical trial for anxiety disorders in youth that compared individual CBT (i.e., ICBT) and parentinvolvement CBTs (i.e., RLST and RFST).

Evaluating treatment mediation is also valuable in contributing to the field's knowledge of how to modify treatments in ways that increase positive treatment outcome. More specifically, this translates into research developed to systematically dismantle and evaluate causal sequences of therapeutic events that are hypothesized as being efficacious (and not efficacious) in generating differential positive treatment outcome (Kazdin, 2007; Kazdin \& Nock, 2003; Kraemer, Wilson, Fairburn, \& Agras, 2002; Weersing \& Weisz, 2002). Considering the substantial number of child and adolescent psychosocial treatments, Kazdin (2007) noted that examining mechanisms of change (i.e., mediators) has the potential to bring order and parsimony to the abundance of psychosocial treatments. Understanding how changes in treatment occur would inform the field on what ought to be included in a given treatment program (e.g., parent reinforcement skills training, parent relationship skills training, both, neither), allowing 
clinicians to focus on techniques that have been empirically established as triggering the critical change process.

The literature indicates the need to evaluate specificity and mediation effects, as the bulk of the research to date has focused on demonstrating that treatment works rather than on understanding what works and how it works (e.g., Kazdin, 2007; MacKinnon, 2008). Even when mediation is examined, "not all programs target all the mediators they set out to change and few research studies measure all of them" (MacKinnon, 2008, p. 104). The present study contributes to the literature by examining the following four putative mediators in the parent involvement conditions: parental autonomy granting and parental acceptance of youth in the RLST condition (i.e., the Parent Relationship Skills Training condition) and positive reinforcement and negative reinforcement in the RFST condition (i.e., the Parent Reinforcement Skills Training condition). The ICBT treatment condition served as a baseline comparison condition relative to the two parent involvement conditions.

Two sets of hypotheses were tested in this dissertation study. The first set of hypotheses tested for treatment specificity effects. Because the two parent involvement treatment conditions target specific types of parenting skills (reinforcement skills versus relationship skills) and involve different therapeutic strategies connected to each of the targeted skills (i.e., increasing parent use of autonomy granting and parent acceptance of child in RLST; increasing parent use of positive reinforcement and decreasing parent use of negative reinforcement in the context of youth's avoidant behaviors in RSFT), each condition will serve as an "alternative comparison model" for the other condition in testing the first set of hypotheses. It was hypothesized that RLST would produce specific 
effects on parent's use of autonomy granting and acceptance of youth, but not on parent's use of positive and negative reinforcement. Conversely, it was hypothesized that RFST would produce specific effects on parent's use of positive and negative reinforcement, but not on parent's use of autonomy granting and acceptance of youth. The research basis underlying the emphasis on these parenting variables in the treatment of youth anxiety will be reviewed in the next section. 


\section{CHAPTER II.}

\section{LITERATURE REVIEW}

Little research has evaluated the influence of parent involved CBT on the parenting variables/skills targeted (i.e., whether there is treatment specificity). Similarly, little research has evaluated whether the targeted parenting variables/skills result in positive treatment outcome (i.e., whether there is treatment mediation). Consequently, the basis of claims made in the field of youth anxiety treatment regarding the importance of including (or not including) parent training of specific parenting variables/skills are derived more from speculation than empirical data (Barmish et al., 2005; Kazdin, 1999; Wood et al., 2003). In consideration of the current state of the treatment research literature, the present study aims to address the expressed need of evaluating the specificity and mediation enhancement effects of parent involvement on positive youth anxiety treatment outcome (e.g., Kazdin, 2001; Kazdin \& Kendall, 1998; Roth, Fonagy, \& Parry, 1994; Silverman \& Kurtines, 1997). Specifically, the present study focused on treatment specificity and mediation in two parent-involvement CBTs.

In this chapter, published treatment studies involving parents are summarized, with a focus on whether the specific parenting variables/skills targeted in treatment actually changed and whether the targeted parenting behavior influenced treatment outcome. Before reviewing that literature, it is important first to provide a background on the association between the specific parenting variables targeted in the present study and youth anxiety. 


\section{Parenting Variables Associated with Youth Anxiety}

Parent-youth relationship. Most of the existing literature on the parent-youth relationship has focused on two parenting dimensions: acceptance-rejection and autonomy granting-psychological control (e.g., Manassis \& Bradley, 1994; McLeod, Wood, \& Weisz, 2007; Rapee, 1997; Wood et al., 2003). These dimensions are considered bipolar, with adaptive parenting practices (e.g., autonomy granting) at one end and maladaptive parenting practices (e.g., psychological control) at the other end.

Parental autonomy granting. Parental autonomy granting refers to parental encouragement of youth's age-normative autonomy and emotional independence. Parental psychological control is at the opposite end of the continuum of autonomy granting and refers to parental overinvolvement by excessive instruction of youth on how to think or feel in various situations (e.g., through guilt induction) and encouragement of excessive dependence on the parent (e.g., Barber 1992; Barber 1996; Steinberg, Elmen, $\&$ Mounts, 1989). Theoretical models have proposed that excessive parental control can result in the development of anxiety in youth (Chorpita \& Barlow, 1998; Ginsburg, Siqueland, Masia-Warner, \& Hedtke, 2004; Rapee, 2001). Parents who employ excessive control over their youth's behavior or psychological wellbeing and do not grant their youth autonomy in developmentally salient tasks are likely to reduce their youth's sense of mastery, control and autonomy. As a consequence, the youth have little basis for believing in their ability to succeed and remain safe without parental assistance, especially in new situations, leading to increased anxiety and avoidant responses in the youth (Wood et al., 2006). Conversely, some models have proposed that parental support of youths' age-normative autonomy and independence (i.e., parental autonomy granting) 
may increase youths' sense of mastery and control, leading to anxiety reduction (e.g., Chorpita et al., 1998; Wood et al., 2003).

McLeod et al.'s (2007) meta-analysis of 47 studies examining parenting and youth anxiety found evidence in support of an the association between parental psychological control and youth anxiety. For example, Hudson and Rapee (2002) compared 37 families with youth (aged 7-16 years) diagnosed with an anxiety disorder and 20 control families with youth with no anxiety disorder diagnosis using self-report measures and independent behavioral observations. Ratings on parental variables of psychological control and rejection were obtained by: 1) the youth rating their parents, 2) parents rating themselves, and 3) independent observers rating family interactions. Parents of youth with anxiety disorders were more controlling and less autonomy granting compared to parents of control youth, as rated by independent observers. Similarly, Siqueland, Kendall, and Steinberg (1996) compared 17 clinically anxious youth (ages 9 to 12 years) and their families with 27 control youth with no anxiety disorder (ages 9 to 12 years) and their families using independent behavioral observations. Each family participated in completing a complex puzzle task that typically produces conflict between family members. Mothers of youth with anxiety disorders granted less autonomy and exerted more psychological control during the task than mothers of control youth with no anxiety disorder.

Parental acceptance. Parental acceptance refers to a parental display of positive regard, warmth and support toward the youth (e.g., Clark \& Ladd, 2000; Maccoby, 1992; McLeod et al., 2007). Parental rejection is on the opposite end of the continuum of parental acceptance and refers to parental coldness and unresponsiveness, disapproval, 
and a lack of emotional support toward the youth (e.g. Clark et al., 2000; Maccoby, 1992). Research indicates that high parental rejection (i.e., low parental acceptance) may contribute to youths' reduced self-efficacy and sense of mastery, and also may lead to increased anxiety and avoidant responses in the youth (e,g., Barber, Olsen, \& Shagle, 1994; Rapee, 1997).

Ginsburg et al.’s (2004) narrative review of studies examining parenting and youth anxiety concluded that a positive relationship exists between parental rejection and youth anxiety. That is, higher levels of parental rejection were associated with higher levels of youth anxiety in a majority of studies included in the review. Similarly, Yap, Pilkington, Ryan and Jorm's (2014) meta-analysis of 181 studies examining parenting and youth anxiety and depression concluded that there is a significant association between high levels of parental rejection and high levels of anxiety. For example, as noted previously, Hudson et al.'s (2002) study compared families with anxiety-disordered youth and control families on the parental acceptance/rejection. Results demonstrated that anxiety-disordered youth rated their parents as less accepting compared to youth in the control group.

In contrast to the findings above, McLeod et al.'s (2007) meta-analysis provided mixed evidence supporting the association between parental rejection and youth anxiety. Results varied depending on specific subdimensions (i.e., warmth, aversiveness and withdrawal) within the broad parenting dimension of rejection. For example, parental warmth was found to play a small role in the parenting-youth anxiety association, whereas the parental aversiveness and withdrawal, conceptualized as the opposites of warmth, played a larger role in the parenting-youth anxiety association. 
Parental reinforcement. Research has provided evidence for the role of parental reinforcement in the development and maintenance of youth anxiety (see review by Barmish et al., 2005). In the context of youth anxiety and operant learning processes, parental positive reinforcement refers to parental use of tangible (e.g., giving youth a prize) or non-tangible (e.g., taking youth to the park) rewards contingent on the youth facing his/her feared situation or object. The use of positive reinforcement increases the probability that the youth will again face his/her feared situation or object (Fisak Jr. \& Grills-Taquechel, 2007)

Parental negative reinforcement refers to parental permission or facilitation of the youth avoiding his/her feared situation or object. Fisak Jr. et al. (2007) provide multiple examples of the ways in which a parent can use negative reinforcement in the context of youth anxiety. For example, a parent may: 1) remove youth from feared situation/object (e.g., by picking youth up early from school on a day the youth has a presentation), 2) support and encourage youth avoidance of feared situation/object (e.g., by allowing youth not to attend a social event), 3) attempt to reduce youth's distress with special treatment (e.g., by providing excessive attention in the form of reassurance or soothing), and/or 4) permit youth avoidance of responsibilities (e.g., by ordering food at a restaurant for the youth).The use of negative reinforcement increases the probability that the youth will again avoid his/her feared situation or object (e.g., Rapee, 2002).

Research has demonstrated that parents of youth with anxiety disorders tend to allow youth's avoidance of situations or objects that provoke fear/anxiety (e.g., Barrett, 1998; Barrett, Rapee, Dadds, \& Ryan, 1996). Because avoidance results in immediate reduction of fear/anxiety, the youth's avoidance is negatively reinforced. Similarly, 
parents of youth with anxiety disorders tend not to appropriately use positive reinforcement to support youth's efforts in confronting their fear-/anxiety-provoking situation in an effort to avoid youth experiencing distress (e.g., Barrett, 1998; Barrett et al., 1996b). For example, in a study by Barrett et al. (1996b), parental use of reinforcement was compared between three groups of youth: 1) a clinically anxious group $(n=152), 2)$ a non-clinical control group $(n=26)$, and 3$)$ an oppositional disordered control group $(n=27)$. First, youth in all groups were asked to separately interpret and provide plans of action to ambiguous threat situations. Next, the youth and parents were asked to come together as a family to discuss the situations and for the youth to provide a final response for dealing with the ambiguous threat situation. Clinically anxious youth were more likely to choose avoidant solutions as opposed to the other two groups. Further, parents of youth with anxiety disorders modeled caution and rewarded avoidant behavior. Lastly, there was an increase in the clinically anxious youths' avoidant plans of actions after the familial discussion, providing evidence for the influence of parental reinforcement on youth anxiety.

In a more recent study, Barrett, Fox, and Farrell (2005) conducted an observational study in which parent-youth interactions with anxious youth $(n=33)$ were compared to parent-youth interactions with: 1) the anxious youth's similar-aged nonclinical siblings, and 3) non-clinical youth $(n=14)$. The study included two discussion tasks related to hypothetical anxiety-provoking situations during which youth interacted with their parents. As one of the tasks, the parents and their youth were asked to discuss together how the youth should interpret and respond to the hypothetical ambiguous social 
situation. Parents of anxious youth expressed more encouragement of avoidant behaviors relative to parents of non-anxious youth.

Additional studies have provided evidence for an association between parental reinforcement and youth anxiety (e.g., Chorpita, Albano, \& Barlow, 1996; Cobham, Dadds, \& Spence, 1999; Dadds, Barrett, Rapee, \& Ryan, 1996; Shortt, Barrett, Dadds, \& Fox, 2001). More specifically, parents of anxious youth may encourage and consequently increase youth avoidance of ambiguous situations. Dadds et al. (1996) conducted a follow-up study with a random subset of youth and parents from the Barrett et al. (1996b) study in an attempt to better understand the processes that occurred within the family discussions. Findings demonstrated that parents of anxious youth were more likely to encourage avoidant responses to hypothetical, ambiguous threat situations than parents of non-clinical youth, whom were more likely to encourage youth solutions that involved prosocial behaviors (i.e., encourage youth's confrontation of anxiety-provoking situation).

\section{Parental Involvement in Youth Anxiety Treatment}

As previously mentioned, treatment research with respect to the enhanced benefits of parent-involvement CBT over individual CBT in youth anxiety treatment has produced mixed findings across studies (Silverman et al., 2008). The considerable variability across studies prevents conclusions about the relative superiority of one treatment approach over other treatment approaches (see review by Barmish et al., 2005). Moreover, treatment research is scare with respect to whether the parenting variables/skills targeted (e.g., parental autonomy granting, parental reinforcement) in parent-involvement CBT produce a change in the targeted parenting variables/skills (e.g., 
an increase in parental autonomy granting, a decrease in parental negative reinforcement (Wood et al., 2003).

The following section will summarize the published treatment studies that involved parents and targeted the parenting behaviors of interest in this dissertation study (i.e., parental autonomy granting/psychological control, parental acceptance/rejection, and parental positive/negative reinforcement), with a particular focus on whether the targeted parent variables/skills changed during treatment. The treatments in the summary below compared the relative efficacy of individual youth CBT versus youth CBT + parent involvement and were administered in different formats. For simplicity, studies that involved parents only and not the family unit were abbreviated as PCBT, and studies that involved parents in a family context were abbreviated as FCBT. The treatment studies obtained parent ratings from mothers, unless otherwise noted.

Studies targeting parental reinforcement. Barrett et al. (1996a) conducted one of the first randomized clinical trials comparing CBT with or without parental involvement for youth anxiety disorders. The treatment study evaluated the effectiveness of Individual CBT (ICBT; $n=28)$, ICBT plus Family Management Training (PCBT; $n=$ 25 ) and a waitlist control condition (WL; $n=26)$ in a sample of 79 youth (ages $7-14$ years) and their parents. Youth were randomly assigned to one of the three conditions. PCBT targeted parental reinforcement by training parents to reward youth for facing their anxiety-provoking situation(s) and to reduce/eliminate avoidant behaviors (e.g., excessive reassurance seeking). Outcome was evaluated using diagnostic recovery rates, independent clinical evaluations, parent and youth self-report measures, and experimental measures. In the experimental measures, threat interpretations and response plans to 
hypothetical, ambiguous situations were measured. To examine whether anxious youth's tendency to report avoidant solutions increased following family discussions, youth and parents were first asked to interpret and respond to these situations separately and then to discuss the situations together. Independent evaluators rated whether the youth provided avoidant solutions (i.e., whether the youth removed him/herself from the situation) and if there was a difference between the solutions given before and after the family discussion.

At posttreatment, the percentage of youth who no longer met diagnostic criteria for an anxiety disorder was significantly lower for both ICBT and PCBT (69.8\%) than for the WL $(26.0 \%)$. There was also a significant difference between the two treatments on diagnostic recovery, with more youth in PCBT recovering $(n=84.0 \%)$ than in ICBT $(n=$ 57.1\%). Independent clinical evaluations of improvement in the youth and family also showed improvement in both the ICBT and PCBT groups, with the PCBT group significantly superior to the ICBT group on three of the seven clinical evaluation scales (i.e., Clinical Global Impression, Change of Family Disruption by the Youth's Behavior, and Change in Parent's Perception of Own Ability to Deal with Youth's Behavior). Further, parent self-report measures showed improvements in both the ICBT and PCBT groups in comparison to the WL, with follow-up analyses showing that the PCBT group consistently maintained lower scores on both the Child Behavior Checklist Internalizing (CBCL-I; Achenbach, 1991) and Externalizing scale (CBCL-E) in comparison to the ICBT group. Youth self-report measures also demonstrated beneficial effects in both active treatment conditions, with significantly lower scores on the Fear Survey Schedule for Children - Revised (FSSC-R; Ollendick, 1983) for the PCBT group than the ICBT group. 
As noted, parental negative reinforcement of youths' avoidance of anxietyprovoking situations/objects is of particular interest to this dissertation study. Results of the Barrett et al. (1996a) treatment study demonstrated a significant decrease in the number of threat interpretations and avoidant plans at posttreatment. More specifically, youths' recorded threat interpretations and avoidant responses before the family discussion were significantly reduced at posttreatment for the PCBT group relative to both the ICBT and WL groups. Youths' recorded threat interpretations and avoidant responses after the family discussion were significantly reduced at posttreatment for both the ICBT and PCBT groups relative to the WL group. These results were in sharp contrast to pretreatment analyses showing that youth in all three conditions increased their avoidant responses after the family discussion. Treatment gains were maintained for both treatment conditions at the 12-month follow-up assessment point, and statistically significant differences remained between ICBT and PCBT on diagnostic recovery, FSSC$\mathrm{R}$ and independent clinical evaluation of improvement. Although parental reinforcement was targeted in PCBT, this parenting variable/skill was not measured as an outcome. Further, it was not examined whether PCBT produced specific effects on parental reinforcement strategies relative to the other conditions (i.e., if there was treatment specificity) and if that parenting variable/skill, in turn, mediated the positive treatment outcome in PCBT (i.e., if there was treatment mediation).

In a subsequent study, Barrett (1998) investigated the efficacies of Group CBT (GCBT; $n=23$ ), GCBT plus Family Management Training (G-PCBT; $n=17$ ) and a WL control condition $(n=20)$ in a sample of 60 anxiety-disordered youth (ages $7-14$ years) and their parents. Youth were randomly assigned to one of the three conditions. The 
parent-involvement condition targeted parental reinforcement. Outcome was evaluated using diagnostic recovery rates, independent clinical evaluations and parent and youth self-report measures.

At posttreatment, the percentage of youth who no longer met diagnostic criteria for an anxiety disorder was significantly lower for both GCBT and G-PCBT (64.8\%) than for the WL (25.2\%), with no significant difference between the two active treatments on diagnostic recovery. On the independent clinical evaluation scales, improvements were found in both GCBT and G-PCBT, with G-PCBT significantly superior to GCBT on two of the seven clinical evaluation scales (i.e., Change of Family Disruption by the Youth's Behavior and Change in Parent's Perception of Own Ability to Deal with Youth's Behavior). Parent and youth ratings on the FSSC-R and parent rating on the CBCL-I were significantly lower for G-PCBT in comparison to both GCBT and WL. Treatment gains were maintained on all measures at the 12-month follow-up assessment point, with G-PCBT participants demonstrating significantly greater improvements than GCBT participants on diagnostic recovery, FSSC-R ratings, and clinician ratings of improvement (e.g., on the Avoidant Behaviors scale).

Barrett (1998) did not examine whether targeting parental reinforcement produced specific effects on this parenting variable/skill (i.e., treatment specificity) and if it, in turn, mediated the positive treatment outcome (i.e., treatment mediation). Similar to Barrett et al. (1996a), the parent-youth relationship was not measured, not allowing for the examination of treatment specificity and mediation.

Spence, Donovan, and Brechman-Toussaint's (2000) treatment study consisted of 50 youth (ages 7 to 14 years) with a primary diagnosis of social phobia (SOP), therefore 
being a more homogeneous sample relative to the other treatment studies. This treatment study examined the efficacy of GCBT ( $n=19)$, GCBT plus Parent Involvement (GPCBT; $n=17)$ and a WL control condition $(n=14)$. Youth were randomly assigned to one of the three conditions. Outcome was evaluated using diagnostic recovery, parent and youth measures and behavioral observations rated by an independent observer. PCBT targeted parental reinforcement by training parents to increase positive reinforcement of youths' participation in social activities and decrease negative reinforcement of youths' socially anxious behavior and avoidance.

Posttreatment results demonstrated a higher percentage of youth who no longer met diagnostic criteria for SOP in GCBT $(n=58.0 \%)$ and P-GCBT $(n=87.5 \%)$ than in the WL control condition $(n=7.0 \%)$, with no significant difference on diagnostic recovery found between the two active treatment conditions. Youth in both active treatment conditions had significantly lower ratings relative to the youth in the WL condition on youth-completed RCMAS, Spence Children's Social Anxiety Scale (SCAS; Spence, 1997), and Social Worries Questionnaire (SWQ-PU; Spence, 1995) and the parent-completed Social Skills Questionnaire (SSQ-P; Spence, 1995) and Social Competence Questionnaire (SCQ-P; 1995), with no significant differences on these measures across the two treatments conditions. Treatment gains were maintained for both treatment conditions at 6- and 12-month follow-ups. No statistically significant differences were found between the active treatment conditions in any of the assessment time points. Further, although parental reinforcement was targeted in the active treatments, this parenting variable/skill was not measured at pre, post or follow-up time 
points, consequently not allowing for the examination of treatment specificity and mediation.

Study targeting parent-youth relationship. Only one study to my knowledge targeted only the parent-youth relationship in an effort to reduce youth anxiety. Wood et al.'s (2006) treatment study evaluated the efficacy of ICBT $(n=19)$ and PCBT $(n=19)$ in a sample of 38 anxiety-disordered youth (ages $7-14$ years) and their primary parent (i.e., their primary caregiver). Youth were randomly assigned to one of the two treatment conditions. Outcome was evaluated using diagnostic recovery rates and parent, youth, and independent evaluator ratings. PCBT targeted both parental autonomy granting (i.e., decreasing parental psychological control) and parental acceptance (i.e., decreasing parental rejection).

At posttreatment, the percentage of youth who no longer met diagnostic criteria for an anxiety disorder was higher in PCBT (70.8\%) than ICBT (52.6\%), but this difference was not statistically significant. However, there was a significant difference between treatment conditions in terms of improvement of youth anxiety symptoms, with significantly more youth in PCBT (78.9\%) than ICBT $(26.3 \%)$ rated by an independent evaluator (IE) as "completely recovered or very much better" on the Clinician's Global Improvement scale (CGI; National Institutes of Health, 1985). Parents' ratings of youth anxiety symptoms also declined more rapidly over the course of treatment in PCBT in comparison to the ICBT group. In contrast to parent and IE ratings, youth self-report of anxiety did not provide evidence of a superior PCBT treatment effect. Follow-up data was not reported. Further, parental autonomy granting and parental acceptance were 
targeted in treatment but not measured, thus not allowing the examination of treatment specificity and mediation.

\section{Studies targeting parent-youth relationship and parental reinforcement.}

Bodden et al. (2008) evaluated the efficacy of ICBT $(n=64)$ and FCBT $(n=64)$ in a sample of 128 youth (ages $8-17$ years) and their families (i.e., mothers, fathers, and siblings). Families were first randomly assigned to ICBT, FCBT, or a 2-3 month WL condition $(\mathrm{n}=25)$. After the 2-3 month wait, 19 of the $25(76 \%) \mathrm{WL}$ families were then randomly assigned to either ICBT or FCBT. Outcome was evaluated using diagnostic recovery rates and parent and youth questionnaires. For those participants that were initially in the WL and were then assigned to an active treatment condition, the post waitlist measures were used as pretreatment measures. FCBT targeted parental autonomy granting (i.e., decreasing parental psychological control), parental acceptance (i.e., decreasing parental rejection) and parental reinforcement (i.e., increasing positive reinforcement and decreasing negative reinforcement).

At posttreatment, the difference in percentage of youth who no longer met diagnostic criteria for an anxiety disorder in ICBT $(n=53 \%)$ relative to FCBT $(n=28 \%)$ was statistically significant. For participants in the WL condition, all youth still met diagnostic criteria for an anxiety disorder after the 2-3 month waitlist period, whereas $41 \%$ of youth no longer met diagnostic criteria for any anxiety disorder at posttreatment and $56 \%$ did not meet diagnostic criteria for their primary anxiety diagnosis. At the 3 month follow-up, these diagnostic recovery rates were $52 \%$ and $68 \%$, respectively; however, the superior effect of ICBT over FCBT was no longer significant. Significant 
pre to post treatment changes were observed on the outcome measures, with no significant differences found between treatment conditions. Consistent with the other treatment studies summarized, the parenting variables (i.e., parental autonomy granting, parental acceptance, and parental reinforcement) were not measured. Consequently, treatment specificity and mediation could not be evaluated. Bodden et al.'s study was the first to support the superiority of ICBT to parent-involvement CBT at posttreatment.

Kendall, Hudson, Gosch, Flannery-Schroeder, and Suveg (2008) evaluated the efficacy of ICBT $(n=55)$, PCBT $(n=56)$, and a family-based education/support/attention condition (FESA; $n=50)$ in a sample of 161 youth (ages 7 to 14 years) and their parents. Outcome was evaluated using diagnostic recovery rates and parent, youth, and teacher measures. Parental autonomy granting and reinforcement strategies (i.e., increasing positive reinforcement and decreasing negative reinforcement) were targeted in this study.

At postreatment, the percentage of youth who no longer met diagnostic criteria for any anxiety disorder was higher in both ICBT $(n=64 \%)$ and PCBT $(n=64 \%)$ relative to FESA $(n=42 \%)$, with statistically significant differences found between ICBT and FESA and between PCBT and FESA. The percentage of youth who no longer met diagnostic criteria for their primary anxiety diagnosis was also higher in both ICBT $(\mathrm{n}=$ $57 \%)$ and PCBT (55\%) than FESA $(n=37 \%)$, with statistically significant differences also found between ICBT-FESA and FCT-FESA. At 12-month follow-up, there were no significant differences found on diagnostic recovery rates between conditions. Further, significant pre to posttreatment changes were found on the MASC and the Coping 
Questionnaire for Children (CQ-C; Kendall \& Marrs-Garcia, 1999), with no significant differences between conditions. Overall, youth in all treatment conditions reported a reduction in anxiety symptoms and an improvement in coping skills at posttreatment. The difference in anxiety symptoms for youth in ICBT and PCBT in comparison to youth in FESA was statistically significant, with no significant difference found between ICBT and PCBT. Again, although parental autonomy granting and reinforcement strategies were targeted in PCBT, these parenting variables/skills were not measures. Consequently, treatment specificity and mediation could not be evaluated.

Summary of studies involving parents in youth anxiety treatment. The treatment studies summarized in this section provide empirical evidence that anxiety disorders in youth are significantly reduced when parents are involved. However, most of the studies did not provide support for enhanced treatment benefits of parental involvement in the youth's anxiety treatment relative to youth individual treatment. When significant enhanced effects were found, findings were generally inconsistent across measures, informants, or both (e.g., Barrett, 1998, Barrett et al., 1996a; Wood et al., 2006).

Of particular relevance to this dissertation study is the issue of treatment specificity and mediation. Although specific parenting variables/skills were targeted in all the studies summarized, none of the studies measured the parenting variables/skills (i.e., parental autonomy granting/psychological control, parental acceptance/rejection, parental positive and negative reinforcement). Consequently, issues of treatment specificity and mediation were not pursued in any study.

Related research on treatment specificity. A search of studies examining issues of treatment specificity in the treatment of youth anxiety produced no results. Given the 
paucity of research in the area of youth anxiety, a study focused on this issue in the treatment of adolescent depression will instead be summarized here. Kolko, Brent, Baugher, Bridge, and Birmaher (2000) compared the efficacy of CBT, systematic behavioral family therapy (SBFT) and nondirective supportive therapy (NST) for reducing adolescent depression in a sample of 102 adolescents (ages 13 to 18 years) diagnosed with major depressive disorder and their parents. Adolescents were randomly assigned to one of the three treatment conditions. Outcome was evaluated using diagnostic recovery rates and parent and youth measures.

At posttreatment, CBT showed a specific effect on one of two cognitive variables, cognitive errors as measured by the Children's Negative Cognitive Errors Questionnaire (CNCEQ; Leitenberg, Yost, \& Carroll-Wilson, 1986). CBT did not produce specific effects on hopelessness, as measured by the Beck Hopelessness Scale (BHS; Beck, Weissman, Lester, \& Trexler, 1974). Findings also revealed that both CBT and SFBT had a greater effect on family functioning than NST, therefore not providing evidence for specific treatment effects of SBFT on that targeted family variable. CBT also showed a greater effect on two other family variables (behavioral control and marital satisfaction) relative to NST, with SBFT not demonstrating any effects on these variables. However, both SBFT and NST showed a specific effect on one of the family variables (family conflict) at the 2-year follow-up. In sum, the one study conducted in a related area (i.e., adolescent depression) found some support for treatment specificity; that is, CBT exerted specific effects on cognitive distortions relative to the other treatments.

Summary of treatment specificity studies. Despite the importance of examining treatment specificity in youth treatment research, the data existing to date can be seen as 
insufficient to warrant acceptance of the notion that treatment results in change in the skills/variables that are specifically targeted. As noted in the literature review of treatments comparing the relative efficacy of individual CBT versus parent-involvement CBT, the targeted parenting variables/skills were not measured in any of the treatment studies. Without measuring the targeted variables/skills, an examination neither of treatment specificity nor of treatment mediation could be pursued.

Another limitation in the treatment studies summarized in the literature review was the treatments chosen as comparison conditions. Many of the randomized controlled trials compared the active treatment condition against a WL. However, to examine issues of treatment specificity, a more useful comparison would be between an active treatment condition that targets a parenting variable (e.g., a condition that trains parents on acceptance of youth and not on appropriate reinforcement strategies) and an alternative active treatment condition that does not target the same parenting variable (e.g., a condition that trains parents on appropriate reinforcement strategies and not on parental acceptance of youth). In this type of comparison, a significant Treatment Condition by Time interaction would provide a direct test of the respective interventions on the respective targeted parenting variables/skills.

The present dissertation study thus addresses the limitations of the current anxiety treatment literature first by measuring the targeted parenting variables/skills and second by targeting different parenting skills in each parent-involvement treatment condition (i.e., increasing parental use of positive reinforcement and decreasing negative reinforcement in the context of youth avoidant behaviors in RFST; increasing parental use of autonomy granting and parental acceptance of youth in RLST), with each 
condition serving as an "alternative comparison control" for the other condition. This will allow for an evaluation of the specificity of treatment effects on targeted parenting behaviors. The third condition, ICBT, will serve as a baseline comparison condition. The use of three active treatment conditions enhances internal validity and allows conclusions to be drawn regarding treatment-specific effects.

\section{Treatment Mediation}

Only a small number of studies have systematically evaluated mediators of treatment response. Six studies in the youth anxiety treatment research literature investigated mediators of treatment response (Alfano et al., 2009; Hogendoorn et al., 2013; Kendall \& Treadwell, 2007; Settipani et al., 2013; Silverman et al. 2009; Treadwell \& Kendall, 1996). Four of these studies (Alfano et al., 2009; Hogendoorn et al., 2013; Kendall et al., 2007; Treadwell et al., 1996) investigated youth variables (i.e., youth cognitions, social skills, and loneliness) as mediators of youth anxiety treatment outcome. Even though the youth variables examined in these mediation studies are not variables of interest in this dissertation study, these studies are briefly summarized below in light of the scarcity of published work on treatment mediators. The other studies (Settipani et al., 2013; Silverman et al., 2009) summarized relate to this dissertation's interest in investigating parenting variables mediating parent-involvement CBT.

Youth variables as treatment mediators. Treadwell et al. (1996) evaluated the mediating role of negative self-statements, positive self-statements, and state-of-mind (SOM) ratios (i.e., the ratio of positive to negative self-statements) in youth anxiety. The sample consisted of 151 youth ages 8 to 13 years. Of the 151 youth, 71 were clinicreferred for a primary diagnosis of anxiety; the remaining 80 youth were within normal 
levels of anxiety, internalizing and externalizing problems, and depression and served as control participants. Youth with anxiety disorders were randomized into a WL or CBT. Only the data for the anxious clinic-referred sample were included in the meditational analysis. Outcome was evaluated using diagnostic status and parent, youth and teacher measures.

At pretreatment, anxiety-disordered youth reported greater numbers of selfstatements and lower SOM ratios. Significant pre to posttreatment improvements were observed in negative self-statements, positive self-statements, and SOM ratios for the treated youth. Negative self-statements and SOM ratios, and not positive self-statements, significantly predicted anxiety severity after treatment. In terms of treatment mediators, negative self-statements mediated youth reported anxiety but did not on parent or teacher reports of diagnostic status. SOM ratio also mediated anxiety after treatment. Positive self-statements did not mediate positive treatment response.

In a subsequent study by Kendall et al. (2007), self-statements were examined as predictors of anxiety in youth with and without an anxiety disorder and as a mediator of positive treatment outcome in anxiety-disordered youth in a sample of 145 youth (ages 9 - 13 years). Similar to Treadwell et al. (1996), changes in negative self-statements mediated treatment response. Moreover, changes in SOM ratios mediated treatment response, as measured by the RCMAS only.

Alfano et al. (2009) examined mediators of treatment outcome in the behavioral treatment of SOP in a sample of 88 youths (ages 7 to 17 years). The data from these youths were derived from two previously published randomized clinical trials (Beidel, Turner, \& Morris, 2000, $n=31$ and Beidel, Turner, Sallee, Ammerman, Crosby, \& 
Pachak, 2007, $n=57)$. Alfano et al. examined whether observer-rated social skill during two behavioral tasks and youth-reported loneliness mediated changes during treatment. Results revealed that social anxiety as measured by only one of the study's main outcome measures (i.e., Social Phobia and Anxiety Inventory for Youth; Beidel, Turner, \& Morris, 1995) mediated by youth-reported loneliness.

Hogendoorn et al. (2013) examined cognitive variables (i.e., negative and positive thoughts, coping strategies, coping strategies, and perceived control over anxietyprovoking situations) as mediators of treatment outcome. Contrary to the mediation studies already summarized (i.e., Alfano et al., 2009; Kendall et al., 2007; Treadwell et al., 1996), Hodendoorn et al.'s study included multiple assessment points during treatment in order to gather data regarding temporal precedence. The sample consisted of 145 youth (ages $8-18$ years) with a primary anxiety disorder who received CBT. Contradictory to the findings of Treadwell et al. (1996) and Kendall et al. (2007), the results of this study demonstrated that a change in positive thoughts, but not negative thoughts, preceded a change in anxiety symptom reduction. Further, several coping strategies (e.g., positive cognitive restructuring and distraction strategies) also preceded a change in anxiety symptom reduction.

Parent variables as treatment mediators. Silverman et al. (2009) compared the relative efficacy of ICBT with minimal parental involvement $(n=48)$ to CBT with active parental involvement (PCBT; $\mathrm{n}=40$ ) in a sample of 119 anxiety-disordered youth (ages 7 -16 years) and their parents. The study examined potential models of the dynamics of change between youth anxiety and the following parental variables in both treatment conditions: 1) parental positive-negative behaviors toward the child (i.e., parental 
acceptance/rejection, which is of interest in this dissertation study), 2) conflict in the parent-youth relationship, and 3) parental anxiety. Outcome was evaluated using diagnostic recovery rates and parent and youth measures.

At posttreatment, $78.4 \%$ of youth across both treatment conditions no longer met criteria for their primary diagnosis. Both ICBT and PCBT produced significant improvements on youth anxiety between pretreatment and posttreatment, and these improvements were maintained at follow-up. The pattern of findings was observed on all primary (RCMAS) and secondary outcome measures (CBCL-Anxious/Depressed subscale; Achenbach, 1991), with no significant differences found between treatment conditions. In terms of the parent variables, parental anxiety was reduced across both treatment conditions, even though parental anxiety was not targeted in ICBT. Statistically significant pre to posttreatment changes were also observed in the youths' appraisal of the parent's positive/negative behaviors (as measured by the Conflict Behavior Questionnaire-Appraisal of Parent; CBQ-P; Prinz, Foster, Kent, \& O’Leary, 1979) and the conflict in the parent-youth relationship (CBQ-D; Prinz et al. 1979) in ICBT. Again, these parent variables were not targeted in ICBT. For PCBT, statistically significant pre to posttreatment changes were observed on the CBQ-P and not on the CBQ-D, with no significant differences found between treatment conditions. This study also preliminarily pursued the question of directionality of effects between youth anxiety and parent variables (i.e., parent to youth, youth to parent, or bidirectionality). Given this issue was not a focus of this dissertation study, the issue of directionality is discussed only later in the Discussion section. 
In a recent study, Settipani et al. (2013) investigated the directionality of change for youth anxiety and parent factors (i.e., parental anxiety, parental psychological control, family affective involvement, and family behavior control) over time in sample of 111 anxiety-disordered youth (ages 7 to 14 years) who were randomized to ICBT $(n=55)$ or FCBT $(n=56)$. Outcome was evaluated using parent-, youth-, and clinician-rated measures. Results in the combined sample demonstrated that decreases in parent-reported youth anxiety led to decreases in parental anxiety, suggesting that decreases in youth anxiety may precede reductions in parental anxiety rather than vice versa. Furthermore, decreases in parental psychological control and family affective involvement preceded decreases in clinician-rated youth anxiety.

Summary of treatment mediation studies. Although the studies summarized above are interesting in that they are the first to identify mediators of treatment response, only Silverman et al. (2009) and Settipani et al.'s (2013) treatment studies are directly relevant to the research questions addressed in this dissertation study. Silverman et al. demonstrated that one of their hypothesized mediators (i.e., the parent-youth relationship) mediated treatment response. Settipani et al. demonstrated that three of their hypothesized parent variables (i.e., parental anxiety, parental psychological control and family affective involvement) mediated treatment response, whereas family behavior control did not mediate treatment response. In both studies there was some evidence to show that the direction of change was not from parent to youth only (the traditional view), but also from youth to parent. 


\section{The Present Study}

The present study evaluated whether RLST (i.e., Parent Relationship Skills Training, which targets increasing parental acceptance of youth and increasing autonomy granting) and RFST (i.e., Parent Reinforcement Skills Training, which targets increasing parental positive and decreasing negative reinforcement) produce specific effects on the targeted parenting variables/skills. The present study also examined whether changes produced on these variables mediated treatment response in each of the respective treatment conditions.

Accordingly, the specific aims of this dissertation study were to test two sets of hypotheses. These hypotheses are depicted in Figure 1,2,3 and 4. The first set of hypotheses was designed to establish empirically whether there were specific treatment effects. Thus, the first set of hypotheses was that RLST would produce significantly greater effects on parental autonomy granting (increase) and parental acceptance of youth (increase) than RFST and ICBT. RFST, on the other hand, was hypothesized to produce significantly greater effects on parental use of positive reinforcement (increase) and negative reinforcement (decrease) than RLST and ICBT. ICBT, as noted, served as an additional comparison control condition because parents were not trained in any skills in this condition, yet these skills were measures in ICBT as they were in the other two conditions.

The second set of hypotheses tested in this study was whether changes produced on these targeted parenting variables mediate treatment response. Thus, the second set of hypotheses tested was that parents' increased use in positive reinforcement, parents' decreased use in negative reinforcement, parents' increased autonomy granting and 
parents' increased acceptance of the youth would be significant mediators of treatment response (i.e., youth anxiety reduction). Mediation tests are within group tests in that analyses are conducted within each condition so that change in each hypothesized mediator is either significantly related to positive change in youth treatment outcome or it is not. 


\section{CHAPTER III. \\ METHODOLOGY}

\section{Participants}

Participants consisted of 337 youth (ages 5 to 16 years; $M=9.50 ; S D=2.45$ ) and their parents (mainly mothers) who presented to the Child Anxiety and Phobia Program (CAPP) at Florida International University, an anxiety disorders specialty research clinic, due to youths' difficulties with excessive fears and/or anxiety. The age range of the participants in the current study is comparable with the age range of previous randomized clinical trials (e.g., Barrett, 1998 Kendall, 1994). After attrition, the number of treatment completers was 253 . There was no statistically significant differential attrition across treatment conditions $(\mathrm{ICBT}=29.5 \%, \mathrm{RLST}=28.3 \%$, and $\mathrm{RSFT}=24.4 \%)$. These rates are comparable for rates reported by other U.S. investigators of youth anxiety (e.g., Kendall, 1994). The present study examined data for the treatment completed sample. Treatment completers and non-completers were compared at pretreatment. Chisquare tests and t-tests were used to compare treatment completers and non-completers along the following sociodemographic and clinical variables: socioeconomic status, parent's marital status, youth ethnicity, youth age, youth sex, interference rating on the youth's primary/target diagnosis, and youth's pretreatment anxiety levels. There were no statistically significant differences between completers and non-completers, with the exception of marital status $\left(\chi^{2}(7)=26.27, \mathrm{p}<.001\right)$. More treatment completers than non-completers were from families in which the mothers were in intact marriages.

The present dissertation provides pre and post treatment outcome, treatment specificity and treatment mediation effects for 253 treatment completers (ages 5 to 16 
years old; $M=9.38 ; S D=2.42$ ) and their parents. A more detailed description of sociodemographic characteristics for participants who completed the treatment is presented in Table 1. The youths' age range of 5 to 16 years reflects the modal age range of the age of onset for separation anxiety disorder (SAD), social phobia (SOP), specific phobia (SP), and generalized anxiety disorder (GAD) in the population and is reflective of CAPP's referral patterns.

The present study's inclusion criteria included the following, all youth must have: A) had a primary diagnosis of a DSM-IV anxiety or phobic disorder, (B) received a mean score of 4 or greater on the Clinician's Rating Scale of Severity (see Measures), (C) ceased all other youth psychosocial treatment after consulting with both CAPP counselor and external service provider, (D) been stable on ADHD stimulants or other such psychopharmacological agents that would confound the study, (E) have been between 6 and 16 years old, (F) had parents/guardians agree to participate in the child's treatment, and $(\mathrm{G})$ agreed to be randomized into either the ICBT condition, RLST condition, or the RFST condition, including weekly involvement in therapy (approximately 60 minutes in length).

The study's exclusion criteria included the following, the youth must have: (A) met a primary diagnosis that was not a DSM-IV anxiety or phobic disorder, or (B) met diagnoses (e.g., primary, secondary, tertiary) for any one of the following disorders: Pervasive Developmental Disorders, Mental Retardation, Organic Mental Disorders, Schizophrenia and Other Psychotic Disorders, or (C) failed to withdraw from other psychosocial treatment, or (D) not been stable on ADHD stimulants or other such psychopharmacological agents, (E) shown high likelihood and/or serious intent of hurting 
themselves or others. Screening for exclusionary criteria was accomplished through a standardized telephone screen, and if necessary, youth and parent interview schedules were administered.

Youth who met criteria for a primary diagnosis of a DSM-IV anxiety and/or phobic disorder were evaluated on the basis of the ADIS-IV: C/P (Silverman \& Albano, 1996), a structured interview administered to the youth and parent individually. Youth that completed treatment in the current study met for a primary diagnoses of: SAD $(n=$ 63), SOP ( $(n=62)$, SP $(n=36), \operatorname{GAD}(n=67), \operatorname{OCD}(n=2)$, PD with agoraphobia $(n=$ 10), PD without agoraphobia $(n=3)$, and Selective Mutism $(n=10)$, with $69.6 \%$ of the youth $(\mathrm{n}=176)$ having at least one comorbid diagnosis.

\section{Measures}

Diagnostic instruments administered to youths and parents. The Anxiety Disorders Interview Schedule for DSM-IV: Child and Parent Versions (ADIS for DSMIV: C/P; Silverman \& Albano, 1996). The ADIS for DSM-IV was administered to each youth and parent to assess anxiety and related disorders in the youth. Interviewers assigned diagnoses that were most interfering based on youth and parent's separate interviews. In cases of disagreement, the interviewer considered both informants' views to derive a final diagnosis. In cases of multiple diagnoses, interviewers assessed the interference of each disorder to prioritize which diagnoses were most interfering. The disorder deemed most interfering was viewed as primary and thus targeted in treatment. The test-retest reliability estimates for the diagnosis of anxiety disorders have been reported to be good to excellent range (e.g., $\kappa=0.63$ to 0.83 for the ADIS-C child version, $\kappa=0.65$ to 0.88 for the ADIS-C parent version, and $\kappa=0.80$ to 0.92 for the 
composite diagnosis; Silverman, Saavedra, \& Pina, 2001). Reliability estimates for the clinician severity ratings have been found to range from 0.74 to 0.88 (Silverman \& Eisen, 1992; Silverman \& Nelles, 1988).

Youth completed outcome measures. Revised Children's Manifest Anxiety Scale (RCMAS; Reynolds \& Richmond, 1978; 1985). The RCMAS is a 37-item self-rating scale intended to assess youth anxiety symptoms. Twenty-eight items, using a Yes (1) or No (0) response system, yield a Total Anxiety score. The RCMAS is the most widely used and widely researched youth self-rating anxiety scale (see review by Silverman \& Ollendick, 2005). The test-retest reliability estimate was reported as $r=0.98$ for the Total Anxiety scale (Pela \& Reynolds, 1982). Concurrent validity estimates were reported to range from ( $r s) 0.65$ to 0.76 (Lee, Piercel, Friedlander, \& Collamer, 1988). The internal consistency coefficient (Cronhach's alpha) was 0.83 for the present sample.

Multidimensional Anxiety Scale for Children (MASC; March, 1997). The MASC is a 39-item self-rating scale intended to assess four dimensions of youth anxiety: physical symptoms, harm avoidance, social anxiety, and separation/panic. This measure uses a 4-point scale: (0) never true about me, (1) rarely true about me, (2) sometimes true about me, (3) often true about me. The MASC demonstrated to have satisfactory testretest reliability estimates (March et al., 1997) and acceptable validity as it correlates with the RCMAS (Kovacs, 1992). The internal consistency coefficient (Cronhach's alpha) was 0.89 for the present sample.

Parent completed outcome measures. Revised Children's Manifest Anxiety Scale (RCMAS-P; Reynolds \& Richmond, 1978; 1985). The 37 items of the RCMAS were changed from "I..." to "My child..." in order for parents to rate the occurrence of 
youth anxious symptoms, as done in past research (e.g., Kendall, 1994; Silverman et al., 1999). Twenty-eight items, using a Yes (1) or No (0) response system, yield a Total Anxiety score. The test-retest reliability estimate was reported as $r=0.85$ for the Total Anxiety scale (Pina, Silverman, Saavedra, \& Weems, 2001). The present study used the RCMAS total anxiety scale, The internal consistency coefficient (Cronhach's alpha) was 0.80 for the present sample.

Parent mediator variables. All variables indicated below were assessed using both youth and parent versions of questionnaires.

Child Development Questionnaire (CDQ; Zabin \& Melamed, 1980). The CDQ is a list of 15 situations representative of youth's most common fears (e.g., injection, approaching a dog, being teased) based on earlier surveys (Jersild, Markey, \& Jersild, 1933; Pratt, 1945). The items selected correspond closely to more contemporary surveys of youth's fears (e.g., Ollendick, 1983). This questionnaire is intended to assess parent's behaviors during youths' feared situations. Parents are asked to indicate which of the five choices given for each situation most accurately represents the way she/he would deal with the situation if it were to arise at the present time with her/his youth. The five choices for each situation fall within the following categories/subscales: Positive Reinforcement, Negative Reinforcement, Punishment, Force, and Modeling. The Positive Reinforcement (CDQ-PR) and Negative Reinforcement (CDQ-NR) subscales were used to assess the hypothesized parent mediator variables: 1) Parent use of positive reinforcement and 2) Parent use of negative reinforcement (i.e., not allowing for youth avoidance behavior). 
Although the questionnaire was developed for use with parents, the present dissertation also used a youth version by changing the stem of the items so that the parent is referred to as the third person and youth as the first person (e.g., "If I told my child..." to "If my mother told me..."). This is commonly done in youth anxiety intervention research (Kendall, 1994; Silverman et al., 1999a, b). To distinguish the youth version from the parent version, from hereon the youth version will be referred to as CDQ-C-PR for the Positive Reinforcement subscale and CDQ-C-NR for Negative Reinforcement subscale. The alpha coefficients for the CDQ-PR and CDQ-NR in the current study were 0.86 and 0.67 , respectively. The alpha coefficients for the CDQ-C-PR and CDQ-C-NR in the current study were 0.90 and 0.78 , respectively.

Parenting Behavior Inventory (Child Report/Parent Report; CRPBI \& PRPBI; Schluderman \& Schluderman, 1970). The CRPBI/PRPBI is a 30-item shortened version of the 108-item revision of Schaefer's original CRPBI (1965). This inventory is intended to assess respondents' perceptions of the parent's behaviors toward the youth (i.e., parenting behaviors) from the perspective of the youth and parent, respectively. The inventory has been found to have three subscales with 10 questions each: Psychological Control, Acceptance, and Firm Control. The Psychological Control (CRPBI-PC/PRPBIPC) subscale was used to assess the hypothesized parent mediator variable, Parent Autonomy Granting, in the present study. The youth completed the forms on their mother. The internal consistency coefficient (Cronhach's alpla) of the subscales have been found to range from 0.65 to 0.74 (Schwartz, Barton-Henry, \& Pruzinsky, 1985). The alpha coefficients for the CRPBI and PRPBI in the current study were 0.79 and 0.72 , respectively. 
Clinically significant improvement variables. Child Behavior Checklist (CBCL;

Achenbach \& Rescorla, 2001). The CBCL is a 118-item parent rating scale intended to assess youth emotional and behavioral problems. This measure uses a 3-point scale: (0) not true, (1) somewhat or sometimes true, and (2) very true or often true. Specifically, the parents' ratings on both the CBCL's Internalizing (CBCL-I) and Anxious/Depressed subscales (CBCL-A/D) were used to evaluate youth treatment response, as in past research studies. The test-retest reliability was reported as $r=0.91$ for the Internalizing subscale and $r=0.82$ for the Anxious/Depressed subscale (Achenbach, 1991). Concurrent validity was reported to range from ( $r s) .52$ to .88 (Achenbach, 1991). Similar to previous research (e.g., Achenbach et al., 2001) clinically significant improvement for both the Internalizing and Anxious/Depressed subscales were defined as a minimum criterion $T$ score of less than 70 (adjusted according to age norms).

Children's Global Assessment Scale (C-GAS; Bird, Shaffer, Fisher, \& Gould, 1993). The C-GAS is a clinician rated scale intended to assess youth's overall functioning. Impairments in school, social, and psychological functioning are considered. The descriptive statements related to the severity of symptoms are divided within ten point intervals. Scores for this scale range from 1 to 100, with higher scores indicating higher levels of functioning. Scores less than 67 are considered to be in the clinical range. As in previous research, C-GAS ratings were derived during case conference meetings headed by Drs. Silverman or Pettit. The inter-rater reliability was reported as 0.66 (ICC) in findings from studies in community (e.g., Shaffer et al., 1983) and clinic (e.g., Dyrborg et al., 2000; Rey, Starling, Wever, Dossetor, \&Plapp, 1995) settings, with validity shown by "caseness" (Bird et al., 1993). 


\section{Procedure}

Assessment interviews and questionnaires were administered after parents provided informed consent and youths provided informed assent. Assessment interviews and questionnaires were generally completed in two sessions by one diagnostician (a trained doctoral student). The order in which the parents and youths were administered the ADIS-C/P was randomized previously to the assessment appointments. While the parent was interviewed, the youth filled out questionnaires with the help of a trained undergraduate assistant. During the second appointment, youth and parents completed any incomplete questionnaires. All measures were completed at pre treatment and post treatment.

Participants who met the study's inclusion criteria were invited back to the clinic and informed consent/assent was obtained for their participation in the study. The participants were randomly assigned to a counselor (another doctoral student) as well as to one of the three manualized treatment conditions: ICBT, RLST, and RFST (discussed below). Participants who did not meet the study's inclusion criteria were referred to an appropriate mental health service.

Study design. The design for the present dissertation was a 3 (Intervention; ICBT versus RLST versus RFST) by 2 (Time; Pre versus Post) between-within design where the Intervention is the between factor and Time is the within factor. Because the study focused on evaluating treatment specificity and mediational effects of parenting variables, participants were randomly assigned to one of the three intervention conditions. Measures were administered to parent, youth and/or clinician at pre treatment and post treatment for all three treatment interventions (ICBT, RLST, RFST). 
Manualized treatment conditions. Participants were assigned to one of three treatment conditions through random assignment. The specific condition (ICBT, RLST, or RFST) used to start the random assignment procedure was determined by the toss of a coin. All subsequent participant assignments to treatment condition were assigned using a table of random numbers.

A manual for each treatment condition was created to standardize the content of each session. Each session within each manual contained the main goals, tasks, homework assignments, treatment schedules and questionnaires needed for that particular session. However, therapists were advised to also consider the youth's developmental needs and the family's expectations when conducting the manualized treatment. Given the high percentage of Hispanic families in the sample, the family conditions were delivered in a bilingual format for non-English speaking parents. ICBT was delivered in English given that the majority of the youth spoke English.

All three treatment conditions included: 1) in-vivo exposures to the youth's fearful situations and 2) training the youth to use cognitive and behavioral strategies to lessen and/or eliminate the fear. The treatment conditions involving the parent (RLST and RFST) differed in the parenting skills taught. RLST taught parental reinforcement skills (i.e., increasing parental use of positive reinforcement and decreasing negative reinforcement); RFST taught parental relationship skills (i.e., increasing autonomy granting and increasing parental acceptance of the youth). All treatment conditions consisted of twelve to fourteen sessions. Treatment sessions for all three conditions were 60 to 80 minutes in length. 
Below is a summary of the core principals in each of the three treatment conditions.

ICBT. Session 1. Introduction and discussion of presenting problems.

Presentation of treatment rationale and goals and the importance of exposure and behavioral and cognitive strategies. Explain out-of-session activities (Show That I Can;

STIC jobs). Session 2. Review treatment rationale and goals. Explain how the youth will be asked to take "small steps" in the program in terms of exposure tasks and construct anxiety hierarchy. Work with youth to devise a hierarchy. Ask youth to continue to work on hierarchy out of session. Session 3. Finalize hierarchy. Assign first STIC task (approach in low anxiety situation). Session 4. Review STIC task. Conduct in-session exposure. Provide modeling, feedback, and praise. Assign STIC task: approach or expose oneself to next anxiety situation on hierarchy. Session 5._Review STIC task. Introduce cognitive component. Identify faulty cognitions, generate incompatible self-statements, explore alternatives, etc. Conduct in-session exposure. Assign STIC task: approach or expose oneself to next anxiety situation on hierarchy. Session 6. Review STIC task. Practice cognitive strategies during in-session exposure. Provide feedback and suggestions. Session 7. Review STIC task. Review cognitive components and continue practice in generating incompatible self-statements, exploring alternatives, etc. Assign next STIC task. Session 8. Review STIC task. Present 4-Step coping plan ("STOP"). For STIC task: Practice using STOP during exposure. Assign next STIC task. Session 9. Review STIC task. Conduct in-session exposure using STOP. Address difficulties in implementation of cognitive strategies. For STIC task: Practice using STOP during exposure. Session 10. Review STIC task. Conduct in-session exposure. Continue practice in using STOP during exposure. Session 11. Review and present relapse prevention. For 
STIC task: Practice STOP. Session 12-14. Review progress, relapse prevention, termination.

RLST. Session 1. Introduction and discussion of presenting problems.

Presentation of treatment rationale and goals and the importance of exposure and behavioral and cognitive strategies. Emphasis is placed on working with anxious youth and their parents. Present rationale for training parents in parental relationship skills, particularly that parents will learn to use autonomy granting of their youth's behaviors coupled with decreased intrusions in their youth's behaviors, as well as the importance of parent acceptance of youth. Explain how these parental behaviors have been found to be related to youth's sense of mastery and confidence. Explain out-of-session activities (Show That I Can; STIC jobs). Session 2. Review treatment rationale and goals. Explain how the youth will be asked to take "small steps" in the program in terms of exposure tasks and how the parent should assist the youth in constructing anxiety hierarchy. Ask parent to work on hierarchy with youth out of session. Session 3. Explain importance of parent-youth relationships in anxiety problems, and how parental granting of autonomy and parent acceptance have been found to be particular issues of concern for families with youth with anxiety and that these behaviors impact negatively on the parent-youth relationship. Indicate that these are the key parenting skills that will be focused on in treatment. Finalize hierarchy and help parents in identifying positive qualities of the youth. Also begin to elicit problem areas (e.g., youth doing chores, youth not doing homework). Assign first STIC task--approach in low anxiety situation. Session 4. Review STIC task. Conduct in-session exposure with youth and have parent provide feedback, and encouragement; point out any observed parental intrusiveness. Continue discussions 
regarding parental autonomy granting and acceptance. Begin training in problem solving skills and emphasize alternative behaviors that involve parent autonomy granting (and not being overly intrusive) and using these skills when faced with conflicts with youth. Create a list of the "conflict" situations and determine how parents can balance the need to "be the parent" while still granting youth autonomy. Assign a parent-youth problem solving session as an out of session task in which parent practices the autonomy granting skills discussed in session; also assign youth next STIC task. Session 5. Review STIC task. Conduct in-session exposure and have parents provide feedback and encouragement; point out any observed parental intrusiveness. Explain to parents how cognitive components were introduced to the youth in youth session. Explain how youth was taught to identify faulty cognitions, generate incompatible self-statements, explore alternatives, etc. Continue practice in problem solving skills, focusing on conflict or problem areas between parent and youth and generating agreeable alternatives and compromising. Ask parent and youth to select problem or conflict area to be targeted as STIC. Practice in session using role-playing, rehearsal, feedback, etc. For STIC task: Arrange time during week when parent and youth will practice problem solving skill. Also assign youth exposure task. Session 6. Review STIC task. Conduct in-session exposure and have parent provide feedback and encouragement; point out any observed parental intrusiveness. Begin training in communication skills training using role-playing, etc. Focus particularly on parents' use of reflective listening of youth's needs and not interrupting the youth. For STIC task: Arrange time during week when parent and youth will work on resolving targeted problem area using new communication skills. Also assign youth exposure task. Session 7. Review STIC task. Explain to parents how youth 
reviewed cognitive components and continued practice in generating incompatible selfstatements, exploring alternatives, etc. Continue discussing with parents issues and difficulties involved in using communication skills and problem solving skills especially within the context of increasing parental autonomy granting and parental acceptance of youth. For STIC task: Arrange time during week when parent and youth will work on resolving targeted problem area using new skills. Also assign youth exposure task.

Session 8. Review STIC task. Explain to parents how youth was presented with the 4Step coping plan ("STOP"). Continue practice in using communication and problemsolving skills that focuses on parental acceptance, and how parents can still maintain the role of parent while still granting youth autonomy and not being overly intrusive. For STIC task: Practice using STOP during exposure. Arrange time during week when parent and youth will work on resolving targeted problem area using new skills. Session 9. Review STIC task. Conduct in-session exposure using STOP and having parent show support and encouragement. Have parent and youth talk about the experience highlighting positive and negative aspects. Problem solve any difficulties in implementation of various strategies. For STIC task: Practice using STOP during exposure. Have parent and youth have a discussion about the exposure experience using communication skills, focusing on parent role in allowing the youth to experience the exposure. Session 10. Review STIC task. Conduct in-session exposure and having parent show support and encouragement. Problem solve any difficulties in implementation of various strategies. For STIC task: Practice using STOP during exposure. Have parent and youth have a discussion about the exposure experience using communication skills or problem solving, if necessary. Session 11. Review and present relapse prevention. For 
STIC task: Practice using STOP during exposure. Have parent and youth have a discussion about the exposure experience using communication skills or problem solving, if necessary. Session 12-14. Review progress, relapse prevention and termination.

RFST. Session 1. Introduction and discussion of presenting problems. Presentation of treatment rationale and goals and the importance of exposure and behavioral and cognitive strategies. Emphasis is placed on working with anxious youth and parents. Present rationale for training parents in parental reinforcement skills, particularly that parents will learn how to use positive reinforcement contingent on youth exposure to anxious situations and will learn how not to allow for negative reinforcement by discouraging youth avoidance (because avoidant behavior functions as a negative reinforcement because youth can escape his/her anxious feelings). Explain out-of-session activities (Show That I Can; STIC jobs). Session 2. Review treatment rationale and goals. Explain how the youth will be asked to take "small steps" in the program in terms of exposure tasks and how the parent should assist the youth in constructing anxiety hierarchy. Ask parent to work on hierarchy with youth out of session. Session 3. Explain importance of parental support and reinforcement. Present behavioral principles to families, including positive and negative reinforcement, extinction and punishment. Explain how the program emphasizes reinforcement and extinction. Finalize hierarchy and devise list of rewards, tangible and nontangible. Assign first STIC task--approach in low anxiety situation, and provide youth with reward as a consequence. Session 4. Review STIC task. Conduct in-session exposure with youth and have parent provide modeling, feedback, and praise. Continue discussions regarding parental positive reinforcement of youth approach and not allowing avoidance behavior by explaining the 
"Protection Trap." Emphasize importance of consistency and following through. Provide rationale for contingency management and begin training in contingency contracting. Devise first contract between parent and youth for next STIC task - approach in anxiety situation and provide contingent reward. Session 5. Review STIC task. Conduct insession exposure. Explain to parents how cognitive components were introduced to the youth in youth session. Explain how youth was taught to identify faulty cognitions, generate incompatible self-statements, explore alternatives, etc. Conduct in-session exposure and have parent provide feedback and reinforcement. Devise contract approach in anxiety situation and provide contingent reward. Session 6. Review STIC task. Have parent provide feedback to youth while youth practices using cognitive strategies during in-session exposure. Devise next contract between parent and youth for next STIC taskapproach in anxiety situation and provide contingent reward. Session 7. Review STIC task. Explain to parents how youth reviewed cognitive components and continued practice in generating incompatible self-statements, exploring alternatives, etc. Continue discussing with parents issues and difficulties involved in appropriate use of contingency management. Devise contract between parent and youth for next STIC task. Session 8. Review STIC task. Explain to parents how youth was presented with the 4-Step coping plan ("STOP"). Explain that this week is last out of session exposure task where parent delivers a reward contingent on youth completion of STIC. From hereon, youth will self reward or Praise using STOP. Devise next contract between parent and youth for next STIC task - approach in anxiety situation and provide last contingent reward. Session 9. Review STIC task. Conduct in-session exposure using STOP and having parent provide praise for youth's use of STOP. Address difficulties in implementation of various 
strategies, particularly the fading of parental reward to youth self reward. Devise contract between parent and youth for next STIC task in which youth engages in an exposure using STOP, without parental delivery of youth external reward but with parental praise only for youth use of STOP. Session 10. Review STIC task. Conduct in-session exposure using STOP and having parent providing positive feedback for use of STOP. Devise contract between parent and youth for next STIC task in which youth engages in an exposure using STOP, without parental delivery of youth reward but with parental praise only for youth use of STOP. Session 11. Review and present relapse prevention. Write last parent-youth contract. For STIC task: Practice STOP during an exposure. Session 1214. Review progress, relapse prevention and termination.

Therapists. The therapists who treated the majority of the cases were doctoral students in psychology. All therapists received clinical training in the proper administration of the treatment conditions under the supervision of Drs. Silverman or Pettit. As recommended by Kazdin (1994), therapists were crossed between treatment conditions, allowing the investigator to analyze if change is due to treatment variance as opposed to therapist variance. The training of the therapists included the following: 1) familiarization of treatment protocols, 2) understanding of the overlap between treatment conditions but also the fundamental distinctions among treatment conditions, 3) extensive role-playing and open discussions of treatment components. Along with the training, weekly supervision meetings were held to process sessions completed and prepare for upcoming sessions. 


\section{CHAPTER IV.}

\section{RESULTS}

\section{Preliminary Analyses}

Outlier analyses were undertaken prior to all major analyses. The analyses were both non-model based and model based. For the former, multivariate outliers were identified by examining leverage indices for each individual and defining an outlier as a leverage score four times greater than the mean leverage. There were no outliers found in the data using this approach.

An additional set of outlier analyses were pursued using model-based outlier analysis. This involved randomly selecting an indicator for each variable and then regressing the indicator for each endogenous variable onto an indicator for variables of which the endogenous variable is assumed to be a linear function. This analysis uses ordinary least squares (OLS) regression in a limited information estimation framework. Standardized dfbetas were examined for each individual and each predictor as well as the intercept. An outlier is defined as anyone with an absolute standardized dfbeta larger than 1.0. There were no outliers found in the data using this approach.

Regarding normality, univariate indices of skewness and kurtosis were evaluated to determine if the absolute value of any of these indices was greater than 2.0. Nonnormality was evident in several of the variables. To account for the non-normality present in the data, structural equation modeling (SEM) analyses were pursued in MPlus Version 6.0 (Muthén \& Muthén, 2011) by using an estimator (MLR) robust to violations of normality based on the Huber-White algorithm. 
Missing data was minimal, not exceeding more than $10 \%$ of the cases for any given variable. Missing data bias was assessed by computing a dummy variable reflecting the presence or absence of missing data for each variable in the model and then this dummy variable will be correlated with all other variables in the model as well as an array of demographic variables. No theoretically meaningful or significant bias in the missing data was observed in any instance Given the absence of significant bias in the missing data coupled with minimal univariate missing data, missing data was accommodated by employing full information maximum likelihood (FIML) missing data methodology (Enders, 2010) on Mplus Version 6.0.

To examine treatment outcome and specificity, the data were analyzed using analysis of variance within an SEM framework using Mplus Version 6.0. Mediation was analyzed via SEM using Mplus. Results for treatment outcome, treatment specificity, and mediation are presented below.

\section{Treatment Outcome}

Treatment outcome or change in reduction of anxiety from pre to post treatment was evaluated using two approaches: clinically significant change and analyses of variance within a SEM framework on Mplus Version 6.0. The correlation between the parents' ratings of youth anxiety and the youths' self-ratings of anxiety were statistically significant (i.e., 0.25 at the pretest and 0.31 at the immediate posttest), but modest in magnitude. These generally modest correlations are typical of past research (Achenbach, McConaughy, \& Howell, 1987). As a result, the parent and youth ratings on the respective versions of the RCMAS were treated as separate primary outcome measures. 
Clinically significant change. Clinically significant change was reported for all treated children across all three treatment conditions, as well as for each treatment condition separately. Youth who received IBCT, youth who received RLST, and youth who received RFST were compared along each of the three clinically significant change indices using a series of logistic regressions via SEM on Mplus Version 6.0. Clinically significant change was evaluated using three methods: 1) diagnostic recovery rates or percent of children no longer meeting diagnostic criteria for their primary/treated diagnosis, 2) percent of children no longer in the clinical range according to the C-GAS using a minimum criterion score of less than 67 , and 3) percent of children no longer in the clinical range according to the CBCL-I subscale, as well as percent of children no longer in the clinical range according to the CBCL-A/D subscale, using a minimum criterion $\mathrm{T}$ score above 70 for both subscales (adjusted according to age norms).

In terms of diagnostic recovery rates, $77.9 \%$ of youth across the three conditions did not have their primary diagnosis present at post treatment, derived using the ADIS: C/P. For participants in ICBT, $76.1 \%$ of youth did not have their primary diagnosis present at post treatment. For participants in RFST, $82.3 \%$ of youth did not have their primary diagnosis present at post treatment. For participants in RLST, $85.7 \%$ of youth did not have their primary diagnosis present at post treatment. There were no significant differences on diagnostic recovery rates between treatment conditions (ICBT versus RLST: $z=-1.49, p>05$; ICBT versus RFST: $z=-1.05, p>05$; RLST versus RFST: $z=$ $0.56, p>05)$.

In terms of the C-GAS scores at post treatment, $63.6 \%$ of youth across the three conditions were no longer in the clinical range. For participants in ICBT, $60.9 \%$ of youth 
were no longer in the clinical range at post treatment. For participants in RFST, $67.7 \%$ of youth were no longer in the clinical range at post treatment. For participants in RLST, $71.4 \%$ of youth were no longer in the clinical range at post treatment. There were no significant differences between treatment conditions on likelihood of being in the nonclinical range according to the C-GAS at post treatment (ICBT versus RLST: $z=-1.22, p$ $>05$; ICBT versus RFST: $z=-1.11, p>05$; RLST versus RFST: $z=0.25, p>05)$.

In terms of CBCL-I scores at post treatment, $87.4 \%$ of youth across the three conditions were no longer in the clinical range. For participants in ICBT, $87.5 \%$ of youth were no longer in the clinical range at post treatment. For participants in RFST, $86.6 \%$ of youth were no longer in the clinical range at post treatment. For participants in RLST, $88.3 \%$ of youth were no longer in the clinical range at post treatment. There were no significant differences between ICBT and RFST nor between RLST and RFST on likelihood of being in the non-clinical range according to CBCL-I scores at post treatment (ICBT versus RFST: $z=-.25, p>05$; RLST versus RFST: $z=1.75, p>05$ ). Only the comparison between ICBT and RLST was statistically significant (ICBT versus $\left.\operatorname{RLST}_{:}=-1.98, p<.05\right)$ but the difference did not remain statistically significant after using a Holm modified Bonferroni correction for the multiple contrasts.

In terms of CBCL-A/D scores at post treatment, $85.8 \%$ of youth across the three conditions were no longer in the clinical range. For participants in ICBT, $83.3 \%$ of youth were no longer in the clinical range at post treatment. For participants in RFST, $89.7 \%$ of youth were no longer in the clinical range at post treatment. For participants in RLST, $83.3 \%$ of youth were no longer in the clinical range at post treatment. There were no significant differences between ICBT and RLST nor between RLST versus RFST on 
likelihood of being in the non-clinical range according to CBCL-A/D scores at post treatment (ICBT versus RLST: $z=-1.13, p>05$; RLST versus RFST: $z=-0.72, p>05$ ). Only the comparison between ICBT and RFST was statistically significant (ICBT versus RFST: $z=-2.10, p<05$ ) but the difference did not remain statistically significant after using a Holm modified Bonferroni correction for the multiple contrasts.

Youth ratings. The SEM equivalent of $2 \times 3$ between-within analyses of variance were conducted on the youth completed measures, the RCMAS and MASC respectively, using the type of treatment intervention (ICBT, RLST, RFST) as a between-subjects factor and time (pre and post) representing a within-subjects factor.

In terms of the youth completed RCMAS, both main effects of time and treatment intervention as well as the interaction effect were statistically significant. Table 2 presents the cell means and standard deviations for the youth completed RCMAS. Table 3 presents the relevant single degree of freedom contrasts and their associated statistics. The contrasts used non-pooled error terms for the contrasts involving repeated measures (across time) but pooled terms for the contrasts across the between-subjects factor (across groups within time).

The first row of Table 3 presents the single degree of freedom contrasts for the main effect of time collapsing across treatment intervention. The mean difference for the main effect of time collapsing across treatment condition was 4.70 with average scores at post showing a significant decrease in youth self-ratings of anxiety relative to average scores at pre. Rows 2, 3, and 4 present the comparison for treatment intervention collapsing across time. Tests of these comparisons were performed both with and without experiment-wise controls across the three contrasts (using the Holm modified Bonferroni 
method). Only the comparison between ICBT and RFST was statistically significant but the difference did not remain statistically significant after using a Holm modified Bonferroni correction for the multiple contrasts.

To determine if this time difference (i.e., pre to post reductions in RCMAS scores) occurred at each treatment intervention, simple main effects (SME) contrasts were performed. Rows 5, 6, and 7 of Table 3 present statistics for these contrasts. The time difference was statistically significant for all three treatment interventions, with post scores showing a decrease relative to pre treatment scores on the youth completed RCMAS.

To formally test if the time difference was statistically significantly stronger for one intervention group than another, three single degree of freedom interaction contrasts were evaluated. These are reported in rows 8,9 and 10. The first contrast compared the time difference at ICBT versus RLST. The second contrast compared the time difference at ICBT versus RFST. The third contrast compared the time difference at RLST versus RFST. After using the Holm Bonferroni procedures, only the contrast comparing the time difference at ICBT versus RLST was statistically significant. The time difference from pre to post for ICBT (3.35) was significantly lower than the time difference from pre to post for RLST (6.56).

In terms of the MASC, both main effects of time and the interaction effect were statistically significant. Table 4 presents the cell means and standard deviations for the youth completed MASC. Table 5 presents the relevant single degree of freedom contrasts and their associated statistics. The contrasts used non-pooled error terms for the contrasts 
involving repeated measures (across time) but pooled terms for the contrasts across the between-subjects factor (across groups within time).

The first row of Table 5 presents the single degree of freedom contrasts for the main effect of time collapsing across treatment intervention. The mean difference for the main effect of time collapsing across treatment condition was 11.18 , with average scores at post showing a significant decrease in youth self-ratings of anxiety relative to average scores at pre. Rows 2, 3, and 4 of Table 5 present the comparison for treatment intervention collapsing across time. Tests of these comparisons were performed both with and without experiment-wise controls across the three contrasts (using the Holm modified Bonferroni method). None of the comparisons were statistically significant.

To determine if this time difference (i.e., pre to post reductions in MASC scores) occurred at each treatment intervention, simple main effects (SME) contrasts were performed. Rows 5, 6, and 7 of Table 5 present statistics for these contrasts. The time difference was statistically significant for all three treatment interventions, with post scores showing a decrease relative to pre treatment scores on the youth completed MASC.

To formally test if the time difference was statistically significantly stronger for one intervention group than another, three single degree of freedom interaction contrasts were evaluated. These are reported in rows 8,9 and 10 . The first contrast compared the time difference at ICBT versus RLST. The second contrast compared the time difference at ICBT versus RFST. The third contrast compared the time difference at RLST versus RFST. Both the first and third contrasts were statistically significant. The time difference from pre to post for ICBT (6.84) was significantly lower than the time difference from 
pre to post for RLST (18.34). The time difference from pre to post for RFST (10.28) was statistically lower than the time difference from pre to post for RLST (18.34).

Parent ratings. The SEM equivalent of $2 \times 3$ between-within analyses of variance were conducted on the parent completed RCMAS, using the type of treatment intervention (ICBT, RLST, RFST) as a between-subjects factor and time (pre and post) representing a within-subjects factor. The main effect of time was statistically significant. Table 6 presents the cell means and standard deviations for the parent completed RCMAS. Table 7 presents the relevant single degree of freedom contrasts and their associated statistics. The contrasts used non-pooled error terms for the contrasts involving repeated measures (across time) but pooled terms for the contrasts across the betweensubjects factor (across groups within time).

The first row of Table 7 presents the single degree of freedom contrasts for the main effect of time collapsing across treatment intervention. The mean difference for the main effect of time collapsing across treatment condition was 4.81, with average scores at post showing a significant decrease in parent ratings of anxiety relative to average scores at pre. Rows 2, 3, and 4 of Table 7 present the comparison for treatment intervention collapsing across time. Tests of these comparisons were performed both with and without experiment-wise controls across the three contrasts (using the Holm modified Bonferroni method). None of the comparisons were statistically significant.

To determine if this time difference (i.e., pre to post reductions in RCMAS-P scores) occurred at each treatment intervention, simple main effects (SME) contrasts were performed. Rows 5, 6, and 7 of Table 7 present statistics for these contrasts. The time difference was statistically significant for all three treatment interventions, with post 
scores showing a decrease relative to pre treatment scores in parent ratings of child anxiety.

To formally test if the time difference was statistically significantly stronger for one intervention group than another, three single degree of freedom interaction contrasts were evaluated. These are reported in rows 8,9 and 10. The first contrast compared the time difference at ICBT versus RLST. The second contrast compared the time difference at ICBT versus RFST. The third contrast compared the time difference at RLST versus RFST. None of the contrasts were statistically significant.

\section{Treatment Specificity}

Youth ratings. The SEM equivalent of $2 \times 3$ between-within analyses of variance were conducted on the youth completed measures using the mediator (CDQ-C-PR, CDQC-NR, CRPBI-A, CRPBI-PC) as a between-subjects factor and time (pre and post) representing a within-subjects factor. Table 12 presents the cell means and standard deviations for the youth completed measures of mediators.

In terms of the youth completed CDQ-C-PR and CDQ-C-NR, main effects of time were statistically significant for both subscales. Table 8 presents the relevant single degree of freedom contrasts and their associated statistics. The contrasts used non-pooled error terms for the contrasts involving repeated measures (across time) but pooled terms for the contrasts across the between-subjects factor (across groups within time).

The first row for CDQ-C-PR and CDQ-C-NR of Table 8 present the single degree of freedom contrasts for the main effect of time collapsing across treatment intervention. The mean difference for the main effect of time collapsing across treatment condition for CDQ-C-PR was -5.34 with average scores at post showing a significant increase in youth 
ratings of parental positive reinforcement scores relative to pre. The mean difference for the main effect of time collapsing across treatment condition for CDQ-C-NR was 2.52 with average scores at post showing a significant decrease in youth ratings of parental negative reinforcement scores relative to pre. Rows 2, 3, and 4 for CDQ-C-PR and CDQC-NR present the comparison for treatment intervention collapsing across time. Tests of these comparisons were performed both with and without experiment-wise controls across the three contrasts (using the Holm modified Bonferroni method). None of the comparisons were statistically significant for either subscale.

To determine if this time difference occurred at each treatment intervention, simple main effects (SME) contrasts were performed. Rows 5, 6, and 7 for CDQ-C-PR and CDQ-C-NR of Table 8 present statistics for these contrasts. The time difference for CDQ-C-PR was statistically significant for ICBT and RFST, with post scores showing an increase relative to pre treatment scores in youth ratings of parental positive reinforcement in both treatment interventions. The time difference for CDQ-C-NR was statistically significantly only for RFST, with post scores showing a decrease relative to pre treatment scores in youth ratings of parental negative reinforcement.

To formally test if the time difference was statistically significantly stronger for one intervention group than another, three single degree of freedom interaction contrasts were evaluated. These are reported in rows 8, 9 and 10 for CDQ-C-PR and CDQ-C-NR. The first contrast compared the time difference at ICBT versus RLST. The second contrast compared the time difference at ICBT versus RFST. The third contrast compared the time difference at RLST versus RFST. None of the contrasts were statistically significant for either subscale. 
In terms of the youth completed CRPBI-A and CRPBI-PC, treatment intervention was statistically significant for both subscales. The main effects of time were statistically significant only for CRPBI-PC. Table 9 presents the relevant single degree of freedom contrasts and their associated statistics. The contrasts used non-pooled error terms for the contrasts involving repeated measures (across time) but pooled terms for the contrasts across the between-subjects factor (across groups within time).

The first row for CRPBI-A and CRPBI-PC of Table 9 present the single degree of freedom contrasts for the main effect of time collapsing across treatment intervention. The mean difference for the main effect of time collapsing across treatment condition for CRPBI-A was 0.11 with average scores at post showing a decrease in youth ratings of parental acceptance scores relative to pre; this difference was not statistically significant. The mean difference for the main effect of time collapsing across treatment condition for CRPBI-PC was 1.63 with average scores at post showing a significant decrease in youth ratings of parental psychological control scores relative to pre. Rows 2, 3, and 4 for CRPBI-A and CRPBI-PC present the comparison for treatment intervention collapsing across time. Tests of these comparisons were performed both with and without experiment-wise controls across the three contrasts (using the Holm modified Bonferroni method). For CRPBI-A, only the comparison between ICBT and RLST was statistically significant, such that CRPBI-A scores were higher for RLST than ICBT. For CRPBI-PC, only the comparison between ICBT and RFST was statistically significant but the difference did not remain statistically significant after using a Holm modified Bonferroni correction for the multiple contrasts. 
To determine if this time difference occurred at each treatment intervention, simple main effects (SME) contrasts were performed. Rows 5, 6, and 7 for CRPBI-A and CRPBI-PC of Table 9 present statistics for these contrasts. The time difference for CRPBI-A was not statistically significant for any of the three treatment interventions. The time difference for CRPBI-PC was statistically significantly for all three treatment interventions, with post scores showing a decrease relative to pre treatment scores in youth ratings of parental acceptance in all treatment interventions.

To formally test if the time difference was statistically significantly stronger for one intervention group than another, three single degree of freedom interaction contrasts were evaluated. These are reported in rows 8,9 and 10 for CRPBI-A and CRPBI-PC. The first contrast compared the time difference at ICBT versus RLST. The second contrast compared the time difference at ICBT versus RFST. The third contrast compared the time difference at RLST versus RFST. None of the contrasts were statistically significant for either subscale.

Parent ratings. The SEM equivalent of $2 \times 3$ between-within analyses of variance were conducted on the parent completed measures using the mediator (CDQ-PR, CDQNR, PRPBI-A, PRPBI-PC as a between-subjects factor and time (pre and post) representing a within-subjects factor. Table 13 present the cell means and standard deviations for the parent completed measures of mediators.

In terms of the parent completed CDQ-PR and CDQ-NR, both main effects of time and the interaction effect were statistically significant for subscales. The treatment intervention was statistically significant only for CDQ-PR. Table 10 presents the relevant single degree of freedom contrasts and their associated statistics. The contrasts used non- 
pooled error terms for the contrasts involving repeated measures (across time) but pooled terms for the contrasts across the between-subjects factor (across groups within time).

The first row for CDQ-PR and CDQ-NR of Table 10 present the single degree of freedom contrasts for the main effect of time collapsing across treatment intervention. The mean difference for the main effect of time collapsing across treatment condition for CDQ-PR was - 10.87 with average scores at post showing a significant increase in youth ratings of parental positive reinforcement scores relative to pre. The mean difference for the main effect of time collapsing across treatment condition for CDQ-NR was 4.29 with average scores at post showing a significant decrease in youth ratings of parental negative reinforcement scores relative to pre. Rows 2, 3, and 4 for CDQ-PR and CDQ-NR present the comparison for treatment intervention collapsing across time. Tests of these comparisons were performed both with and without experiment-wise controls across the three contrasts (using the Holm modified Bonferroni method). For CDQ-PR, only the comparison between ICBT and RFST was statistically significant, such that CDQ-PR scores were higher for RLST than ICBT. For CDQ-NR, none of the comparisons were statistically significant.

To determine if this time difference occurred at each treatment intervention, simple main effects (SME) contrasts were performed. Rows 5, 6, and 7 for CDQ-PR and CDQ-NR of Table 10 present statistics for these contrasts. The time difference for CDQPR was statistically significant for all three treatment interventions, with post scores showing a decrease relative to pre treatment scores in parent ratings of parental positive reinforcement. The time difference for CDQ-NR was also statistically significantly for all 
three treatment conditions, with post scores showing an increase relative to pre treatment scores in parent ratings of parental negative reinforcement.

To formally test if the time difference was statistically significantly stronger for one intervention group than another, three single degree of freedom interaction contrasts were evaluated. These are reported in rows 8, 9 and 10 for CDQ-PR and CDQ-NR. The first contrast compared the time difference at ICBT versus RLST. The second contrast compared the time difference at ICBT versus RFST. The third contrast compared the time difference at RLST versus RFST. For CDQ-PR, the time difference from pre to post for ICBT (-8.06) was significantly lower than the time difference from pre to post for RFST (-16.18). The time difference from pre to post for RLST (-7.35) was statistically lower than the time difference from pre to post for RFST (-16.18). For CDQ-NR, the time difference from pre to post for ICBT (3.36) was significantly lower than the time difference from pre to post for RFST (5.80). The time difference from pre to post for RLST (3.29) was statistically lower than the time difference from pre to post for RFST (5.80) but the difference did not remain statistically significant after using a Holm modified Bonferroni correction for the multiple contrasts.

In terms of the parent completed PRPBI-A and PRPBI-PC, main effects of time were statistically significant for subscales. The treatment intervention was statistically significant only for PRPBI-A. Table 11 presents the relevant single degree of freedom contrasts and their associated statistics. The contrasts used non-pooled error terms for the contrasts involving repeated measures (across time) but pooled terms for the contrasts across the between-subjects factor (across groups within time). 
The first row for PRPBI-A and PRPBI-PC of Table 11 present the single degree of freedom contrasts for the main effect of time collapsing across treatment intervention. The mean difference for the main effect of time collapsing across treatment condition for PRPBI-A was -0.46 with average scores at post showing a significant increase in youth ratings of parental acceptance scores relative to pre. The mean difference for the main effect of time collapsing across treatment condition for PRPBI-PC was 0.49 with average scores at post showing a significant decrease in youth ratings of parental psychological control scores relative to pre. Rows 2, 3, and 4 for PRPBI-A and PRPBI-PC present the comparison for treatment intervention collapsing across time. Tests of these comparisons were performed both with and without experiment-wise controls across the three contrasts (using the Holm modified Bonferroni method). None of the comparisons were statistically significant for either subscale.

To determine if this time difference occurred at each treatment intervention, simple main effects (SME) contrasts were performed. Rows 5, 6, and 7 for PRPBI-A and PRPBI-PC of Table 11 present statistics for these contrasts. The time difference for PRPBI-A was statistically significant for RLST and RFST, with post scores showing an increase relative to pre treatment scores in parent ratings of parental acceptance. The time difference for PRPBI-PC was also statistically significantly for RLST and RFST, with post scores showing a decrease relative to pre treatment scores in parent ratings of parental psychological control.

To formally test if the time difference was statistically significantly stronger for one intervention group than another, three single degree of freedom interaction contrasts were evaluated. These are reported in rows 8, 9 and 10 for PRPBI-A and PRPBI-PC. The 
first contrast compared the time difference at ICBT versus RLST. The second contrast compared the time difference at ICBT versus RFST. The third contrast compared the time difference at RLST versus RFST. For PRPBI-A, the time difference from pre to post for ICBT (0.11) was significantly lower than the time difference from pre to post for RFST (0.98). For PRPBI-PC, none of the comparisons were statistically significant.

\section{Treatment Mediation Analyses}

The conceptual models depicted in Figures 1, 2, 3, and 4 were analyzed via SEM using MPlus Version 6. 0. The scores of the pre treatment measures were used as covariates for the analysis of group differences (ICBT versus RLST, ICBT versus RFST, and RLST versus RFST) in post treatment means (Rausch, Maxwell, \& Kelley, 2003). Two dummy variables with two values $(\mathrm{D}$, scored 1 or 0$)$ for the three treatment conditions (ICBT, RLST, RFST) were defined and assumed to impact the outcome (i.e., youth anxiety) at the post treatment. Youth age, sex, and ethnicity were entered as covariates in the models that included mediator or outcome variables that showed statistically significant differences in scores across these covariates. Paths were included from age, sex, and ethnicity to all endogenous variables that showed differences in scores across these covariates. Figures 1, 2, 3, and 4 exclude the covariates as well as the correlations between exogenous variables to avoid clutter, but these were included in all model tests. Separate analyses were conducted for youth self-ratings of anxiety and the parent ratings of youth anxiety and for each of the hypothesized mediators (i.e., CDQ/CDQ-C-PR, CDQ-/CDQ-C-NR, CRPBI-/PRPBI-PC, CRPBI-PRPBI-PC).

Following recommendations of Bollen and Long (1993), a variety of global fit indices were used, including indices of absolute fit, indices of relative fit and indices of 
fit with a penalty function for lack of parsimony. These include the traditional overall chi square test of model fit (which should be statistically non-significant), the Root Mean Square Error of Approximation (RMSEA; which should be less than 0.08 to declare satisfactory fit), the Comparative Fit Index (CFI; which should be greater than 0.95); and the standardized root mean square residual (SRMR; which should be less than 0.05).

With respect to treatment mediation effects, the joint significance test was used to examine these effects as recommended by MacKinnon, Lockwood, Hoffman, West, and Sheets (2002) and as such, the paths of interest in Figures 1, 2, 3, and 4 are $a$ and $b$. Path $a$ represents the differential effects of treatment on the mediator (CDQ-/CDQ-C-PR, CDQ-/CDQ-C-NR, CRPBI-/PRPBI-PC, CRPBI-PRPBI-PC); path $b$ represents the effect of the mediator on youth anxiety (RCMAS, RCMAS-P, MASC). In accordance with the recommendations of MacKinnon et al., paths $a$ and $b$ need to be statistically significant to conclude that mediation is present to some extent.

Youth ratings. CDQ-C-PR and RCMAS. Figures 5a and 5b represent the models that tested parental positive reinforcement (CDQ-C-PR) as a mediator of treatment outcome as measured by the RCMAS. The models yielded a good fit to the data. The overall chi square test of model fit was not statistically significant $\left(\chi^{2}(2)=0.67, p>.05\right)$. The CFI was 1.00 . The RMSEA was 0.00 . The SRMR was 0.01 . More focused tests of fit revealed no theoretically meaningful or sizeable modification indices. The standardized residuals indicate the proportion of unexplained variance in the endogenous variables. The variables in the models accounted for $32 \%$ of the variance in CDQ-C-PR scores and $30 \%$ of the variance in RCMAS scores. 
Figures 5a represents the model using ICBT as the reference group. Treatment condition was a statistically significant predictor of self-reported youth anxiety at post treatment. Post treatment RCMAS scores were significantly higher for ICBT than RLST $(B=-2.59, S E=0.91, p<.01,95 \% \mathrm{CI}=-4.37$ to -0.80$)$ and $\mathrm{RFST}(B=-2.09, S E=0.73$, $p<.01,95 \% \mathrm{CI}=-3.52$ to -0.65 ), holding age constant. Because treatment condition was not a significant predictor of parental negative reinforcement at post treatment and parental positive reinforcement was not a significant predictor of youth anxiety at post treatment, there is no evidence that CDQ-C-PR mediates youth treatment response.

Figures $5 \mathrm{~b}$ represents the model using RLST as the reference group. Treatment condition was a statistically significant predictor of self-reported youth anxiety at post treatment. Post treatment RCMAS scores were significantly lower for RLST than ICBT $(B=2.59, S E=0.91, p<.01,95 \% \mathrm{CI}=0.80$ to 4.37$)$, holding age constant. Because treatment condition was not a significant predictor of parental negative reinforcement at post treatment and parental positive reinforcement was not a significant predictor of youth anxiety at post treatment, there is no evidence that CDQ-C-PR mediated youth treatment response.

CDQ-C-NR and RCMAS. Figures $6 \mathrm{a}$ and $6 \mathrm{~b}$ represent the models that tested parental negative reinforcement (CDQ-C-NR) as a mediator of treatment outcome as measured by the RCMAS. The models yielded a good fit to the data. The overall chi square test of model fit was not statistically significant $\left(\chi^{2}(2)=4.79, p>.05\right)$. The CFI was 0.98 . The RMSEA was 0.07 . The SRMR was 0.02 . More focused tests of fit revealed no theoretically meaningful or sizeable modification indices. The standardized residuals indicate the proportion of unexplained variance in the endogenous variables. The 
variables in the models accounted for $25 \%$ of the variance in CDQ-C-NR scores and $31 \%$ of the variance in RCMAS scores.

Figures 6a represents the model using ICBT as the reference group. Parental negative reinforcement at post treatment was a statistically significant predictor of youth anxiety at post treatment. Low CDQ-C-NR scores predicted low RCMAS scores $(B=$ $0.09, S E=0.03, p<.01,95 \% \mathrm{CI}=-0.03$ to 0.16 ), holding age constant. Treatment condition also was a statistically significant predictor of self-reported youth anxiety at post treatment. Post treatment RCMAS scores were significantly higher for ICBT than RLST $(B=-2.45, S E=0.92, p<.01,95 \% \mathrm{CI}=-4.81$ to -0.65$)$ and $\mathrm{RFST}(B=-1.92, \mathrm{SE}$ $=0.73, p<.01,95 \% \mathrm{CI}=-3.34$ to -0.50 ), holding age constant. Because treatment condition was not a significant predictor of parental negative reinforcement at post treatment, there is no evidence that CDQ-C-NR mediated youth treatment response.

Figures $6 \mathrm{~b}$ represents the model using RLST as the reference group. Parental negative reinforcement at post treatment was a statistically significant predictor of youth anxiety at post treatment. Low CDQ-C-NR scores predicted low RCMAS scores $(B=$ $0.09, S E=0.03, p<.01,95 \% \mathrm{CI}=0.03$ to 0.16$)$, holding age constant. Treatment condition also was a statistically significant predictor of self-reported youth anxiety at post treatment. Post treatment RCMAS scores were significantly lower for RLST than ICBT $(B=2.45, S E=.92, p<.01,95 \% \mathrm{CI}=0.65$ to 4.25$)$, holding age constant. Because treatment condition was not a significant predictor of parental negative reinforcement at post treatment, there is no evidence that CDQ-C-NR mediated youth treatment response.

CRPBI-A and RCMAS. Figures $7 \mathrm{a}$ and $7 \mathrm{~b}$ represent the models that tested parental acceptance (CRPBI-A) as a mediator of treatment outcome as measured by the 
RCMAS. The models yielded a good fit to the data. The overall chi square test of model fit was not statistically significant $(\chi 2(2)=1.99, \mathrm{p}>.05)$. The CFI was 1.00 . The RMSEA was 0.00 . The SRMR was 0.02 . More focused tests of fit revealed no theoretically meaningful or sizeable modification indices. The standardized residuals indicate the proportion of unexplained variance in the endogenous variables. The variables in the models accounted for $26 \%$ of the variance in CRPBI-A scores and $31 \%$ of the variance in RCMAS scores.

Figure 7a represents the model using ICBT as the reference group. Treatment condition was a statistically significant predictor of self-reported youth anxiety at post treatment. Post treatment RCMAS scores were significantly higher for ICBT than RLST $(B=-2.30, S E=0.91, p<.05,95 \% \mathrm{CI}=-4.09$ to -0.52$)$ and $\mathrm{RFST}(B=-2.03, S E=0.74$, $p<.001,95 \% \mathrm{CI}=-3.48$ to -0.58$)$. Because treatment condition was not a significant predictor of parental acceptance at post treatment and parental acceptance was not a significant predictor of youth anxiety at post treatment, there is no evidence that CRPBIA mediated youth treatment response.

Figure $7 \mathrm{~b}$ represents the model using RLST as the reference group. Treatment condition was a statistically significant predictor of self-reported youth anxiety at post treatment. Post treatment RCMAS scores were significantly lower for RLST than ICBT $(B=2.30, S E=.91, p<.05,95 \% \mathrm{CI}=0.52$ to 4.09$)$. Because treatment condition was not a significant predictor of parental acceptance at post treatment and parental acceptance was not a significant predictor of youth anxiety at post treatment, there is no evidence that CRPBI-A mediated youth treatment response. 
CRPBI-PC and RCMAS. Figures $8 \mathrm{a}$ and $8 \mathrm{~b}$ represent the models that tested parental psychological control (CRPBI-PC) as a mediator of treatment outcome as measured by the RCMAS. The models yielded a good fit to the data. The overall chi square test of model fit was statistically significant $\left(\chi^{2}(2)=6.22, p>.05\right)$. The CFI was 0.98. The RMSEA was 0.09. The SRMR was 0.02 . More focused tests of fit revealed no theoretically meaningful or sizeable modification indices. The standardized residuals indicate the proportion of unexplained variance in the endogenous variables. The variables in the models accounted for $37 \%$ of the variance in CRPBI-PC scores and $36 \%$ of the variance in RCMAS scores.

Figure 8a represents the model using ICBT as the reference group. Parental psychological control at post treatment was a statistically significant predictor of youth anxiety at post treatment. Low CRPBI-PC scores predicted low RCMAS scores $(B=$ $0.39, S E=0.08, p<.001,95 \% \mathrm{CI}=0.23$ to 0.55$)$, holding age constant. Because treatment condition was not a significant predictor of parental psychological control at post treatment, there is no evidence that CRPBI-PC mediated youth treatment response. Figure $8 \mathrm{~b}$ represents the model using RLST as the reference group. Parental psychological control at post treatment was a statistically significant predictor of youth anxiety at post treatment. Low CRPBI-PC scores predicted low RCMAS scores $(B=$ $0.39, S E=0.08, p<.001,95 \% \mathrm{CI}=0.23$ to 0.55$)$, holding age constant. Because treatment condition was not a significant predictor of parental psychological control at post treatment, there is no evidence that CRPBI-PC mediated youth treatment response.

CDQ-C-PR and MASC. Figures $9 \mathrm{a}$ and $9 \mathrm{~b}$ represent the models that tested parental positive reinforcement (CDQ-C-PR) as a mediator of treatment outcome as 
measured by the MASC. The models yielded a good fit to the data. The overall chi square test of model fit was not statistically significant $(\chi 2(2)=1.11, p>.05)$. The CFI was 1.00. The RMSEA was 0.00 . The SRMR was 0.01 . More focused tests of fit revealed no theoretically meaningful or sizeable modification indices. The standardized residuals indicate the proportion of unexplained variance in the endogenous variables. The variables in the models accounted for $32 \%$ of the variance in CDQ-C-PR scores and 23\% of the variance in MASC scores.

Figure 9a represents the model using ICBT as the reference group. Treatment condition was a statistically significant predictor of self-reported youth anxiety at post treatment. Post treatment MASC scores were significantly higher for ICBT than RLST ( $B$ $=-9.67, S E=2.58, p<.001,95 \% \mathrm{CI}=-14.73$ to -4.60 ), holding age constant. Because treatment condition was not a significant predictor of parental positive reinforcement and parental positive reinforcement was not a significant predictor of youth anxiety at post treatment, there is no evidence that CDQ-C-PR mediated youth treatment response.

Figure $9 \mathrm{~b}$ represents the model using RLST as the reference group. Treatment condition was a statistically significant predictor of self-reported youth anxiety at post treatment. Post treatment MASC scores were significantly lower for RLST than ICBT ( $B$ $=9.67, S E=2.58, p<.001,95 \% \mathrm{CI}=4.60$ to 14.73$)$ and $\operatorname{RFST}(B=6.15, S E=2.46, p<$ $.05,95 \% \mathrm{CI}=1.33$ to 10.98$)$, holding age constant. Because treatment condition was not a significant predictor of parental positive reinforcement and parental positive reinforcement was not a significant predictor of youth anxiety at post treatment, there is no evidence that CDQ-C-PR mediated youth treatment response. 
CDQ-C-NR and MASC. Figures 10a and 10b represent the models that tested parental negative reinforcement (CDQ-C-NR) as a mediator of treatment outcome as measured by the MASC. The models yielded a good fit to the data. The overall chi square test of model fit was not statistically significant $(\chi 2(2)=6.73, p<.05)$. The CFI was 0.96. The RMSEA was 0.10. The SRMR was 0.02 . More focused tests of fit revealed no theoretically meaningful or sizeable modification indices. The standardized residuals indicate the proportion of unexplained variance in the endogenous variables. The variables in the models accounted for $25 \%$ of the variance in CDQ-C-NR scores and $25 \%$ of the variance in MASC scores.

Figure 10a represents the model using ICBT as the reference group. Parental negative reinforcement at post treatment was a statistically significant predictor of youth anxiety at post treatment. Low CDQ-C-NR scores predicted low MASC scores $(B=0.36$, $S E=0.10, p<.001,95 \% \mathrm{CI}=0.16$ to 0.55$)$, holding age constant. Treatment condition also was a statistically significant predictor of self-reported youth anxiety at post treatment. Post treatment MASC scores were significantly higher for ICBT than RLST (B $=-8.97, S E=2.53, p<.001,95 \% \mathrm{CI}=-13.93$ to -4.01 ), holding age constant. Because treatment condition was not a significant predictor of parental negative reinforcement at post treatment, there is no evidence that $\mathrm{CDQ}-\mathrm{C}-\mathrm{NR}$ mediated youth treatment response.

Figure 10b represents the model using RLST as the reference group. Parental negative reinforcement at post treatment was a statistically significant predictor of youth anxiety at post treatment. Low CDQ-C-NR scores predicted low MASC scores $(B=0.36$, $S E=0.10, p<.001,95 \% \mathrm{CI}=0.11$ to 0.37$)$, holding age constant. Treatment condition also was a statistically significant predictor of self-reported youth anxiety at post 
treatment. Post treatment MASC scores were significantly lower for RLST than ICBT $(B$ $=8.97, S E=2.53, p<.001,95 \% \mathrm{CI}=0.11$ to 0.38$)$ and $\operatorname{RFST}(B=6.33, S E=2.42, p<$ $.01,95 \% \mathrm{CI}=0.05$ to 0.30 ) and for holding age constant. Because treatment condition was not a significant predictor of parental negative reinforcement at post treatment, there is no evidence that CDQ-C-NR mediated youth treatment response.

CRPBI-A and MASC. Figures 11a and $11 \mathrm{~b}$ represent the models that tested parental acceptance (CRPBI-A) as a mediator of treatment outcome as measured by the MASC. The models yielded a good fit to the data. The overall chi square test of model fit was not statistically significant $(\chi 2(2)=3.78, p>.05)$. The CFI was 0.98 . The RMSEA was 0.06 . The SRMR was 0.02 . More focused tests of fit revealed no theoretically meaningful or sizeable modification indices. The standardized residuals indicate the proportion of unexplained variance in the endogenous variables. The variables in the models accounted for $25 \%$ of the variance in CRPBI-A scores and $19 \%$ of the variance in MASC scores.

Figure 11a represents the model using ICBT as the reference group. Treatment condition was a statistically significant predictor of self-reported youth anxiety at post treatment. Post treatment MASC scores were significantly higher for ICBT than RLST (B $=-8.50, S E=2.70, p<.01,95 \% \mathrm{CI}=-13.79$ to -3.20$)$. Because treatment condition was not a significant predictor of parental acceptance and parental acceptance was not a significant predictor of youth anxiety at post treatment, there is no evidence that CRPBIA mediated youth treatment response.

Figure $11 \mathrm{~b}$ represents the model using RLST as the reference group. Treatment condition was a statistically significant predictor of self-reported youth anxiety at post 
treatment. Post treatment MASC scores were significantly lower for RLST than ICBT $(B$ $=8.50, S E=2.70, p<.01,95 \% \mathrm{CI}=3.20$ to 13.79$)$. Because treatment condition was not a significant predictor of parental acceptance and parental acceptance was not a significant predictor of youth anxiety at post treatment, there is no evidence that CRPBIA mediated youth treatment response.

CRPBI-PC and MASC. Figures $12 \mathrm{a}$ and $12 \mathrm{~b}$ represent the models that tested parental acceptance (CRPBI-PC) as a mediator of treatment outcome as measured by the MASC. The models yielded a good fit to the data. The overall chi square test of model fit was not statistically significant $(\chi 2(2)=0.79, \mathrm{p}>.05)$. The CFI was 1.00 . The RMSEA was 0.00 . The SRMR was 0.01 . More focused tests of fit revealed no theoretically meaningful or sizeable modification indices. The standardized residuals indicate the proportion of unexplained variance in the endogenous variables. The variables in the models accounted for $37 \%$ of the variance in CRPBI-PC scores and $28 \%$ of the variance in MASC scores.

Figure 12a represents the model using ICBT as the reference group. Parental psychological control at post treatment was a statistically significant predictor of youth anxiety at post treatment. Low CRPBI-PC scores predicted low MASC scores $(B=1.06$, $S E=0.25, p<.001,95 \% \mathrm{CI}=0.87$ to 1.56$)$, holding age constant. Treatment condition also was a statistically significant predictor of self-reported youth anxiety at post treatment. Post treatment MASC scores were significantly higher for ICBT than RLST ( $B$ $=-8.05, S E=2.45, p<.01,95 \% \mathrm{CI}=-12.86$ to -3.25$)$, holding age constant. Because treatment condition was not a significant predictor of parental psychological and parental 
psychological was not a significant predictor of youth anxiety at post treatment, there is no evidence that CRPBI-PC mediated youth treatment response.

Figure $12 \mathrm{~b}$ represents the model using RLST as the reference group. Parental psychological control at post treatment was a statistically significant predictor of youth anxiety at post treatment. Low CRPBI-PC scores predicted low MASC scores $(B=1.06$, $0.25, p<.001,95 \% \mathrm{CI}=0.57$ to 1.56 ), holding age constant. Treatment condition also was a statistically significant predictor of self-reported youth anxiety at post treatment. Post treatment MASC scores were significantly lower for RLST than ICBT $(B=8.05, S E$ $=2.45, p<.01,95 \% \mathrm{CI}=3.25$ to 12.86$)$ and $\mathrm{RFST}(B=6.20, \mathrm{SE}=2.34, p<.01,95 \% \mathrm{CI}$ $=1.61$ to 10.79), holding age constant. Because treatment condition was not a significant predictor of parental psychological and parental psychological was not a significant predictor of youth anxiety at post treatment, there is no evidence that CRPBI-PC mediated youth treatment response.

Parent ratings. CDQ-PR and RCMAS-P. Figures 13a and 13b represent the models that tested parental positive reinforcement (CDQ-PR) as a mediator of treatment outcome as measured by the RCMAS-P. The models yielded a good fit to the data. The overall chi square test of model fit was not statistically significant $\left(\chi^{2}(2)=2.80, p>.05\right)$. The CFI was 1.00 . The RMSEA was 0.04 . The SRMR was 0.02 . More focused tests of fit revealed no theoretically meaningful or sizeable modification indices. The standardized residuals indicate the proportion of unexplained variance in the endogenous variables. The variables in the models accounted for $41 \%$ of the variance in CDQ-PR scores and $33 \%$ of the variance in RCMAS-P scores. 
Figure 13a represents the model using ICBT as the reference group. Treatment condition was a statistically significant predictor of parental positive reinforcement at post treatment. Post treatment CDQ-PR scores were significantly lower for ICBT than $\operatorname{RFST}(B=8.65, S E=1.61, p<.001,95 \% \mathrm{CI}=5.49$ to 11.81$)$. Because parental positive reinforcement was not a significant predictor of youth anxiety at post treatment, there is no evidence that CDQ-PR mediated youth treatment response.

Figure $13 \mathrm{~b}$ represents the model using RLST as the reference group. Treatment condition was a statistically significant predictor of parental positive reinforcement at post treatment. Post treatment CDQ-PR scores were significantly lower for RLST than $\operatorname{RFST}(B=8.51, S E=1.77, p<.001,95 \% \mathrm{CI}=5.04$ to 11.98$)$. Because parental positive reinforcement was not a significant predictor of youth anxiety at post treatment, there is no evidence that CDQ-PR mediated youth treatment response.

CDQ-NR and RCMAS-P. Figures $14 \mathrm{a}$ and $14 \mathrm{~b}$ represent the models that tested parental negative reinforcement (CDQ-NR) as a mediator of treatment outcome as measured by the RCMAS-P. The models yielded a good fit to the data. The overall chi square test of model fit was not statistically significant $(\chi 2(2)=6.53, \mathrm{p}<.05)$. The CFI was 0.98 . The RMSEA was 0.10 . The SRMR was 0.02 . More focused tests of fit revealed no theoretically meaningful or sizeable modification indices. The standardized residuals indicate the proportion of unexplained variance in the endogenous variables. The variables in the models accounted for $42 \%$ of the variance in CDQ-NR scores and $34 \%$ of the variance in RCMAS-P scores.

Figure 14a represents the model using ICBT as the reference group. Treatment condition was a statistically significant predictor of parental negative reinforcement at 
post treatment. Post treatment CDQ-NR scores were significantly higher for ICBT than RFST $(B=-2.48, S E=.90, p<.01,95 \% \mathrm{CI}=-4.25$ to -0.71$)$. Because parental negative reinforcement was not a significant predictor of youth anxiety at post treatment, there is no evidence that CDQ-NR mediated youth treatment response.

Figure $14 \mathrm{~b}$ represents the model using RLST as the reference group. None of the paths were statistically significant. Thus, there is no evidence that CDQ-NR mediated youth treatment response.

PRPBI-A and RCMAS-P. Figures 15a and 15b represent the models that tested parental acceptance (PRPBI-A) as a mediator of treatment outcome as measured by the RCMAS-P. The models yielded a good fit to the data. The overall chi square test of model fit was not statistically significant $(\chi 2(2)=0.19, p>.05)$. The CFI was 1.00 . The RMSEA was 0.00 . The SRMR was 0.00 . More focused tests of fit revealed no theoretically meaningful or sizeable modification indices. The standardized residuals indicate the proportion of unexplained variance in the endogenous variables. The variables in the models accounted for $24 \%$ of the variance in PRPBI-A scores and $33 \%$ of the variance in RCMAS-P scores.

Figure 15a represents the model using ICBT as the reference group. Treatment condition was a statistically significant predictor of parental acceptance at post treatment. Post treatment PRPBI-A scores were significantly lower for ICBT than RLST $(B=0.93$, $S E=0.38, p<.05,95 \% \mathrm{CI}=0.19$ to 1.68$)$ and $\operatorname{RFST}(B=0.81, S E=0.31, p<.01,95 \%$ $\mathrm{CI}=0.21$ to 1.41$)$. Because parental acceptance was not a significant predictor of youth anxiety at post treatment, there is no evidence that PRPBI-A mediated youth treatment response. 
Figure $15 \mathrm{~b}$ represents the model using RLST as the reference group. Treatment condition was a statistically significant predictor of parental acceptance at post treatment. Post treatment PRPBI-A scores were significantly higher for RLST than ICBT $(B=$ $0.93, S E=0.38, p<.05,95 \% \mathrm{CI}=0.36$ to 0.59$)$. Because parental acceptance was not a significant predictor of youth anxiety at post treatment, there is no evidence that PRPBIA mediated youth treatment response.

PRPBI-PC and RCMAS-P. Figures 16a and 16b represent the models that tested parental psychological control (PRPBI-PC) as a mediator of treatment outcome as measured by the RCMAS-P. The models yielded a good fit to the data. The overall chi square test of model fit was not statistically significant $(\chi 2(2)=4.29, \mathrm{p}>.05)$. The CFI was 0.99 . The RMSEA was 0.07 . The SRMR was 0.02 . More focused tests of fit revealed no theoretically meaningful or sizeable modification indices. The standardized residuals indicate the proportion of unexplained variance in the endogenous variables. The variables in the models accounted for 30\% of the variance in PRPBI-PC scores and 35\% of the variance in RCMAS-P scores.

Figure 16a represents the model using ICBT as the reference group. None of the paths were statistically significant. Thus, there is no evidence that PRPBI-PC mediated youth treatment response.

Figure $16 \mathrm{~b}$ represents the model using RLST as the reference group. None of the paths were statistically significant. Thus, there is no evidence that PRPBI-PC mediated youth treatment response. 


\section{CHAPTER V.}

\section{DISCUSSION}

The aims of the present dissertation study were to evaluate treatment specificity and mediation effects of parenting variables in two parent-involvement cognitive behavioral treatments. Specifically, the primary aim of this study was to evaluate whether RLST (i.e., Parent Relationship Skills Training, which targets increasing parental acceptance of youth and increasing autonomy granting) and RFST (i.e., Parent Reinforcement Skills Training, which targets increasing parental positive reinforcement and decreasing negative reinforcement) produce specific effects on the targeted parenting variables. ICBT was used as a baseline comparison condition. A secondary aim of the study was to examine whether changes on these parenting variables mediated positive youth treatment response (i.e., anxiety reduction) in each of the respective treatment conditions. The present study was, in part, a response to calls made in the treatment research literature regarding the need not only to emphasize outcome issues, but also treatment specificity and mediation issues (e.g., Kazdin, 2001; Roth et al., 1994;

Silverman et al., 1997).

\section{Summary of Dissertation Findings}

Treatment outcome. Although the evaluation of treatment outcome was not the main focus of this dissertation study, a discussion of the outcome findings is warranted given the equivocal results of past research on the differential treatment benefits of parent involvement in CBT relative to ICBT for youth anxiety disorders (e.g., Mendlowitz, et al., 1999; Nautaet al., 2003; Spence et al., 2000; Wood et al., 2006).). 
ICBT, RLST and RFST were efficacious in reducing anxiety and its disorders in youth. A pattern of anxiety reduction was observed across all indices of change. Clinically significant change was evidenced by diagnostic recovery and a return to nonclinical levels of functional status as measured by C-GAS, CBCL-I and CBCL-A/D scores. Anxiety symptom reduction was evidenced by significantly lower posttreatment scores on the primary outcome measures of anxiety (i.e., youth and parent completed RCMAS and youth completed MASC). In terms of the youth completed RCMAS, the pre to post difference was higher for participants in the RLST condition than in the ICBT condition. For the youth completed MASC, the pre to post difference was higher for RLST than both ICBT and RFST. For the parent completed RCMAS, the pre to post difference was high for participants in the three treatment conditions, with no significant differences between conditions. The findings support the efficacy of all three treatment conditions in reducing youth anxiety, and provide limited support for the superiority of RLST relative to ICBT and RFST, at least based on youth self-ratings of anxiety.

Treatment specificity. Treatment specificity effects were found for participants in RFST as per parent report only. In terms of parental positive reinforcement, RFST, which targeted increasing parental positive reinforcement, had a greater effect on parental positive reinforcement in comparison to both ICBT and RLST at posttreatment. RFST also had a greater effect on parental negative reinforcement in comparison to ICBT. That is, parents in RFST, which targeted the decrease of parental negative reinforcement, were less likely to engage in negative reinforcement of avoidant behaviors at posttreatment than parents with youth in ICBT, which did not target the decrease of parental negative reinforcement. 
Interestingly, in terms of the parent-youth relationship, RFST had a greater effect on parental acceptance at posttreatment than ICBT as per parent report, with no significant differences found between RLST and RFST. RFST, however, did not target the parent-youth relationship. No differences were found between treatment conditions on parental autonomy granting. There were no significant findings found in any of the parenting variables based on youth reports.

Treatment mediation. Treatment mediation was not found for any of the hypothesized parenting variables (i.e., parental acceptance, parental autonomy granting, parental reinforcement). That is, changes in measured parenting variables did not statistically account for reductions in anxiety symptoms from pre to post.

\section{Contribution of the Present Study and Implications}

The present study contributes on theoretical, empirical, and clinical levels. The contributions on each of these levels are summarized below.

Theoretical and empirical implications. The findings of the present study are consistent with past studies demonstrating the efficacy of CBT for reducing anxiety and its disorders in youth when delivered in formats involving only the youth (e.g., Kendall, 1994; Kendall et al., 1997) and involving the parent and youth together (e.g., Barret et al., 1996a; Silverman et al., 2009). The outcome results also suggest that including a parent relationship skills training that focuses on increasing parental acceptance and autonomy granting may be associated with incremental reduction in youth anxiety symptoms beyond individual CBT, at least according to youth self ratings on anxiety symptoms. The association between parental acceptance/rejection, autonomy granting/psychological 
control and youth anxiety has been shown in previous research (e.g., Barrett, 1998; Barrett et al., 1996a; Bodden et al., 2008; Spence et al., 2000).

The study extends past research by focusing on the specificity of treatment effects on intended targets. The present study found partial evidence of treatment specificity. Parents in the RFST condition, which targeted increasing positive reinforcement, were more likely to use positive reinforcement with their anxious youth relative to parents in the RLST condition and parents in the ICBT condition. Parents in the RFST condition, which also targeted decreasing negative reinforcement (i.e., discouraging youth to avoid anxiety-provoking situations/objects) were less likely to engage in negative reinforcement relative to parents in ICBT.

Although an association between RFST and parental acceptance was not hypothesized, parents in the RFST condition were more likely to provide parental acceptance of youth relative to parents in the ICBT condition as per parent report. This finding is interesting given that RFST targeted parental reinforcement skills, not the parent-youth relationship. As previously mentioned, parental acceptance is defined as parental demonstration of positive regard, warmth and support toward the youth (e.g., Clark et al., 2000; Maccoby, 1992; McLeod et al., 2007). It is possible that as parents reward their youth for courageous behavior, a parent feels supportive of their youth and consequently perceives her/himself as high on parental acceptance. It is important for future research to replicate these findings before conclusions can be drawn.

The present study did not find evidence that targeted parenting variables mediated positive treatment outcome. It is plausible that the absence of mediation effects is related to all treatment conditions involving the "basic" components of CBT anxiety reduction 
programs. That is, all three treatment conditions included youth gradually face anxiety provoking situations/events (i.e., in-vivo exposures) and training youth to use cognitive strategies to reduce their anxiety. It is thus possible that the in-vivo exposures and/or the cognitive strategies may be mediating the positive treatment response in all conditions instead of the parenting variables/skills.

Further, the lack of mediation may also be related to the direction of change that these variables are exerting their effects. In Silverman et al.'s (2009) examination of the directionality of change in a randomized clinical trial that involved parents, the traditional view of parents playing a role in their youth's anxiety was not strongly supported. Rather, stronger support was found for youth to parent influence than parent to youth or the bidirectional influence. In terms of the present study, it is plausible that reductions in youth anxiety produced improvements in the targeted parenting variables instead of the common assumption that improvement in parenting variables produce reductions in youth anxiety.

Lastly, including analyses of various follow-up time points may provide evidence for lagged effects in respect to treatment mediation. Follow-up assessments can examine what happens as time passes and parents are allowed to implement what they learned in treatment. For example, if parents continue to reward youth for facing their anxietyprovoking situations (i.e., provide positive reinforcement) and reduce/eliminate avoidant behaviors (i.e., not provide negative reinforcement) after the termination of treatment, it is likely that the youth will continue to make gains. That is, it may take time for parents to implement newly acquired parenting skills in meaningful ways and for these to then have an impact on the anxiety levels of the child. 
Examining directionality of change and various time points were beyond the scope of the current study and thus these relations were not pursued. Future studies should pursue these research questions.

These findings highlight the importance of evaluating issues of treatment specificity and mediation in that they inform theory construction in youth anxiety treatment. Addressing these issues in treatment research allows for a check on the fit of a given therapeutic approach between theory and practice. That is, such an examination allows for the systematic "unpacking" and evaluation of hypothesized causal sequences of therapeutic events that are (or are not) efficacious in producing symptomatic improvement (e.g., Brent et al., 1998; Kazdin et al., 2003; Kraemer et al., 2002; Weersing et al., 2002). As a result of clarifying the mechanisms of change in youth anxiety treatment, researchers and clinicians can focus on the variables that will lead to significant symptom reduction. The findings of the present study do not provide evidence that the training of parents in parental reinforcement skills and/or parental relationship skills lead to positive treatment outcome for anxiety-disordered youth. Further research is needed to empirically establish whether targeting these parenting variables ought to be included in youth anxiety treatment.

Clinical implications. The study's findings provide further evidence that clinicians have the flexibility in deciding whether to deliver CBT to only the youth or to the youth and parent together without compromising treatment efficacy. Findings also suggest that including a parent relationship skills training that focuses on increasing parental acceptance and autonomy granting may enhance positive anxiety treatment outcome beyond individual CBT. 
Given the scarcity of treatment specificity research in the youth treatment literature, finding at least partial support for treatment specificity represents an important clinical finding. At least in terms of parental reinforcement skills, the findings suggest that when parents are taught to reward youth for facing his/her fear (i.e., increasing positive reinforcement) and not encouraging/allowing youth to avoid anxiety-provoking situations/objects (i.e., decreasing negative reinforcement), these parenting skills are indeed learned. Targeting parental reinforcement skills is important considering the substantial body of research providing evidence for the role of parental reinforcement in the development and maintenance of youth anxiety (see review by Barmish et al., 2005).

\section{Limitations and Future Research Directions}

Although the current dissertation study's findings are promising, it is important to note some limitations of the study. First, the hypothesized mediators were only analyzed using two points (pretreatment and posttreatment). Given that changes in the mediators need to precede changes in the outcome, the study did not allow for an examination of these temporal issues. As noted above, a plausible explanation for not finding mediation in the hypothesized parenting variables is that these effects could be operating at a later point in time (i.e., there may be lagged effects). To better evaluate the mediators of positive treatment response, future analyses of the treatment study must include data from additional assessment waves (Kraemer, Wilson, Fairburn, \& Agras, 2002).

Second, a limitation of the design of the treatment conditions is that perhaps the treatments were saturated with information with respect to the parenting variables. For example, the Parent Relationship Skills Training condition (i.e., RLST) targeted both parental acceptance/rejection and parental autonomy granting/psychological control. A 
purer test of treatment specificity might be obtained by targeting only one parenting skill, instead of two parenting skills, in each parenting condition.

Third, the intent-to-treat data were not analyzed in this dissertation study. Conducting intent-to-treat analyses is important to draw appropriate conclusions regarding possible differences between treatment completers and non-completers on the mediator and outcome measures. However, treatment completers and non-completers were compared at pretreatment and no significant differences were found between groups. Future analyses of the treatment study should include intent-to-treat analyses. In sum, the current study sets the path for future avenues of youth anxiety treatment research. There is a continued need to move beyond basic comparative research to an examination of treatment specificity and mediation. It is important for future research to advance knowledge in the field of youth anxiety by evaluating evidence-based explanations of treatment as well as exploring the more contemporaneous view of directionality of change (i.e., the bidirectional pathways of the parent-youth relationship). 


\section{REFERENCES}

Achenbach, T. M. (1991). Manual for the Child Behavior Checklist and Revised Child Behavior Profile (Revised). Department of Psychiatry, University of Vermont, Burlington.

Achenbach, T. H., McConaughy, S. H., \& Howell, C. T. (1987). Child/adolescent behavioral emotional problems: Implications of cross-informant correlations for situational specificity. Psychological Bulletin, 101, 213-232.

Achenbach, T. M., \& Rescorla, L. A. (2001). Manual for ASEBA school-age forms \& profiles. Research Center for Children, Youth, and Families, University of Vermont, Burlington.

Alfano, C. A., Pina, A. A., Villalta, I. K., Beidel, D. C., Ammerman, R. T, \& Crosby, L. E. (2009). Mediators and moderators of outcome in the behavioral treatment of childhood social phobia. Journal of the American Academy of Child and Adolescent Psychiatry, 48, 945-953.

Barber, B. K. (1992). Family, personality, and adolescent problem behaviors. Journal of Marriage and the Family, 54, 69-79.

Barber, B. K. (1996). Parental psychological control: Revisiting a neglected construct. Child Development, 67, 3296-3319.

Barber, B. K., Olsen, J. E., \& Shagle, S. C. (1994). Associations between parental psychological and behavioral control and youth internalized and externalized behaviors. Child Development, 65, 1120-1136.

Barmish, A. J. \& Kendall, P. C. (2005). Should parents be co-clients in cognitive behavioral therapy for anxious youth? Journal of Clinical Child and Adolescent Psychology, 34, 569-581.

Barrett, P. M. (1998). Evaluation of cognitive-behavioral group treatments for childhood anxiety disorders. Journal of Clinical Child Psychology, 27, 459-468.

Barrett, P. M. (2000). Treatment of childhood anxiety: developmental aspects. Clinical Psychology Review, 20, 479-494.

Barrett, P. M., Dadds, M. R., \& Rapee, R. M. (1996a). Family treatment of childhood anxiety: A controlled trial. Journal of Consulting and Clinical Psychology, 64, 333-342. 
Barrett, P. M., Rapee, R. M., Dadds, M. M., \& Ryan, S. M. (1996b). Family enhancement of cognitive style in anxious and aggressive children. Journal of Abnormal Child Psychology, 24, 187-203.

Barrett, P. M., Fox, T., \& Farrell, L. J. (2005). Parent-child interactions with anxious children and with their siblings: an observational study. Behaviour Change, 22, 220-235.

Beck, A. T., Weissman, A., Lester, D., \& Trexler, L. (1974). The measurement of pessimism: The Hopelessness Scale. Journal of consulting and Clincial Psychology, 42, 861-865.

Beidel, D. C., Turner, S. M., \& Morris, T. L. (1995). A new inventory to assess childhood social anxiety and phobia: The Social Phobia and Anxiety Inventory for Children. Psychological Assessment, 7, 73-79.

Beidel, D. C., Turner, S. M., \& Morris, T. L. (1999). Psychopathology of childhood social phobia. Journal of the American Academy of Child and Adolescent Psychiatry, 38, 643-650.

Beidel, D. C., Turner, S. M., Sallee, F. R., Ammerman, R. T., Crosby, L. A., \& Pachak, S. (2007). SET-C versus fluoxetine in the treatment of childhood social phobia. Journal of the American Academy of Child and Adolescent Psychiatry, 46, 16221632.

Bird, H. R., Shaffer, D., Fisher, P., Gould, M. S. et al. (1993). The Columbia Impairment Scale (CIS): Pilot findings on a measure of global impairment for children and adolescents. International Journal of Methods in Psychiatric Research, 3, $167-$ 176.

Bodden, D. H. M., Bögels, S. M., Nauta, M. H., de Hann, E. Ringrose, J., Abbelboom, C., ... Appelboom-Geers, K. (2008). Child versus family cognitive-behavioral therapy in clinically anxious youth: An efficacy and partial effectiveness study. Journal of the American Academy of Child and Adolescent Psychiatry, 47, 13841394.

Bögels, S. M., \& Siqueland, L. (2006). Family cognitive behavioral therapy for children and adolescents with clinical anxiety disorders. Journal of the American Academy of Child and Adolescent Psychiatry, 45, 134-141.

Bollen, K.A. and J.S. Long (eds). 1993. Testing Structural Equation Models. Newbury Park, CA: Sage. 
Brent, D. A., \& Kolko, D. J. (1998). Psychotherapy: Definitions, mechanisms of action, and relationship to etiological models. Journal of Abnormal Child Psychology, 26, 17-25.

Chorpita, B. F., Albano, A. M., \& Barlow, D. H. (1996). Cognitive processing in children: Relation to anxiety and family influences. Journal of Clinical Child Psychology, 25, 170-176.

Chorpita, B. F., \& Barlow, D. H. (1998). The development of anxiety: The role of control in the early environment. Psychological Bulletin, 124, 3-21.

Chow, C. \& Pincus, D. B. (2014). Anxiety disorders in children and adolescents. In S. G. Hofman, D. J. A. Dozois, W. Rief, J. A. J. Jasper (Eds.), The Wiley handbook of cognitive behavioral therapy (pp. 849-873). New York: Wiley.

Clark, K. E., \& Ladd, G. W. (2000). Connectedness and autonomy support in parentchild relationships: Links to children's socioemotional orientation and peer relationships. Developmental Psychology, 36, 485-498.

Cobham, V. E., Dadds, M. R., \& Spence, S. H. (1998). The role of parental anxiety in the treatment of childhood anxiety. Journal of Consulting and Clinical Psychology, 66, 893-905.

Cobham, V. E., Dadds, M. R., \& Spence, S. H. (1999). Anxious children and their parents: What do they expect? Journal of Clinical Child Psychology, 28, 220-231.

Cole, D. A., Peeke, L. G., Martin, J. M., Truglio, R., Serocynski, A. D., (1998). A longitudinal look at the relation between depression and anxiety in children and adolescents. Journal of Consulting and Clinical Psychology, 66, 451-460.

Compton, S. N., Peris, T. S., Almirall, D., Birmaher, B., Sherrill, J., Kendall, P. C., ... Albano, A. M. (2014). Predictors and moderators of treatment response in childhood anxiety disorders: Results from the CAMS trial. Journal of Consulting and Clinical Psychology, 82, 212-224.

Copeland, W. E., Shanahan, L., Costello, J., \& Angold, A. (2009). Childhood and Adolescent psychiatric disorders as predictors of young adult disorders. Archives of General Psychiatry, 66, 764-772.

Costello, E. J., Egger, H. L., Copeland, W., Erkanli, A., \& Angold, A. (2011). The developmental epidemiology of anxiety disorders, phenomenology, prevalence, and comorbidity. In Silverman, W. K., \& Fields, A. (2011). Anxiety disorders in children and adolescents: Research, assessment, and intervention, $2^{\text {nd }}$ edition. Cambridge, U. K.: Cambridge University Press. 
Dadds, M. R., Barrett, P. M., Rapee, R. M. (1996). Family process and child anxiety and aggression: An observational analysis. Journal of Abnormal Child Psychology, 24, 715-734.

Dyrborg, J., Larsen, F. W., Nielsen, S., Byman, J., Buhl, N. B., \& Gautrè-Delay, F. (2000). The Children's Gobal Assessment Scale (CGAS) and Global Assessment of Psychosocial Disability (GAPD) in clinical practice-Substance and reliability as judged by intraclass correlations. European Child \& Adolescent Psychiatry, 9, 195-201.

Enders, C. K. (2010). Applied missing data analysis. New York, NY: Guilford.

Fisak Jr., B \& Grills-Taquechel, A. E. (2007). Parental modeling, reinforcement, and information transfer: Risk factors in the development of child anxiety? Clinical Child and Family Psychology Review, 10, 213-231.

Ginsburg, G. S., Siqueland, L., Masia-Warner, C., \& Hedtke, K. A. (2004). Anxiety disorders in children: Family matters. Cognitive and Behavioral Practice, 11, 28 43.

Hill, R.M., Castellanos, D., \& Pettit, J.W. (2011). Suicide-related behaviors and anxiety in children and adolescents: A review. Clinical Psychology Review, 31, 11331144.

Hogemdoorn, S. M., Prins, P. J. M., Boer, F., Vervoort, L., Wolters, L. H., Moorlag, H., ... de Haan, E. (2013). Mediators of Cognitive Behavioral Therapy for anxietydisordered children and adolescents: Cognition, perceived control, and coping. Journal of Clinical Child and Adolescent Psychology, 43, 1-15.

Hollon, S. D. \& Beck, A. T. (2013). Cognitive and cognitive behavioral therapies. In M. J. Lambert (Ed.), Bergin and Garfield's Handbook of Psychotherapy and Behavioral Change ( $6^{\text {th }}$ ed., pp. 447-492). New York, NY: Wiley.

Hudson, J. L. \& Rapee, R. M. (2002). Parent-child interactions in clinically anxious children and their siblings. Journal of Clinical Child and Adolescent Psychology, 31, 548-555.

Hudson, J. L. \& Rapee, R. M. (2005). Psychopathology and the family. New York, NY: Elsevier Science.

Jersild, A. T., Markey, F. V., \& Jersild, C. L. (1933). Children's fears, dreams, wishes, daydreams, likes, dislikes, pleasant and unpleasant memories. Child Development, 12 . 
Kazdin, A. E. (1994). Methodology, design, and evaluation in psychotherapy research. In A. E. Bergin \& S. L. Garfield (Eds.), Handbook of psychotherapy and behavior change (4th ed.) (pp. 19-71). New York: Wiley.

Kazdin, A. E. (1999). Current (lack of) status of theory in child and adolescent psychotherapy research. Journal of Clinical Child Psychology, 28, 533-543.

Kazdin, A. E. (2001). Progression of therapy research and clinical application of treatment require better understanding of the change process. Clinical Psychology: Science and Practice, 8, 143-151.

Kazdin, A. E. (2007). Mediators and mechanisms of change in psychotherapy research. Annual Review of Clinical Psychology, 3, 1-27.

Kazdin, A. E. \& Kendall, P. C. (1998). Current progress and future plans for developing effective treatments: Comments and perspectives. Journal of Clinical Child Psychology, 27, 217-226.

Kazdin, A. E. \& Nock, M. K. (2003). Delineating mechanisms of change in child and adolescent therapy: Methodological issues and research recommendations. Journal of Child Psychology and Psychiatry, 44, 1116-1129.

Kendall, P. C. (1994). Treating anxiety disorders in children: Results of a randomized clinical trial. Journal of Consulting and Clinical Psychology, 62, 200-210.

Kendall , P. C., Hudson, J. L., Gosch, E., Flannery-Schroeder, E., \& Suveg, C. (2008). Cognitive-behavioral therapy for anxiety disordered youth: A randomized clinical trial evalauting child and fmaily modalities. Journal of Consulting and Clinical Psychology, 76, 282-297.

Kendall, P. C., Flannery-Schroeder, E. C., Penichelli-Mindel, S. M., Southam-Gerow, M., Henin, A., \& Warman, M. (1997). Therapy for youths with anxiety disorders: A second randomized clinical trial. Journal of Consulting and Clinical Psychology, 65, 366-380.

Kendall, P. C., \& Marrs-Garcia, A. (1999). Psychometric analyses of a therapy-sensitive measure: The Coping Questionnaire (CQ). Unpublished manuscript, Temple University.

Kendall, P. C. \& Treadwell, K. R. H. (2007). The role of self-statements as a mediator in treatment for youth with anxiety disorders. Journal of Consulting and Clinical Psychology, 75, 380-389. 
Kolko, D. J., Brent, D. A., Baughter, M., Bridge, J., \& Birmaher, B. (2000). Cognitive and family therapies for adolescent depression: Treatment specificity, mediation, and moderation. Journal of Consulting and Clinical Psychology, 68, 603-614.

Kovacs, M. (1992). Children's Depression Inventory Manual. New York: Multi-Health Systems.

Kraemer, H. C., Wilson, T., Fairburn, C. G., \& Agras, S. (2002). Mediators and moderators of treatment effects in randomized clinical trials. Archives of General Psychiatry, 59, 877-883.

Last, C. G., Perrin, S., Hersen, M., \& Kazdin, A. E. (1996). A prospective study of childhood anxiety disorders. Journal of the American Academy of Child and Adolescent Psychiatry, 35, 1502-1510.

Lee, S. W., Piercel, W. C., Friedlander, R., \& Collamer, W. (1988). Concurrent validity of the Revised Children's Manifest Anxiety Scale (RCMAS) for adolescents. Educational and Psychological Measurement, 48, 429-433.

Leitenberg, H., Yost, L. W., \& Carroll-Wilson, M. (1986). Negative cognitive errors in children: Questionnarie development, normative data, and comparisons between children with and without self-reported symptoms of depression, low self-esteem, and evaluation anxiety. Journal of Consulting and Clinical Psychology, 54, 528536.

Maccoby, E. E. (1992). The role of parents in the socialization of children: An historical overview. Developmental Psychology, 28, 1006-1017.

MacKinnon, D. P. (2008). Introduction to statistical mediation analysis. New York, NY: Taylor \& Francis Group, LLC.

MacKinnon, D. P., Lockwood, C. M., Hoffman, J. M., West, S. G., \& Sheets, V. (2002). A comparison of methods to test mediation and other intervening variable effects. Psychological Methods, 7, 83-104.

Manassis, K. \& Bradley, S. J. (1994). The development of childhood anxiety disorders: Toward an integrated model. Journal of Applied Developmental Psychology, 15, $345-366$.

March, J. S., Parker, J., Sullivan, K., Stallings, P., \& Conners, K. (1997). The Multidimensional Anxiety Scale for Children (MASC): Factor structure, reliability and validity. Journal of the American Academy of Child and Adolescent Psychiatry, 36, 554-565. 
Mattison, R. E. (1992). Anxiety disorders. In Child psychopathology: Diagnostic criteria and clinical assessment. (pp. 179-202). Hillsdale, N. J., England: Lawrence Erlbaum Associates.

McLeod, B. D., Wood, J. J.. \& Weisz, J. R. (2007). Examining the association between parenting and childhood anxiety: A meta-analysis. Clinical Psychology Review, 27, $155-172$.

Mendlowitz, S. L., Manassis, K., Bradley, S., Scapillato, D., Miezitis, S., \& Shaw, B. F. (1999). Cognitive-behavioral group treatments in childhood anxiety disorders: The role of parental involvement. Journal of the American Academy of Child and Adolescent Psychiatry, 38, 1223-1229.

Muthén, L.K. and Muthén, B.O. (1998-2011). Mplus User's Guide. Sixth Edition. Los Angeles, CA: Muthén \& Muthén.

National Institutes of Health (1985). Global Improvement Scale. Psychopharmacological Bulletin, 21, 839-843.

Nauta, M. H., Schooling, A., Rapee, R. M., Abbott, M., Spence, S. H. (2004). Development of a parent report measure of children's anxiety: Psychometric properties and comparison with child report in a clinic and normal sample. Behaviour Research and Therapy, 42, 813-839.

Ollendick, T. H. (1983). Reliability and validity of the revised Fear Survey Schedule for Children (FSSC-R). Behaviour Research and Therapy, 21, 685-692.

Pela, O. A., \& Reynolds, C. R. (1982). Cross-cultural application of the revised-children's manifest anxiety scale: Normative and reliability data for Nigerian primary school children. Psychological Reports, 51, 1135-1138.

Pina, A. A., Silverman, W. K., Saavedra, L. M., \& Weems, C. F. (2001). An analysis of the RCMAS lie scale in a clinic sample of anxious children. Anxiety Disorders, $15,443-457$.

Pratt, K. C. (1945). A study of the "fears" of rural children. Journal of Genetic Psychology, 67, 179-194.

Prinz, R. J., Foster, S. L., Kent, R. N., \& O’Leary, D. K. (1979). Multivariate assessment of conflict in distressed and nondistressed mother-adolescent dyads. Journal of Applied Behavior Analysis, 12, 691-700.

Rapee, R. M. (1997). Potential role in childrearing practices in the development of anxiety and depression. Clinical Psychology Review, 17, 47-67. 
Rapee, R. M. (2001). The development of generalized anxiety. In M. W. Vasey \& M. R. Dadds (Eds.), The developmental psychopathology of anxiety (pp. 481-503). Oxford: Oxford University Press.

Rapee, R. M. (2002). The development and modification of temperamental risk for anxiety disorders: Prevention of a lifetime of anxiety? Biological Psychiatry, 52, 947-957.

Rausch, J. R., Maxwell, S.E., \& Kelley, K. (2003). Analytic methods for questions pertaining to a randomized pretest, post-treatment, follow-up design. Journal of Clinical Child and Adolescent Psychology, 32, 467-486.

Rey, J. M., Starling, J., Wever, C., \&Dossetor, D. R. (1995). Inter-rater reliability of global assessment of functioning in a clinical setting. Journal of Child Psychology and Psychiatry, 36, 787-792.

Reynolds, C. R., \& Richmond, B. O. (1978). What I think and feel: A revised measure of children's manifest anxiety. Journal of Abnormal Child Psychology, 6, 271-280.

Reynolds, C. R., \& Richmond, B. O. (1985). Revised Children's Manifest Anxiety Scale. Los Angeles, CA : Western Psychological Services.

Roth, A., Fonagy, P., \& Parry, G. (1994). What works for whom? New York: Guilford Press.

Saavedra, L.M., Silverman, W.K., Morgan-Lopez, A.A., \& Kurtines, W.M. (2010). Cognitive behavioral treatment for childhood anxiety disorders: long-term effects on anxiety and secondary disorders in young adulthood. Journal of Child Psychology and Psychiatry 51, 924-934.

Schaefer, E. S. (1965). Children's reports of parental behavior: An inventory. Child Development, 36, 413-424.

Schludermann, E., \& Schludermann, S. (1970). Replicability of factors in children's report of parent behavior (CRPBI). Journal of Psychology, 76, 239-249.

Schwartz, J., Barton-Henry, M., \& Pruzinsky, T. (1985). Assessing child rearing behaviors: A comparison of ratings made by mother, father, child, and siblings on the CRPBI. Child Development, 56, 462-479.

Settipani, C. A., O’Neil, K. A., Podell, J. L., Beidas, R. S., \& Kendall, P. C. (2013). Youth anxiety and parent factors over time: Directionality of change among youth treated for anxiety. Journal of Clinical Child and Adolescent Psychology, 42, 921. 
Shortt, A. L., Barrett, P. M., \& Fox, T. L. (2001). Evaluating the FRIENDS program: a cognitive-behavioral group treatment for anxious children and their parents. Journal of Clinical Child Psychology, 30, 525-535.

Silverman, W. K., \& Albano, A. M. (1996). Anxiety Disorders Interview Schedule for Children-IV (Child and Parent Versions). San Antonio, TX: Psychological Corporation.

Silverman, W. K. \& Berman, S. L. (2001). Psychosocial interventions for anxiety disorders in children: Status and future directions. In W. K. Silverman \& P. D. A. Treffers (Eds.), Anxiety disorders in children and adolescents: Research, assessment, and intervention. (pp. 313-334). New York: Cambridge University Press.

Silverman, W. K. \& Eisen, A. R. (1992). Age differences in the reliability of parent and child reports of child anxious symptomatology using a structured interview. Journal of American Academy of Child and Adolescent Psychiatry, 31, 117-124.

Silverman, W. K. \& Kurtines, W. M. (1996b). Childhood anxiety and phobic disorders: A pragmatic approach. New York: Plenum Press.

Silverman, W. K., \& Kurtines, W. M. (1997). Theory in youth psychosocial treatment research: Have it or had it? A pragmatic alternative. Journal of Abnormal Youth Psychology, 25, 359-367.

Silverman, W. K., Kurtines, W. M., Ginsburg, G. S., Weems, C. F., Lumpkin, P. W., \& Hicks-Carmichael, D. (1999a). Treating anxiety disorders in children with group cognitive behavior therapy: A randomized clinical trial. Journal of Consulting and Clinical Psychology, 67, 995-1003.

Silverman, W. K., Kurtines, W. M., Ginsburg, G. S., Weems, C. F., Rabian, B., \& Serafini, L. T. (1999b). Contingency management, self-control, and education support in the treatment of childhood phobic disorders: A randomized clinical trial. Journal of Consulting and Clinical Psychology, 67, 675-687.

Silverman, W. K., Kurtines, W. M., Jaccard, J., \& Pina, A. A. (2009). Directionality of change in youth anxiety treatment involving parents: An initial examination. Journal of Consulting and Clinical Psychology, 77, 474-485.

Silverman, W. K. \& Nelles, W. M. (1988). The Anxiety Disorders Interview Schedule for Children. Journal of the American Academy of Child and Adolescent Psychiatry, 27, 772-778.

Silverman, W. K., \& Ollendick, T. H. (2005). Evidence-based assessment of anxiety and disorders in children and adolescents. Journal of Clinical Child and Adolescent Psychology, 34, 380-411. 
Silverman, W. K., Pina, A. A., \& Viswesvaran, C. (2008). Evidence-based psychosocial treatments for phobic and anxiety disorders in children and adolescents. Journal of Clinical Child and Adolescent Psychology, 37, 105-130.

Silverman, W. K., Saavedra, L. M., \& Pina, A. A. (2001). Test-retest reliability of anxiety symptoms and diagnoses with the Anxiety Disorders Interview Schedule for DSM-IV: Child and Parent Versions. Journal of the American Academy of Child and Adolescent Psychiatry, 40, 937-944.

Siqueland, L., Kendall, P. C., \& Steinberg, L. (1996). Anxiety in children: Perceived family environments and observed family interactions. Journal of Clinical Child Psychology, 25, 225-237.

Spence, S. H. (1995). Social skills training: Enhancing social competence with children and adolescents.Windsor, U. K.: NFER-Nelson.

Spence, S. H. (1997). Structure of anxiety symptoms among children: A confirmatory factor-analytic study. Journal of Abnormal Psychology, 106, 280-297.

Spence, S. H., Donovan, C., \& Brechman-Toussaint, M. (2000). The treatment of childhood social phobia: the effectiveness of a social skills training-based, cognitive behavioural intervention, with and without parental involvement. Journal of Child Psychology and Psychiatry, 41, 713-726.

Steinberg, L., Elmer, J. D., \& Mounts, N. S. (1989). Authoritative parenting, psychosocial maturity, and academic success among adolescents. Youth Development, 60, 1424-1436.

Treadwell, K. R. H., \& Kendall, P. C. (1996). Self-talk in youth with anxiety disorders: States of mind, content specificity, and treatment outcome. Journal of Consulting and Clinical Psychology, 64, 941-950.

Weersing, V. R. \& Weisz, J. R. (2002). Mechanisms of action in youth psychotherapy. Journal of Child Psychology and Psychiatry, 43, 3-29.

Wood, J. J., McLeod, B. D., Sigman, M., Hwang, W., \& Chu, B. C. (2003). Parenting and childhood anxiety: Theory, empirical findings, and future directions. Journal of Child Psychology and Psychiatry, 44, 134-151.

Wood, J. J., Piacentini, J. C., Southam-Gerow, M., Chu, B.C., \& Sigman, M. (2006). Family cognitive behavioral therapy for child anxiety disorders. Journal of the American Academy of Child and Adolescent Psychiatry, 45, 314-321. 
Yap, M. B. H., Pilkington, P. D., Ryan, S. M., \& Jorm, A. F. (2014). Parental factors associated with depression and anxiety in young people: A systematic review and meta-analysis. Journal of Affective Disorders, 156, 8-23.

Zabin, M. A. \& Melamed, B. G. (1980). Relationship between parental discipline and children's ability to cope with stress. Journal of Behavioral Assessment, 2, 17-38. 
APPENDICES 
Table 1

Demographic and Diagnostic Information by Treatment Condition

\begin{tabular}{|c|c|c|c|c|c|c|c|c|c|c|c|c|}
\hline \multirow[b]{2}{*}{ Variable } & \multicolumn{4}{|c|}{$\operatorname{ICBT}(\mathrm{n}=87)$} & \multicolumn{4}{|c|}{$\operatorname{RLST}(\mathrm{n}=53)$} & \multicolumn{4}{|c|}{ RFST (n=86) } \\
\hline & $n$ & $\%$ & M & SD & $n$ & $\%$ & M & SD & $n$ & $\%$ & $\mathrm{M}$ & SD \\
\hline $\begin{array}{l}\text { Age } \\
\text { (years) } \\
\text { Gender (male) }\end{array}$ & & & 9.40 & 2.58 & & & 9.05 & 2.18 & & & 9.56 & 2.40 \\
\hline $\begin{array}{l}\text { Target } \\
\text { Diagnosis }\end{array}$ & 61 & 63.5 & & & 28 & 46.7 & & & 51 & 52.6 & & \\
\hline $\begin{array}{l}\text { Separation } \\
\text { Anxiety }\end{array}$ & 23 & 24.0 & & & 18 & 30.0 & & & 27 & 27.8 & & \\
\hline $\begin{array}{l}\text { Social } \\
\text { Phobia }\end{array}$ & 16 & 16.7 & & & 16 & 26.7 & & & 29 & 29.9 & & \\
\hline $\begin{array}{l}\text { Specific } \\
\text { Phobia }\end{array}$ & 16 & 16.7 & & & 6 & 10.0 & & & 14 & 14.4 & & \\
\hline GAD & 24 & 25.0 & & & 15 & 25.0 & & & 19 & 19.6 & & \\
\hline OCD & 3 & 3.1 & & & 0 & 0.0 & & & 0 & 0.0 & & \\
\hline $\begin{array}{l}\text { PD w/ } \\
\text { Agoraphobia } \\
\text { PD w/out }\end{array}$ & 4 & 4.2 & & & 3 & 5.0 & & & 3 & 3.1 & & \\
\hline $\begin{array}{l}\text { Agoraphobia } \\
\text { Selective }\end{array}$ & 3 & 3.1 & & & 0 & 0.0 & & & 0 & 0.0 & & \\
\hline $\begin{array}{l}\text { Mutism } \\
\text { Ethnic }\end{array}$ & 7 & 7.3 & & & 2 & 3.3 & & & 5 & 5.2 & & \\
\hline Background & & & & & & & & & & & & \\
\hline $\begin{array}{l}\text { Euro- } \\
\text { American }\end{array}$ & 10 & 10.4 & & & 7 & 11.7 & & & 12 & 12.4 & & \\
\hline $\begin{array}{l}\text { Hispanic- } \\
\text { Latino }\end{array}$ & 81 & 84.4 & & & 50 & 83.3 & & & 79 & 81.4 & & \\
\hline $\begin{array}{l}\text { African- } \\
\text { American }\end{array}$ & 1 & 1.0 & & & 1 & 1.7 & & & 1 & 1.0 & & \\
\hline $\begin{array}{l}\text { Other/Not } \\
\text { Reported }\end{array}$ & 4 & 4.2 & & & 1 & 1.7 & & & 5 & 5.2 & & \\
\hline $\begin{array}{l}\text { Annual } \\
\text { Income }\end{array}$ & & & & & & & & & & & & \\
\hline$\$ 0-20,999$ & 15 & 15.6 & & & 5 & 8.3 & & & 16 & 16.5 & & \\
\hline $\begin{array}{l}\$ 21,000- \\
40,999\end{array}$ & 14 & 14.6 & & & 7 & 11.7 & & & 24 & 24.7 & & \\
\hline $\begin{array}{l}\$ 41,000- \\
60,999\end{array}$ & 18 & 18.8 & & & 8 & 13.3 & & & 11 & 11.3 & & \\
\hline
\end{tabular}

Note. $\mathrm{GAD}=$ Generalized Anxiety Disorder. $\mathrm{OCD}=$ Obsessive Compulsive Disorder. $\mathrm{PD}=$ Panic Disorder. w/ = with. ICBT = Individual Cognitive Behavior Treatment. RLST $=$ Parent Relationship Training. RFST $=$ Reinforcement Skills Training. 
Table 1 (continued)

Demographic and Diagnostic Information by Treatment Condition

\begin{tabular}{|c|c|c|c|c|c|c|c|c|c|c|c|c|}
\hline \multirow[b]{2}{*}{ Variable } & \multicolumn{4}{|c|}{$\operatorname{ICBT}(n=87)$} & \multicolumn{4}{|c|}{$\operatorname{RLST}(n=53)$} & \multicolumn{4}{|c|}{ RFST $(n=86)$} \\
\hline & $n$ & $\%$ & M & SD & $n$ & $\%$ & $\mathrm{M}$ & SD & $n$ & $\%$ & M & SD \\
\hline $\begin{array}{l}\$ 61,000- \\
80,999\end{array}$ & 14 & 14.6 & & & 14 & 23.3 & & & 13 & 13.4 & & \\
\hline $\begin{array}{l}\$ 81,000- \\
99,999\end{array}$ & 8 & 8.3 & & & 8 & 13.3 & & & 12 & 12.4 & & \\
\hline $\begin{array}{l}\$ 100,000- \\
149,999\end{array}$ & 17 & 17.7 & & & 7 & 11.7 & & & 16 & 16.5 & & \\
\hline$>\$ 150,000$ & 2 & 2.1 & & & 6 & 10.0 & & & 4 & 4.1 & & \\
\hline $\begin{array}{l}\text { Not } \\
\text { Reported }\end{array}$ & 8 & 8.4 & & & 5 & 8.3 & & & 1 & 1.0 & & \\
\hline \multicolumn{13}{|l|}{ Marital Status } \\
\hline Married & 80 & 83.3 & & & 51 & 85.0 & & & 79 & 81.4 & & \\
\hline Divorced & 7 & 7.3 & & & 6 & 10.0 & & & 10 & 10.3 & & \\
\hline Single & 3 & 3.1 & & & 1 & 1.7 & & & 5 & 5.2 & & \\
\hline Separated & 0 & 0.0 & & & 0 & 0.0 & & & 2 & 2.1 & & \\
\hline Remarried & 0 & 0.0 & & & 0 & 0.0 & & & 1 & 1.0 & & \\
\hline $\begin{array}{l}\text { Living } \\
\text { w/partner }\end{array}$ & 2 & 2.1 & & & 2 & 3.3 & & & 0 & 0.0 & & \\
\hline Widowed & 1 & 1.0 & & & 0 & 0.0 & & & 0 & 0.0 & & \\
\hline $\begin{array}{l}\text { Not } \\
\text { Reported }\end{array}$ & 3 & 3.1 & & & 0 & 0.0 & & & 0 & 0.0 & & \\
\hline $\begin{array}{l}\text { Mother's } \\
\text { Education }\end{array}$ & & & & & & & & & & & & \\
\hline $\begin{array}{l}\text { Grade } \\
\text { School }\end{array}$ & 1 & 1.0 & & & 1 & 1.7 & & & 1 & 1.0 & & \\
\hline $\begin{array}{l}\text { Some High } \\
\text { School }\end{array}$ & 0 & 0.0 & & & 0 & 0.0 & & & 1 & 1.0 & & \\
\hline High School & 8 & 8.3 & & & 3 & 5.0 & & & 7 & 7.2 & & \\
\hline GED & 3 & 3.1 & & & 1 & 1.9 & & & 3 & 3.1 & & \\
\hline $\begin{array}{l}\text { Some } \\
\text { College }\end{array}$ & 13 & 13.5 & & & 8 & 13.3 & & & 9 & 9.3 & & \\
\hline College & 8 & 8.3 & & & 9 & 15.0 & & & 12 & 12.4 & & \\
\hline Bachelor's & 26 & 27.1 & & & 20 & 33.3 & & & 31 & 32.0 & & \\
\hline Master's & 21 & 21.9 & & & 9 & 15.0 & & & 13 & 13.4 & & \\
\hline Ph.D. & 3 & 3.1 & & & 0 & 0.0 & & & 1 & 1.0 & & \\
\hline $\begin{array}{l}\text { Technical } \\
\text { Degree }\end{array}$ & 8 & 8.3 & & & 6 & 10.0 & & & 10 & 10.5 & & \\
\hline $\begin{array}{l}\text { Advanced } \\
\text { Degree }\end{array}$ & 1 & 1.0 & & & 2 & 3.3 & & & 8 & 8.2 & & \\
\hline $\begin{array}{l}\text { Other/Not } \\
\text { Reported }\end{array}$ & 3 & 3.1 & & & 1 & 1.7 & & & 1 & 1.0 & & \\
\hline
\end{tabular}


Table 1 (continued)

Demographic and Diagnostic Information by Treatment Condition

\begin{tabular}{|c|c|c|c|c|c|c|c|c|c|c|c|c|}
\hline \multirow[b]{2}{*}{ Variable } & \multicolumn{4}{|c|}{ ICBT $(n=87)$} & \multicolumn{4}{|c|}{$\operatorname{RLST}(\mathrm{n}=53)$} & \multicolumn{4}{|c|}{ RFST (n=86) } \\
\hline & $n$ & $\%$ & M & SD & $n$ & $\%$ & M & SD & $n$ & $\%$ & M & SD \\
\hline \multicolumn{13}{|l|}{$\begin{array}{l}\text { Father's } \\
\text { Education }\end{array}$} \\
\hline $\begin{array}{l}\text { Grade } \\
\text { School }\end{array}$ & 0 & 0.0 & & & & & & & 2 & 2.0 & & \\
\hline $\begin{array}{l}\text { Some High } \\
\text { School }\end{array}$ & 2 & 2.1 & & & 1 & 1.7 & & & 2 & 2.1 & & \\
\hline High School & 12 & 12.5 & & & 6 & 10.0 & & & 11 & 11.3 & & \\
\hline GED & 1 & 1.0 & & & 1 & 1.7 & & & 7 & 7.2 & & \\
\hline $\begin{array}{l}\text { Some } \\
\text { College }\end{array}$ & 17 & 17.7 & & & 11 & 18.3 & & & 10 & 10.3 & & \\
\hline College & 10 & 10.4 & & & 9 & 15.0 & & & 11 & 11.3 & & \\
\hline Bachelor's & 19 & 19.8 & & & 14 & 23.3 & & & 22 & 22.7 & & \\
\hline Master's & 13 & 13.5 & & & 5 & 8.3 & & & 12 & 12.4 & & \\
\hline Ph.D. & 1 & 1.0 & & & 0 & 0.0 & & & 1 & 1.0 & & \\
\hline $\begin{array}{l}\text { Technical } \\
\text { Degree }\end{array}$ & 9 & 9.4 & & & 4 & 6.7 & & & 7 & 7.2 & & \\
\hline $\begin{array}{l}\text { Advanced } \\
\text { Degree }\end{array}$ & 1 & 1.0 & & & 3 & 5.0 & & & 6 & 6.2 & & \\
\hline $\begin{array}{l}\text { Other/Not } \\
\text { Reported }\end{array}$ & 11 & 11.4 & & & 6 & 10.1 & & & 6 & 6.2 & & \\
\hline
\end{tabular}

Note. Mother's Education $=$ Highest education mother attained. Father's Education $=$ Highest education father attained. 
Table 2

Means and Standard Deviations for RCMAS

\begin{tabular}{|c|c|c|c|c|}
\hline & \multicolumn{2}{|c|}{ Pre-treatment } & \multicolumn{2}{|c|}{ Post-treatment } \\
\hline & $M$ & $S D$ & $M$ & $S D$ \\
\hline \multicolumn{5}{|c|}{ Treatment Outcome Measure } \\
\hline \multicolumn{5}{|c|}{ RCMAS } \\
\hline ICBT $(n=96)$ & 11.96 & 6.48 & 8.57 & 6.52 \\
\hline $\operatorname{RLST}(\mathrm{n}=50)$ & 13.04 & 6.53 & 6.67 & 5.99 \\
\hline RFST ( $\mathrm{n}=97)$ & 10.98 & 6.08 & 5.98 & 5.47 \\
\hline
\end{tabular}

Note. RCMAS = Revised Children's Manifest Anxiety Scale. ICBT = Individual Cognitive Behavior Treatment. RLST = Parent Relationship Training. RFST = Reinforcement Skills Training. 
Table 3

Single Degree of Freedom Contrasts: Treatment Outcome, RCMAS

\begin{tabular}{llllll}
\hline & Parameter & SE & $t$ value & $p$ Value & $95 \%$ CI \\
\hline RCMAS & & & & & \\
ME: Time & 14.33 & 2.97 & 4.83 & $<.001$ & 8.51 to 20.14 \\
ME: Treatment for ICBT-RLST & -0.10 & 0.91 & -0.10 & 0.91 & -1.88 to 1.69 \\
ME: Treatment for ICBT-RFST & -1.56 & 0.79 & -1.99 & $<.05$ & -3.10 to -0.02 \\
ME: Treatment for RLST-RFST & -1.47 & 0.87 & -1.69 & 0.09 & -3.17 to 0.78 \\
SME: Pre-Post for ICBT & 20.67 & 4.53 & 4.57 & $<.001$ & 11.80 to 29.54 \\
SME: Pre-Post for RLST & 5.12 & 6.69 & 0.77 & 0.44 & -8.01 to 18.25 \\
SME: Pre-Post for RFST & 11.63 & 4.61 & 2.52 & $<.05$ & 2.60 to 20.66 \\
IC: (pre-post) at ICBT - (pre-post) at RLST & 3.21 & 1.11 & 2.90 & $<.01$ & 1.04 to 5.38 \\
IC: (pre-post) at ICBT - (pre-post) at RFST & 1.52 & 0.88 & 1.74 & 0.08 & -0.19 to 3.22 \\
IC: (pre-post) at RLST - (pre-post) at RFST & -1.69 & 1.09 & -1.56 & 0.12 & -3.82 to 0.43 \\
& & & & & \\
\hline
\end{tabular}

Note. $\mathrm{ME}=$ Main effects. $\mathrm{SME}=$ Simple Main Effects. $\mathrm{IC}=$ Interaction contrast. RCMAS $=$ Revised Children's Manifest Anxiety Scale. ICBT = Individual Cognitive Behavior Treatment. RLST $=$ Parent Relationship Training. RFST $=$ Reinforcement Skills Training 
Table 4

Means and Standard Deviations for MASC

\begin{tabular}{|c|c|c|c|c|}
\hline & \multicolumn{2}{|c|}{ Pre-treatment } & \multicolumn{2}{|c|}{ Post-treatment } \\
\hline & $M$ & $S D$ & $M$ & $S D$ \\
\hline \multicolumn{5}{|c|}{ Treatment Outcome Measure } \\
\hline \multicolumn{5}{|l|}{ MASC } \\
\hline ICBT $(n=96)$ & 51.82 & 16.92 & 45.04 & 20.10 \\
\hline $\operatorname{RLST}(\mathrm{n}=60)$ & 57.58 & 18.43 & 38.18 & 16.28 \\
\hline $\operatorname{RFST}(\mathrm{n}=97)$ & 52.26 & 17.56 & 41.75 & 16.32 \\
\hline
\end{tabular}

Note. $\mathrm{MASC}=$ Multidimensional Anxiety Scale for children. $\mathrm{ICBT}=$ Individual Cognitive Behavior Treatment. RLST $=$ Parent Relationship Training. RFST $=$ Reinforcement Skills Training. 
Table 5

Single Degree of Freedom Contrasts: Treatment Outcome, MASC

\begin{tabular}{llllll}
\hline & Parameter & SE & $t$ value & $p$ Value & $95 \%$ CI \\
\hline MASC & & & & & \\
ME: Time & 93.79 & 21.84 & 4.29 & $<.001$ & 50.98 to 136.60 \\
ME: Treatment for ICBT-RLST & -0.45 & 2.57 & 0.18 & 0.86 & -4.58 to 5.49 \\
ME: Treatment for ICBT-RFST & -1.08 & 2.19 & -0.50 & 0.62 & -5.37 to 3.21 \\
ME: Treatment for RLST-RFST & -1.53 & 2.50 & -0.61 & 0.54 & -6.44 to 3.37 \\
SME: Pre-Post for ICBT & 126.26 & 33.66 & 3.76 & $<.001$ & 60.78 to 192.74 \\
SME: Pre-Post for RLST & 45.83 & 52.63 & 0.87 & 0.38 & -57.32 to 148.98 \\
SME: Pre-Post for RFST & 88.61 & 32.95 & 2.69 & $<.01$ & 24.03 to 153.19 \\
IC: (pre-post) at ICBT - (pre-post) at RLST & 11.49 & 3.25 & 3.53 & $<.001$ & 5.12 to 17.87 \\
IC: (pre-post) at ICBT - (pre-post) at RFST & 3.44 & 2.86 & 1.20 & 0.23 & -2.18 to 9.05 \\
IC: (pre-post) at RLST - (pre-post) at RFST & -8.06 & 3.14 & -2.57 & $<.05$ & -14.20 to -1.91 \\
& & & & & \\
\hline
\end{tabular}

Note. $\mathrm{ME}=$ Main effects. $\mathrm{SME}=$ Simple Main Effects. $\mathrm{IC}=$ Interaction Contrasts. MASC $=$ Multidimensional Anxiety Scale for children. ICBT $=$ Individual Cognitive Behavior Treatment. RLST $=$ Parent Relationship Training. RFST $=$ Reinforcement Skills Training. 
Table 6

Means and Standard Deviations for RCMAS-P

\begin{tabular}{|c|c|c|c|c|}
\hline & \multicolumn{2}{|c|}{ Pre-treatment } & \multicolumn{2}{|c|}{ Post-treatment } \\
\hline & $M$ & $S D$ & $M$ & $S D$ \\
\hline \multicolumn{5}{|c|}{ Treatment Outcome Measure } \\
\hline \multicolumn{5}{|l|}{$R C M A S-P$} \\
\hline ICBT $(n=96)$ & 13.68 & 6.02 & 9.01 & 6.04 \\
\hline $\operatorname{RLST}(\mathrm{n}=60)$ & 13.20 & 5.32 & 8.33 & 5.77 \\
\hline RFST ( $\mathrm{n}=97)$ & 12.56 & 5.59 & 7.67 & 5.14 \\
\hline
\end{tabular}

Note. RCMAS-P $=$ Revised Children's Manifest Anxiety Scale-Parent Version. ICBT = Individual Cognitive Behavior Treatment. RLST $=$ Parent Relationship Training. RFST $=$ Reinforcement Skills Training. 
Table 7

Single Degree of Freedom Contrasts: Treatment Outcome, RCMAS-P

\begin{tabular}{llllll}
\hline & Parameter & SE & $t$ value & $p$ Value & $95 \%$ CI \\
\hline RCMAS-P & & & & & \\
ME: Time & 12.78 & 2.57 & 4.98 & $<.001$ & 7.75 to 17.81 \\
ME: Treatment for ICBT-RLST & -0.83 & 0.81 & -1.03 & 0.30 & -2.42 to 0.78 \\
ME: Treatment for ICBT-RFST & -1.20 & 0.76 & -1.59 & 0.11 & -2.70 to 0.28 \\
ME: Treatment for RLST-RFST & -0.37 & 0.78 & -0.48 & 0.63 & -1.91 to 1.16 \\
SME: Pre-Post for ICBT & 16.06 & 4.40 & 3.65 & $<.001$ & 7.44 to 24.68 \\
SME: Pre-Post for RLST & 5.91 & 4.76 & 1.24 & 0.21 & -3.41 to 15.22 \\
SME: Pre-Post for RFST & 13.29 & 3.88 & 3.43 & $<.01$ & 5.69 to 20.88 \\
IC: (pre-post) at ICBT - (pre-post) at RLST & 0.82 & 0.98 & 0.83 & 0.40 & -1.10 to 2.73 \\
IC: (pre-post) at ICBT - (pre-post) at RFST & 0.12 & 0.75 & -0.18 & 0.86 & -1.34 to 1.61 \\
IC: (pre-post) at RLST - (pre-post) at RFST & -0.68 & 0.91 & -0.75 & 0.45 & -2.47 to 1.11 \\
& & & & & \\
\hline
\end{tabular}

Note. $\mathrm{ME}=$ Main effects. SME = Simple Main Effects. RCMAS-P = Revised Children's Manifest Anxiety Scale-Parent Version. ICBT $=$ Individual Cognitive Behavior Treatment. RLST $=$ Parent Relationship Training. RFST $=$ Reinforcement Skills Training. 
Table 8

Single Degree of Freedom Contrasts: Treatment Specificity, CDQ-C-PR/NR

\begin{tabular}{|c|c|c|c|c|c|}
\hline & Parameter & SE & $t$ value & $p$ value & $95 \% \mathrm{CI}$ \\
\hline \multicolumn{6}{|l|}{$C D Q-C-P R$} \\
\hline ME: Time & 111.90 & 15.01 & 7.46 & $<.001$ & 82.48 to 141.31 \\
\hline ME: Treatment for ICBT-RLST & 3.44 & 2.28 & 1.51 & 0.13 & -1.02 to 7.90 \\
\hline ME: Treatment for ICBT-RFST & 2.56 & 1.86 & 1.37 & 0.17 & -1.09 to 6.20 \\
\hline ME: Treatment for RLST-RFST & -0.89 & 2.24 & -0.40 & 0.69 & -5.27 to 3.49 \\
\hline SME: Pre-Post for ICBT & 122.94 & 21.20 & 5.80 & $<.001$ & 81.39 to 164.50 \\
\hline SME: Pre-Post for RLST & 112.96 & 34.68 & 3.26 & $<.01$ & 44.99 to 180.94 \\
\hline SME: Pre-Post for RFST & 94.74 & 24.34 & 3.89 & $<.001$ & 47.04 to 142.45 \\
\hline IC: (pre-post) at ICBT - (pre-post) at RLST & 1.34 & 2.66 & 0.50 & 0.62 & -3.88 to 6.56 \\
\hline IC: (pre-post) at ICBT - (pre-post) at RFST & -0.67 & 2.04 & -0.33 & 0.74 & -4.66 to 3.33 \\
\hline IC: (pre-post) at RLST - (pre-post) at RFST & -2.01 & 2.72 & -0.74 & 0.46 & -7.34 to 3.32 \\
\hline \multicolumn{6}{|l|}{$C D Q-C-N R$} \\
\hline ME: Time & 51.63 & 8.88 & 5.81 & $<.001$ & 34.22 to 69.04 \\
\hline ME: Treatment for ICBT-RLST & 1.13 & 1.54 & 0.73 & 0.47 & -1.90 to 4.15 \\
\hline ME: Treatment for ICBT-RFST & -0.24 & 1.353 & -0.18 & 0.86 & -2.89 to 2.41 \\
\hline ME: Treatment for RLST-RFST & -1.37 & 1.56 & -0.88 & 0.38 & -4.42 to 1.68 \\
\hline SME: Pre-Post for ICBT & 53.29 & 12.52 & 4.26 & $<.001$ & 28.76 to 77.83 \\
\hline SME: Pre-Post for RLST & 34.71 & 19.27 & 1.80 & 0.07 & -3.06 to 72.48 \\
\hline SME: Pre-Post for RFST & 59.98 & 15.38 & 3.90 & $<.001$ & 29.85 to 90.12 \\
\hline IC: (pre-post) at ICBT - (pre-post) at RLST & 1.13 & 1.54 & 0.73 & 0.47 & -1.90 to 4.15 \\
\hline IC: (pre-post) at ICBT - (pre-post) at RFST & -0.24 & 1.35 & -0.18 & 0.86 & -2.89 to 2.41 \\
\hline IC: (pre-post) at RLST - (pre-post) at RFST & -1.37 & 1.56 & -0.88 & 0.38 & -4.42 to 1.68 \\
\hline
\end{tabular}

Note. $\mathrm{ME}=$ Main effects. $\mathrm{SME}=$ Simple Main Effects. $\mathrm{IC}=$ Interaction contrast. CDQ-C-PR $=$ Child Report of the Child

Development Questionnaire-Positive Reinforcement. CDQ-C-NR = Child Report of the Child Development Questionnaire-

Negative Reinforcement. ICBT = Individual Cognitive Behavior Treatment. RLST = Parent Relationship Training. RFST $=$

Reinforcement Skills Training. 
Table 9

Single Degree of Freedom Contrasts: Treatment Specificity, CRPBI-A/PC

\begin{tabular}{|c|c|c|c|c|c|}
\hline & Parameter & SE & $t$ value & $p$ value & $95 \% \mathrm{CI}$ \\
\hline \multicolumn{6}{|l|}{ CRPBI-A } \\
\hline ME: Time & 7.41 & 1.46 & 5.06 & $<.001$ & 4.54 to 10.28 \\
\hline ME: Treatment for ICBT-RLST & 1.62 & 0.52 & 3.12 & $<.01$ & 0.60 to 2.64 \\
\hline ME: Treatment for ICBT-RFST & 0.76 & 0.51 & 1.50 & 0.13 & -0.23 to 1.75 \\
\hline ME: Treatment for RLST-RFST & -0.87 & 0.47 & -1.85 & 0.06 & -1.79 to 0.05 \\
\hline SME: Pre-Post for ICBT & 9.90 & 3.06 & 3.24 & $<.01$ & 3.90 to 15.90 \\
\hline SME: Pre-Post for RLST & 4.34 & 1.45 & 3.00 & $<.01$ & 1.50 to 7.18 \\
\hline SME: Pre-Post for RFST & 5.81 & 1.51 & 3.84 & $<.001$ & 2.85 to 8.78 \\
\hline IC: (pre-post) at ICBT - (pre-post) at RLST & 0.88 & 0.60 & 1.46 & 0.14 & -0.30 to 2.06 \\
\hline IC: (pre-post) at ICBT - (pre-post) at RFST & 0.87 & 0.61 & 1.41 & 0.16 & -0.34 to 2.08 \\
\hline IC: (pre-post) at RLST - (pre-post) at RFST & -0.00 & 0.58 & -0.00 & 0.99 & -1.14 to 1.14 \\
\hline \multicolumn{6}{|l|}{$C R P B I-P C$} \\
\hline ME: Time & 0.53 & 0.05 & 11.67 & $<.001$ & 0.44 to 0.62 \\
\hline ME: Treatment for ICBT-RLST & -1.03 & 0.61 & -1.69 & 0.09 & -2.23 to 0.17 \\
\hline ME: Treatment for ICBT-RFST & -1.18 & 0.53 & -2.23 & $<.05 * *$ & -2.22 to -0.14 \\
\hline ME: Treatment for RLST-RFST & -0.15 & 0.61 & -0.24 & 0.81 & -1.33 to 1.04 \\
\hline SME: Pre-Post for ICBT & 9.09 & 1.88 & 4.83 & $<.001$ & 5.41 to 12.78 \\
\hline SME: Pre-Post for RLST & 9.20 & 2.37 & 3.88 & $<.001$ & 4.55 to 13.85 \\
\hline SME: Pre-Post for RFST & 8.93 & 1.78 & 5.03 & $<.001$ & 5.45 to 12.41 \\
\hline IC: (pre-post) at ICBT - (pre-post) at RLST & 0.68 & 0.65 & 1.04 & 0.30 & -0.60 to 1.96 \\
\hline IC: (pre-post) at ICBT - (pre-post) at RFST & 0.45 & 0.56 & 0.80 & 0.42 & -0.65 to 1.53 \\
\hline IC: (pre-post) at RLST - (pre-post) at RFST & -0.24 & 0.62 & -0.38 & 0.70 & -1.46 to 0.98 \\
\hline
\end{tabular}

Note. $\mathrm{ME}=$ Main effects. $\mathrm{SME}=$ Simple Main Effects. $\mathrm{IC}=$ Interaction contrast. CRPBI-A = Child Report of the Parenting Behavior Inventory-Acceptance. CRPBI-PC $=$ Child Report of the Parenting Behavior Inventory-Psychological Control. ICBT $=$ Individual Cognitive Behavior Treatment. RLST $=$ Parent Relationship Training. RFST $=$ Reinforcement Skills Training. ** $=$ non-significant after Holm modified Bonferroni 
Table 10

Single Degree of Freedom Contrasts: Treatment Specificity), CDQ-PR/NR

\begin{tabular}{|c|c|c|c|c|c|}
\hline & Parameter & SE & $t$ value & $p$ value & $95 \% \mathrm{CI}$ \\
\hline \multicolumn{6}{|l|}{$C D Q-P R$} \\
\hline ME: Time & 51.06 & 11.85 & 4.31 & $<.001$ & 27.83 to 74.28 \\
\hline ME: Treatment for ICBT-RLST & 1.05 & 1.66 & 0.63 & 0.53 & -2.21 to 4.30 \\
\hline ME: Treatment for ICBT-RFST & 5.23 & 1.52 & 3.45 & $<.01$ & 2.26 to 8.19 \\
\hline ME: Treatment for RLST-RFST & 4.18 & 1.78 & 2.34 & $<.05$ & 0.69 to 7.67 \\
\hline SME: Pre-Post for ICBT & 53.17 & 12.96 & 4.10 & $<.001$ & 27.76 to 78.58 \\
\hline SME: Pre-Post for RLST & 67.01 & 21.78 & 3.08 & $<.01$ & 24.33 to 109.69 \\
\hline SME: Pre-Post for RFST & 29.32 & 26.60 & 1.10 & $<.27$ & -22.81 to 81.46 \\
\hline IC: (pre-post) at ICBT - (pre-post) at RLST & 0.71 & 1.64 & 0.43 & 0.67 & -2.51 to 3.93 \\
\hline IC: (pre-post) at ICBT - (pre-post) at RFST & -8.12 & 1.70 & -4.77 & $<.001$ & -11.45 to -4.78 \\
\hline IC: (pre-post) at RLST - (pre-post) at RFST & -8.83 & 1.89 & -4.68 & $<.001$ & -12.52 to -5.13 \\
\hline \multicolumn{6}{|l|}{$C D Q-N R$} \\
\hline ME: Time & 29.09 & 4.71 & 6.18 & $<.001$ & 19.86 to 38.32 \\
\hline ME: Treatment for ICBT-RLST & -0.76 & 1.06 & -0.72 & 0.48 & -2.83 to 1.32 \\
\hline ME: Treatment for ICBT-RFST & -0.98 & 1.01 & -0.97 & 0.33 & -2.96 to 1.00 \\
\hline ME: Treatment for RLST-RFST & -0.22 & 1.03 & -0.22 & 0.83 & -2.24 to 1.80 \\
\hline SME: Pre-Post for ICBT & 39.06 & 9.34 & 4.18 & $<.001$ & 20.75 to 57.38 \\
\hline SME: Pre-Post for RLST & 19.45 & 6.20 & 3.15 & $<.01$ & 7.39 to 31.70 \\
\hline SME: Pre-Post for RFST & 24.72 & 6.31 & 3.92 & $<.001$ & 12.36 to 37.09 \\
\hline IC: (pre-post) at ICBT - (pre-post) at RLST & -0.08 & 1.14 & -0.07 & 0.95 & -2.31 to 2.15 \\
\hline IC: (pre-post) at ICBT - (pre-post) at RFST & 2.44 & 0.94 & 2.60 & $<.01$ & 0.60 to 4.28 \\
\hline IC: (pre-post) at RLST - (pre-post) at RFST & 2.52 & 1.15 & 2.19 & $<.05 * *$ & 0.26 to 4.77 \\
\hline
\end{tabular}

Note. $\mathrm{ME}=$ Main effects. $\mathrm{SME}=$ Simple Main Effects. $\mathrm{IC}=$ Interaction contrast. $\mathrm{CDQ}-\mathrm{PR}=$ Parent Report of the Child

Development Questionnaire-Positive Reinforcement. CDQ-NR = Parent Report of the Child Development Questionnaire-Negative Reinforcement. ICBT $=$ Individual Cognitive Behavior Treatment. RLST $=$ Parent Relationship Training. RFST $=$ Reinforcement Skills Training. ** = non-significant after Holm modified Bonferroni 
Table 11

Single Degree of Freedom Contrasts: Treatment Specificity, PRPBI-A/PC

\begin{tabular}{|c|c|c|c|c|c|}
\hline & Parameter & $\mathrm{SE}$ & $t$ value & $p$ value & $95 \% \mathrm{CI}$ \\
\hline \multicolumn{6}{|l|}{$P R P B I-A$} \\
\hline ME: Time & 2.84 & 0.53 & 5.35 & $<.001$ & 1.80 to 3.89 \\
\hline ME: Treatment for ICBT-RLST & 0.39 & 0.34 & 1.14 & 0.25 & -0.28 to 1.04 \\
\hline ME: Treatment for ICBT-RFST & -0.03 & 0.33 & -0.08 & 0.94 & -0.66 to 0.61 \\
\hline ME: Treatment for RLST-RFST & -0.41 & 0.33 & -1.26 & 0.21 & -1.05 to 1.23 \\
\hline SME: Pre-Post for ICBT & 4.31 & 1.07 & 4.04 & $<.001$ & 2.22 to 6.40 \\
\hline SME: Pre-Post for RLST & 1.34 & 0.56 & 2.41 & $<.05$ & 0.25 to 2.43 \\
\hline SME: Pre-Post for RFST & 2.60 & 0.81 & 3.20 & $<.01$ & 1.01 to 4.18 \\
\hline IC: (pre-post) at ICBT - (pre-post) at RLST & -0.84 & 0.47 & -1.79 & 0.07 & -1.75 to 0.08 \\
\hline IC: (pre-post) at ICBT - (pre-post) at RFST & -0.84 & 0.34 & -2.45 & $<.05$ & -1.51 to -0.17 \\
\hline IC: (pre-post) at RLST - (pre-post) at RFST & -0.00 & 0.50 & -0.01 & 0.99 & -0.97 to 0.97 \\
\hline \multicolumn{6}{|l|}{$P R P B I-P C$} \\
\hline ME: Time & 4.03 & 0.74 & 5.44 & $<.001$ & 2.58 to 5.49 \\
\hline ME: Treatment for ICBT-RLST & -0.44 & 0.38 & -1.14 & 0.25 & -1.19 to 0.31 \\
\hline ME: Treatment for ICBT-RFST & -0.69 & 0.36 & -1.90 & 0.06 & -1.40 to 0.02 \\
\hline ME: Treatment for RLST-RFST & -0.25 & 0.36 & -0.69 & 0.49 & -0.96 to 0.46 \\
\hline SME: Pre-Post for ICBT & 5.27 & 1.51 & 3.49 & $<.001$ & 2.31 to 8.24 \\
\hline SME: Pre-Post for RLST & 1.98 & 0.82 & 2.43 & $<.05$ & 0.38 to 3.59 \\
\hline SME: Pre-Post for RFST & 3.78 & 0.97 & 3.90 & $<.001$ & 1.88 to 5.68 \\
\hline IC: (pre-post) at ICBT - (pre-post) at RLST & 0.68 & 0.65 & 1.04 & 0.30 & -0.60 to 1.96 \\
\hline IC: (pre-post) at ICBT - (pre-post) at RFST & 0.45 & 0.56 & 0.80 & 0.42 & -0.64 to 1.96 \\
\hline IC: (pre-post) at RLST - (pre-post) at RFST & -0.24 & 0.62 & -0.38 & 0.70 & -1.46 to 0.98 \\
\hline
\end{tabular}

Note. $\mathrm{ME}=$ Main effects. $\mathrm{SME}=$ Simple Main Effects. $\mathrm{IC}=$ Interaction contrast. PRPBI-A $=$ Parent Report of the Parenting Behavior Inventory-Acceptance. PRPBI-PC $=$ Parent Report of the Parenting Behavior Inventory-Psychological Control. ICBT $=$ Individual Cognitive Behavior Treatment. RLST = Parent Relationship Training. RFST = Reinforcement Skills Training 
Table 12

Mean (Standard Deviations) for Youth Completed Mediator Measures

\begin{tabular}{|c|c|c|c|c|c|c|}
\hline & \multicolumn{2}{|c|}{ ICBT $(n=96)$} & \multicolumn{2}{|c|}{$\operatorname{RLST}(n=50)$} & \multicolumn{2}{|c|}{$\operatorname{RFST}(n=97)$} \\
\hline & Pre-treatment & Post-treatment & Pre-treatment & Post-treatment & Pre-treatment & Post-treatment \\
\hline \multicolumn{7}{|c|}{ Parent Mediator Measures } \\
\hline CDQ-C-PR & $33.86(12.92)$ & $38.57(16.00)$ & $38.04(14.35)$ & $41.68(16.86)$ & $35.40(12.71)$ & $42.25(14.99)$ \\
\hline CDQ-C-NR & $42.49(9.61)$ & $41.58(11.38)$ & $44.51(11.48)$ & $41.36(10.95)$ & $43.71(10.22)$ & $39.92(11.08)$ \\
\hline CRPBI-A & $25.70(4.63)$ & $26.29(4.19)$ & $27.93(2.53)$ & $27.43(3.23)$ & $26.96(3.25)$ & $26.61(3.94)$ \\
\hline CRPBI-PC & $18.56(4.08)$ & $17.16(4.25)$ & $17.76(3.91)$ & $16.05(4.42)$ & $17.56(4.16)$ & $15.87(3.76)$ \\
\hline
\end{tabular}

Note. CDQ-C-PR = Child Report of the Child Development Questionnaire-Positive Reinforcement. CDQ-C-NR $=$ Child Report of the Child Development Questionnaire-Negative Reinforcement. CRPBI-A = Child Report of the Parenting Behavior InventoryAcceptance. CRPBI-PC = Child Report of the Parenting Behavior Inventory-Psychological Control 
Table 13

Mean (Standard Deviations) for Parent Completed Mediator Measures

\begin{tabular}{|c|c|c|c|c|c|c|}
\hline & \multicolumn{2}{|c|}{ ICBT $(n=96)$} & \multicolumn{2}{|c|}{$\operatorname{RLST}(n=60)$} & \multicolumn{2}{|c|}{$\operatorname{RLST}(n=97)$} \\
\hline & Pre-treatment & Post-treatment & Pre-treatment & Post-treatment & Pre-treatment & Post-treatment \\
\hline \multicolumn{7}{|c|}{ Parent Mediator Measures } \\
\hline CDQ-PR & $34.70(9.93)$ & $42.03(11.38)$ & $35.11(9.96)$ & $43.28(11.50)$ & $34.91(10.25)$ & $50.89(14.60)$ \\
\hline CDQ-NR & $40.72(6.59)$ & $37.40(8.62)$ & $39.75(6.03)$ & $36.85(7.23)$ & $41.27(6.90)$ & $35.21(7.59)$ \\
\hline PRPBI-A & $27.94(2.18)$ & $27.80(2.83)$ & $27.86(2.40)$ & $28.68(2.24)$ & $27.38(2.98)$ & $28.34(2.23)$ \\
\hline PRPBI-PC & $14.01(2.74)$ & $13.69(3.24)$ & $13.90(2.36)$ & $12.91(2.68)$ & $13.41(2.87)$ & $12.78(2.43)$ \\
\hline
\end{tabular}

Note. CDQ-PR = Parent Report of the Child Development Questionnaire-Positive Reinforcement. CDQ-NR = Parent Report of the Child Development Questionnaire-Negative Reinforcement. PRPBI-A = Parent Report of the Parenting Behavior Inventory-

Acceptance. PRPBI-PC = Parent Report of the Parenting Behavior Inventory -Psychological Control 


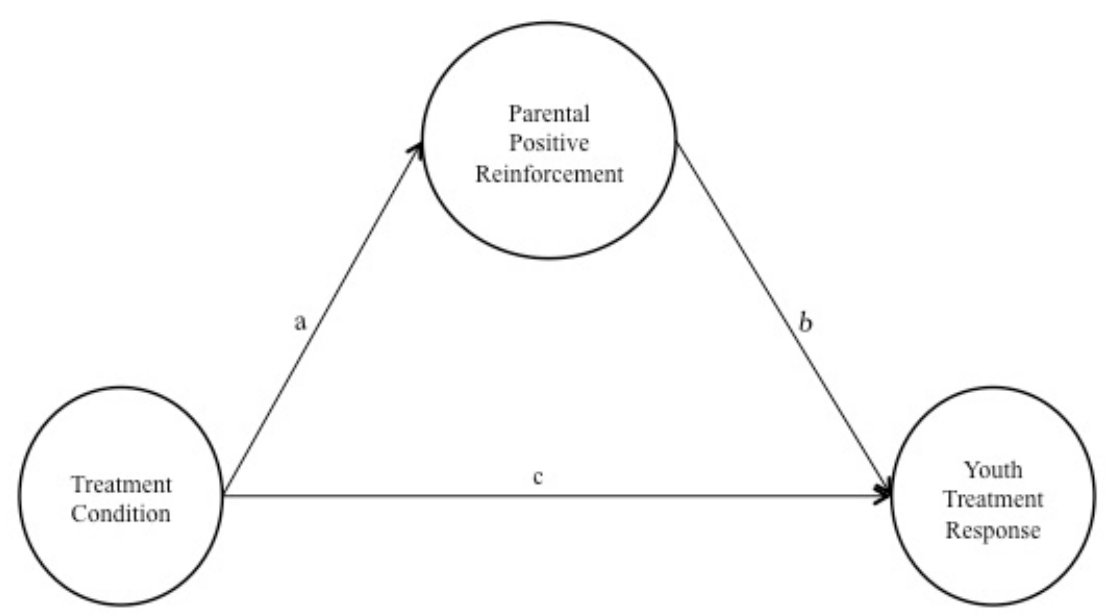


Figure 2. Conceptual Model for Parental Negative Reinforcement

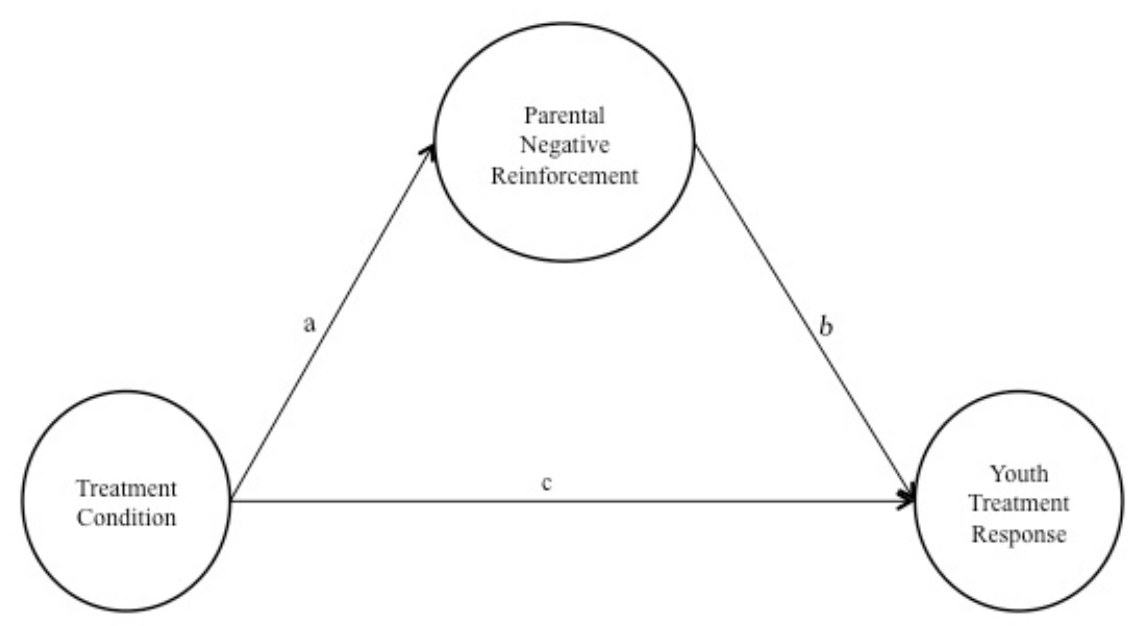




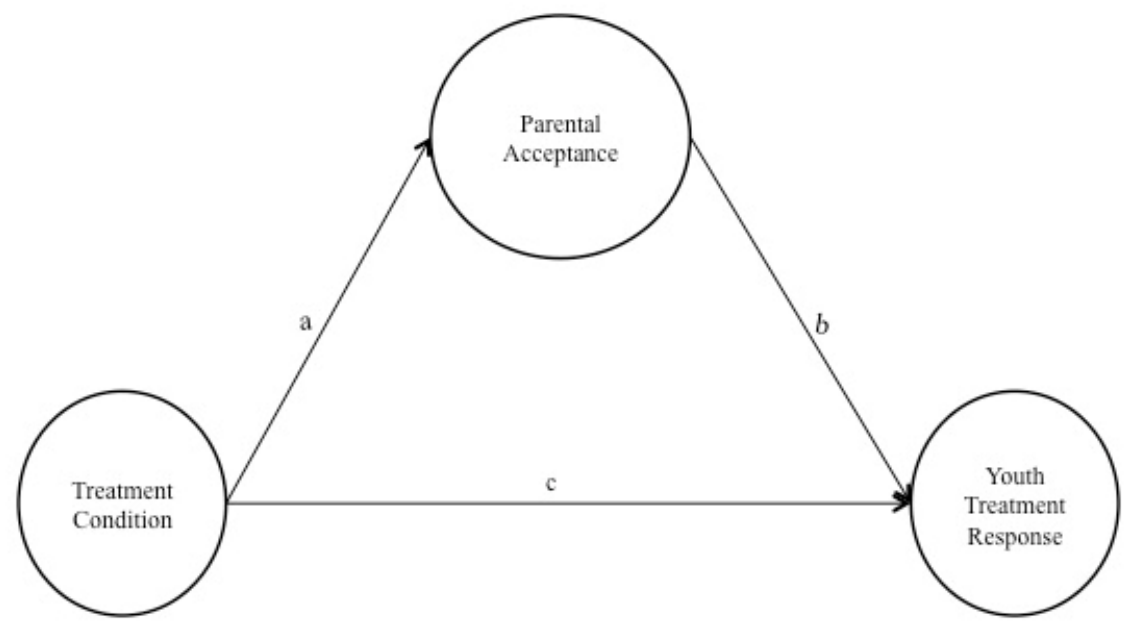




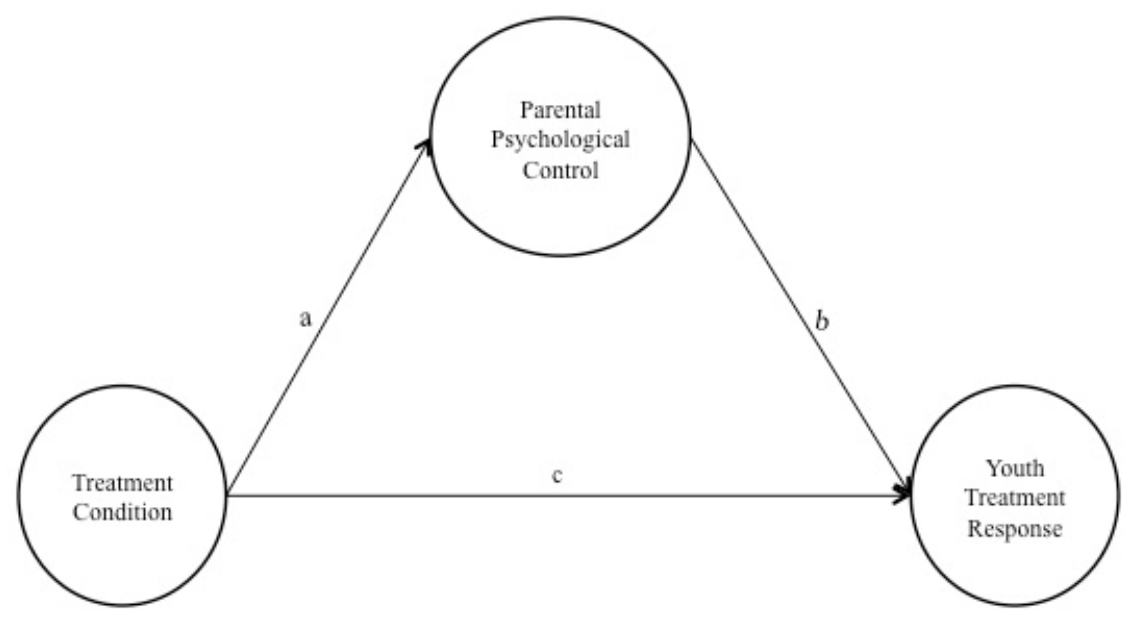


Figure 5a. CDQ-C-PR RCMAS Model with ICBT as Reference Group

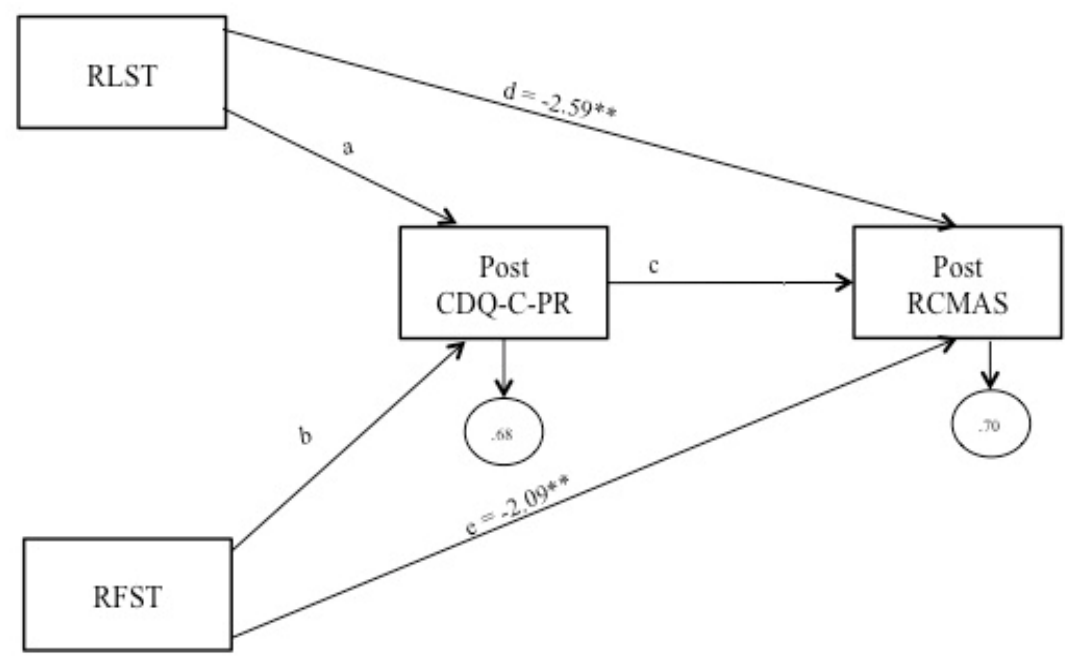

Note. ICBT (Individual Cognitive Behavior Treatment) is the reference group. RLST $=$ Parent Relationship Training. RFST $=$ Reinforcement Skills Training. CDQ-C-PR $=$ Child Report of the Child Development Questionnaire-Positive Reinforcement. RCMAS = Revised Children's Manifest Anxiety Scale. ${ }^{+*}=p<.01$ 
Figure $5 b$. CDQ-C-PR RCMAS Model with RLST as Reference Group

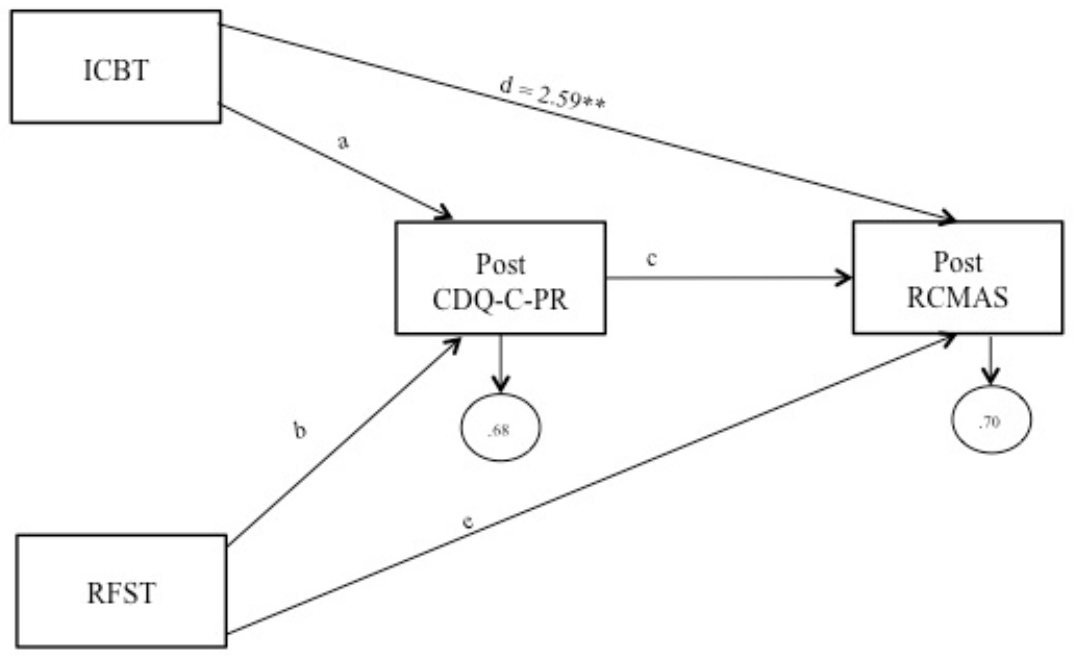

Note. RLST (Parent Relationship Training) is the reference group. ICBT = Individual Cognitive Behavior Treatment. RFST $=$ Reinforcement Skills Training. CDQ-C-PR $=$ Child Report of the Child Development Questionnaire-Positive Reinforcement. RCMAS = Revised Children's Manifest Anxiety Scale. ${ }^{\circ}=p<.01$ 
Figure 6a. CDQ-C-NR RCMAS Model with ICBT as Reference Group

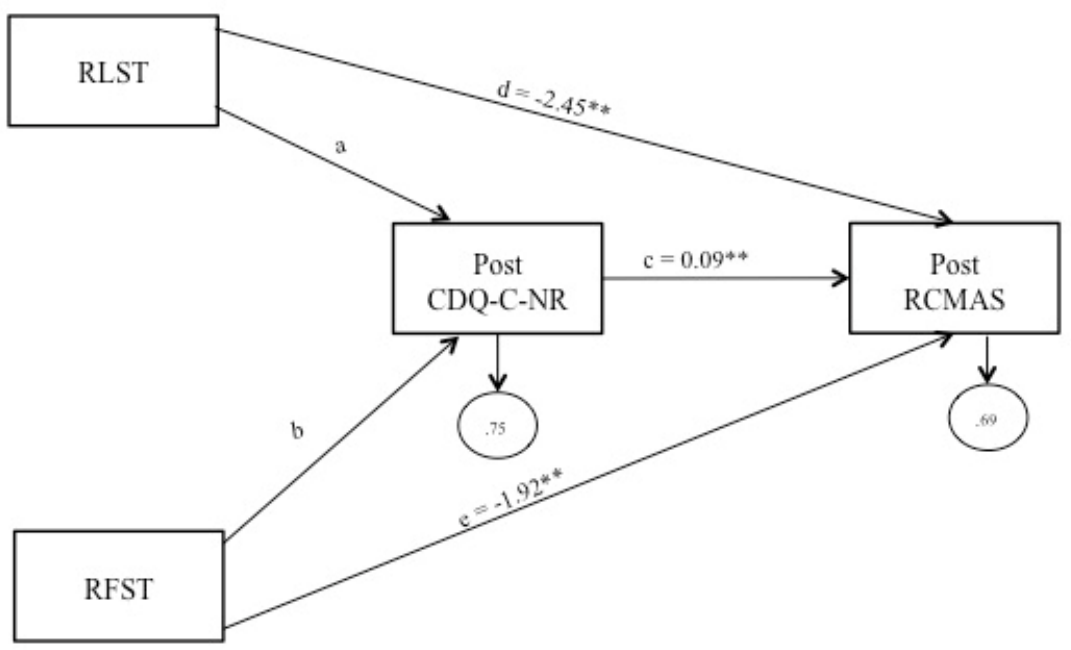

Note. ICBT (Individual Cognitive Behavior Treatment) is the reference group. RLST $=$ Parent Relationship Training. RFST $=$ Reinforcement Skills Training. CDQ-C-NR $=$ Child Report of the Child Development Questionnaire-Negative Reinforcement. RCMAS = Revised Children's Manifest Anxiety Scale. ${ }^{*+}=p<.01$ 
Figure $6 b$. CDQ-C-NR RCMAS Model with RLST as Reference Group

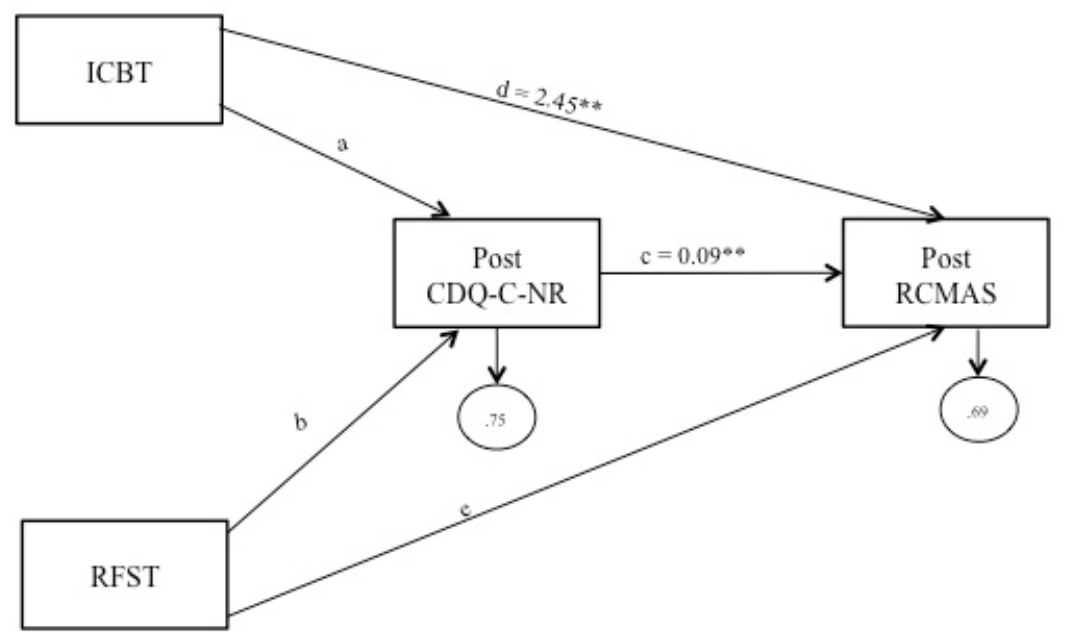

Note. RLST (Parent Relationship Training) is the reference group. ICBT = Individual Cognitive Behavior RFST $=$ Reinforcement Skills Training. CDQ-C-NR $=$ Child Report of the Child Development Questionnaire-Negative Reinforcement. RCMAS = Revised Children's Manifest Anxiety Scale. ${ }^{* *}=p<.01$ 
Figure $7 a$. CRPBI-A RCMAS Model with ICBT as Reference Group

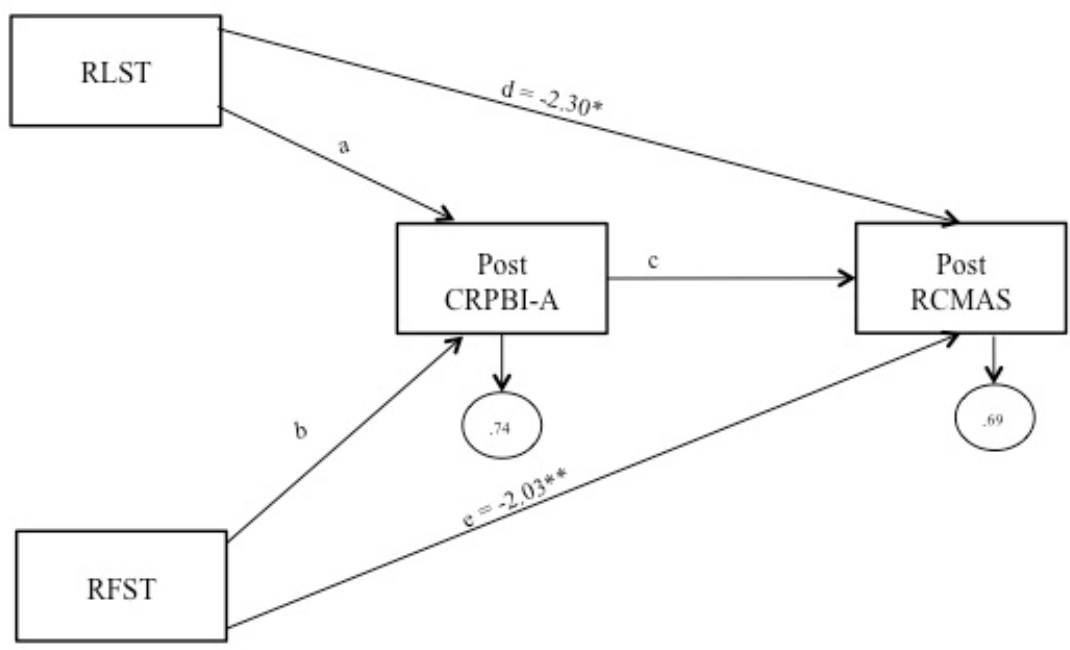

Note. ICBT (Individual Cognitive Behavior Treatment) is the reference group. RLST $=$ Parent Relationship Training. RFST $=$ Reinforcement Skills Training. CRPBI-A $=$ Child Report of the Parenting Behavior Inventory-Acceptance. RCMAS = Revised Children's Manifest Anxiety Scale. ** $=p<.01 .{ }^{*}=p<.05$ 
Figure $7 b$. CPRBI-A RCMAS Model with RLST as Reference Group

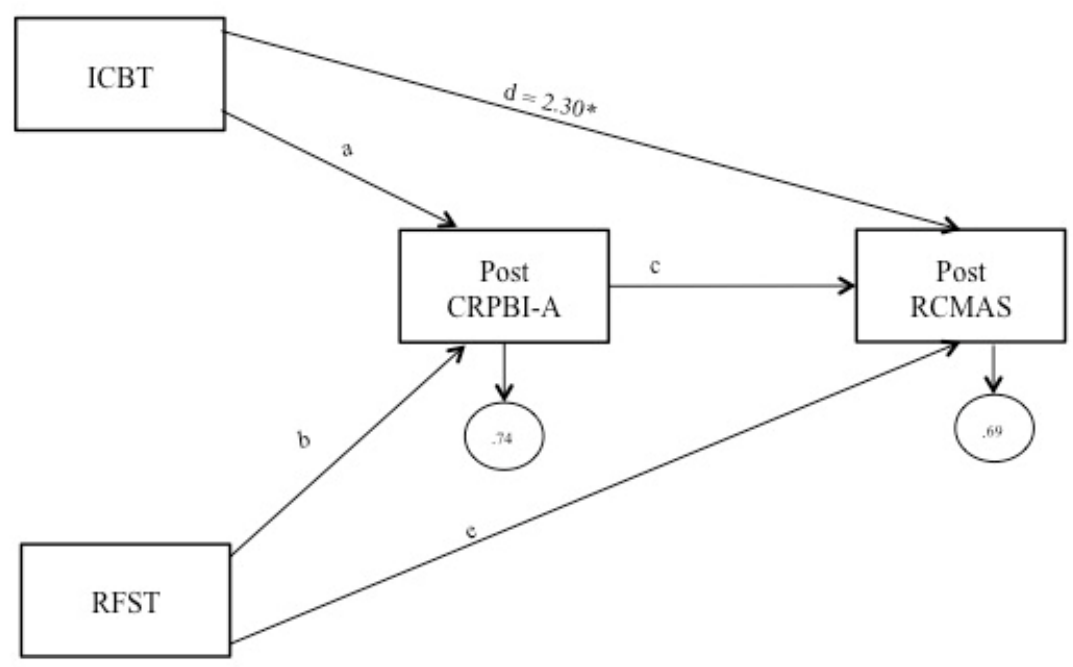

Note. RLST (Parent Relationship Training) is the reference group. ICBT $=$ Individual Cognitive Behavior Treatment. RFST $=$ Reinforcement Skills Training. CRPBI-A $=$ Child Report of the Parenting Behavior Inventory-Acceptance. RCMAS = Revised Children's Manifest Anxiety Scale. * $=p<.05$ 
Figure $8 a$. CRPBI-PC RCMAS Model with ICBT as Reference Group

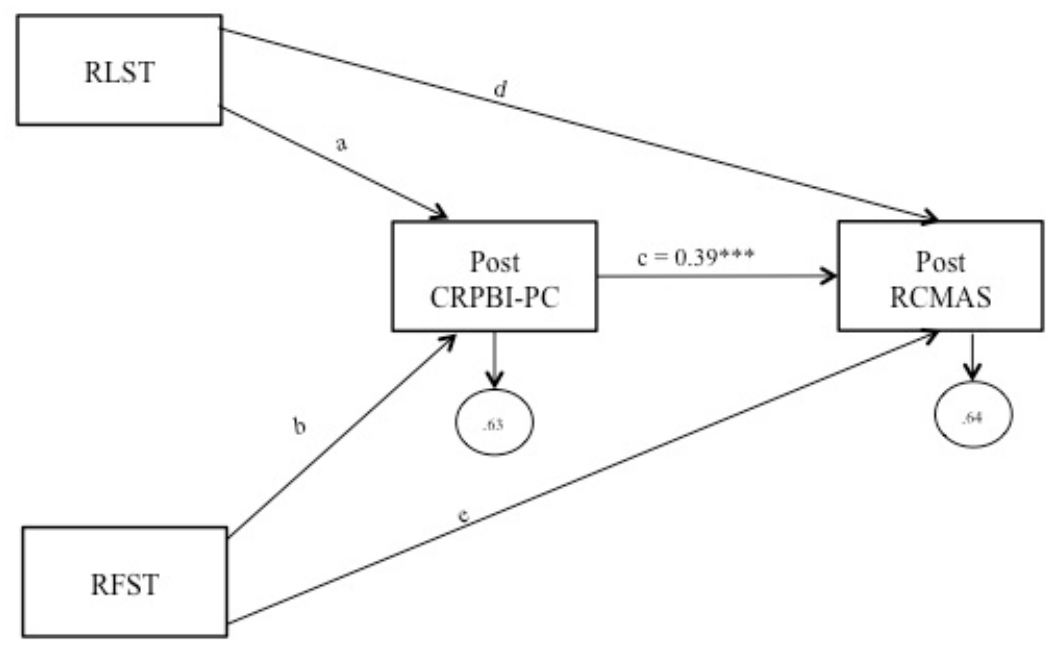

Note. ICBT (Individual Cognitive Behavior Treatment) is the reference group. RLST $=$ Parent Relationship Training. RFST $=$ Reinforcement Skills Training. $\mathrm{CRPBI}-\mathrm{PC}=$ Child Report of the Parenting Behavior Inventory-Psychological Control. RCMAS = Revised Children's Manifest Anxiety Scale. ${ }^{*+*}=p<.001$ 
Figure $8 b$. CRPBI-PC RCMAS Model with RLST as Reference Group

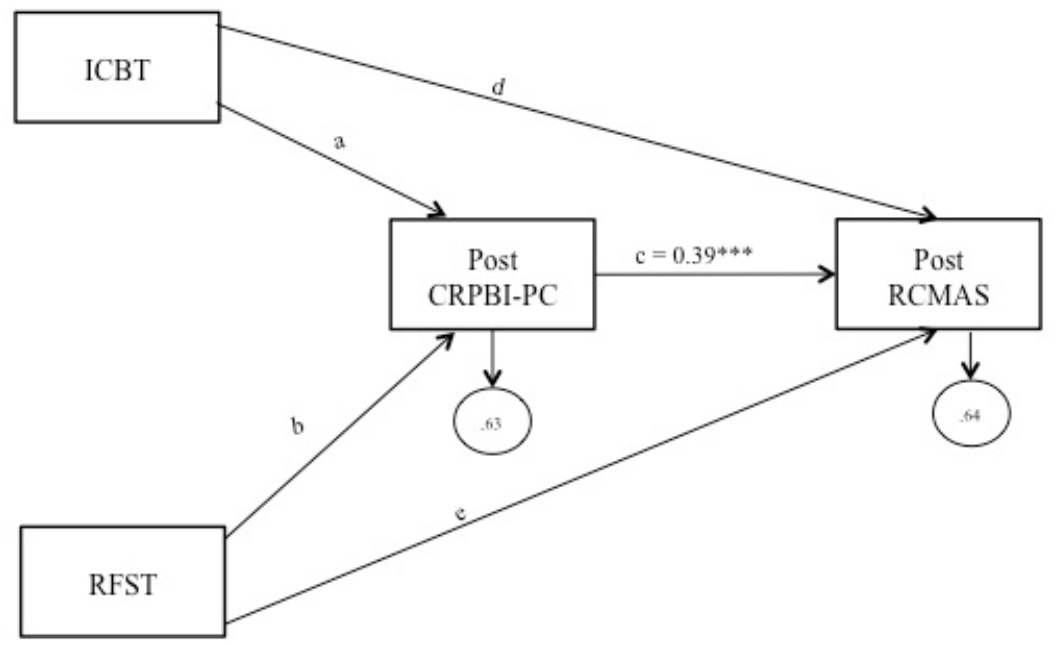

Note. RLST (Parent Relationship Training) is the reference group. ICBT $=$ Individual Cognitive Behavior Treatment. RFST $=$ Reinforcement Skills Training. CRPBI-PC $=$ Child Report of the Parenting Behavior Inventory-Psychological Control. RCMAS = Revised Children's Manifest Anxiety Scale. ${ }^{+* *}=p<.001$ 
Figure 9a. CDQ-C-PR MASC Model with ICBT as Reference Group

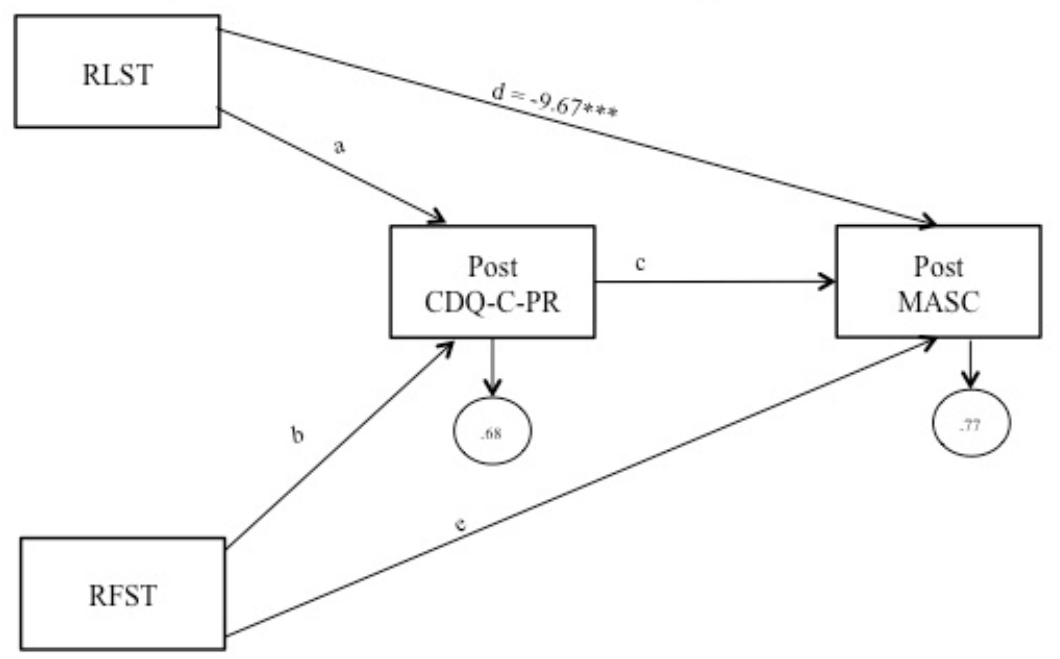

Note. ICBT (Individual Cognitive Behavior Treatment) is the reference group. RLST $=$ Parent Relationship Training. RFST = Reinforcement Skills Training. CDQ-C-PR $=$ Child Report of the Child Development Questionnaire-Positive Reinforcement. MASC $=$ Multidimensional Anxiety Scale for Children. ${ }^{\cdots \bullet}=p<.05$ 
Figure 9b. CDQ-C-PR MASC Model with RLST as Reference Group

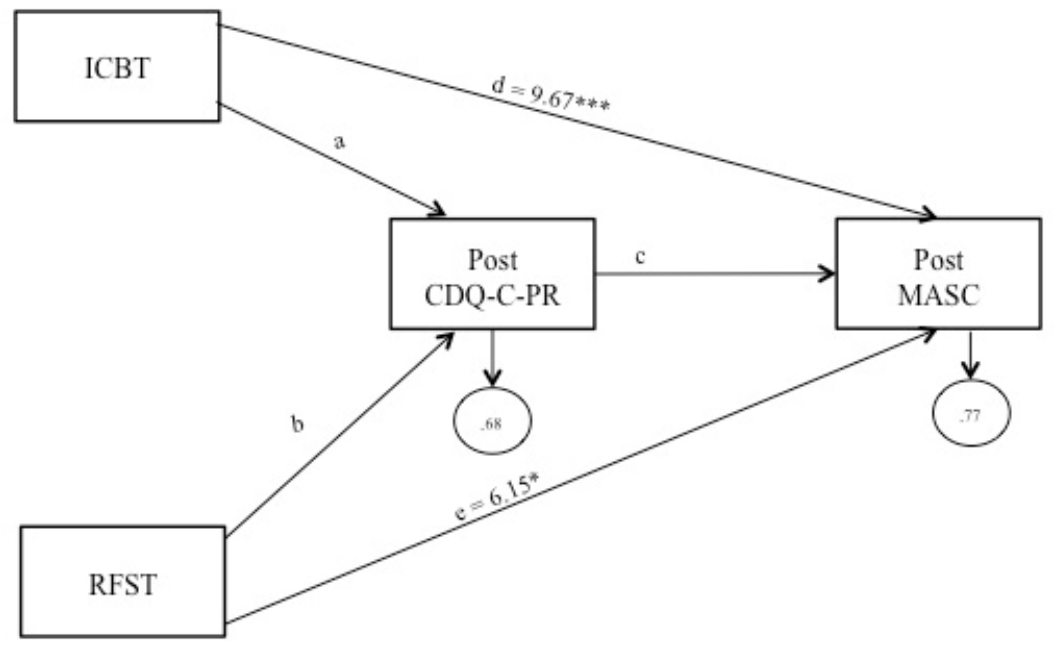

Note. RLST (Parent Relationship Training) is the reference group. ICBT = Individual Cognitive Behavior Treatment. RFST $=$ Reinforcement Skills Training. CDQ-C-PR $=$ Child Report of the Child Development Questionnaire-Positive Reinforcement. MASC $=$ Multidimensional Anxiety Scale for Children. ${ }^{\cdots}=p<.05{ }^{*}=p<.05$ 
Figure 10a. CDQ-C-NR MASC Model with ICBT as Reference Group

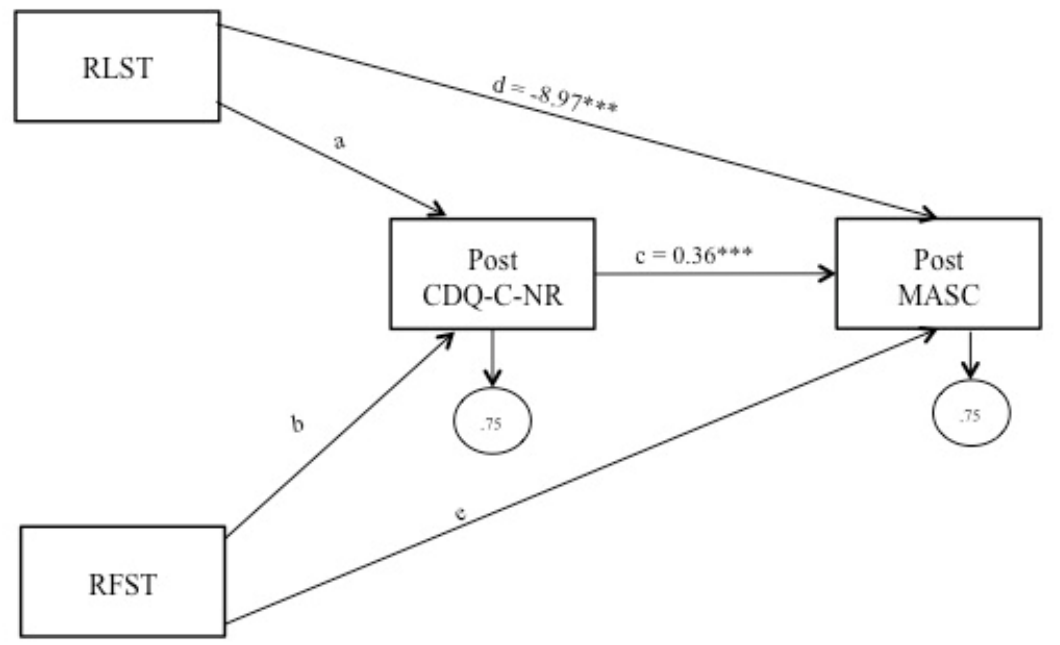

Note. ICBT (Individual Cognitive Behavior Treatment) is the reference group. RLST $=$ Parent Relationship Training. RFST $=$ Reinforcement Skills Training. CDQ-C-NR $=$ Child Report of the Child Development Questionnaire-Negative Reinforcement. MASC $=$ Multidimensional Anxiety Scale for Children. ${ }^{\cdots *}=p<.05$ 
Figure 10b. CDQ-C-NR MASC Model with RLST as Reference Group

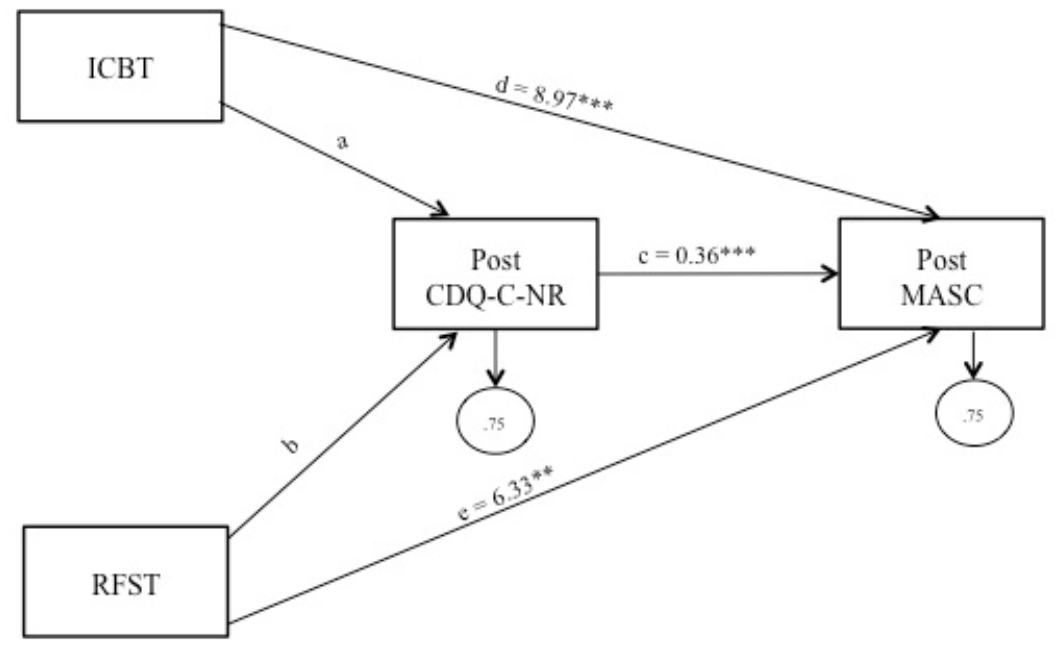

Note. RLST (Parent Relationship Training) is the reference group. ICBT = Individual Cognitive Behavior Treatment. RFST $=$ Reinforcement Skills Training. CDQ-C-NR $=$ Child Report of the Child Development Questionnaire-Negative Reinforcement. MASC $=$ Multidimensional Anxiety Scale for Children. ${ }^{\cdots *}=p<.05 .^{* *}=p<.05$ 
Figure lla. CRPBI-A MASC Model with ICBT as Reference Group

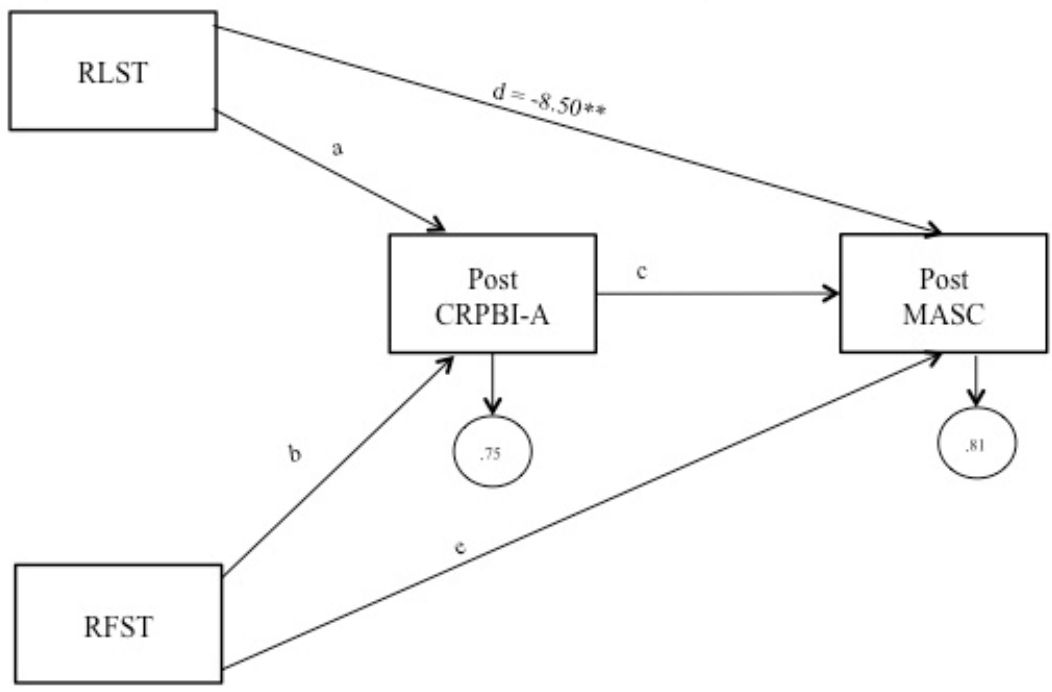

Note. ICBT (Individual Cognitive Behavior Treatment) is the reference group. RLST $=$ Parent Relationship Training. RFST $=$ Reinforcement Skills Training. CRPBI-A = Child Report of the Parenting Behavior Inventory-Acceptance. MASC $=$ Multidimensional Anxiety Scale for Children. $\cdots=p<.01$ 
Figure $11 b$. CPRBI-A MASC Model with RLST as Reference Group

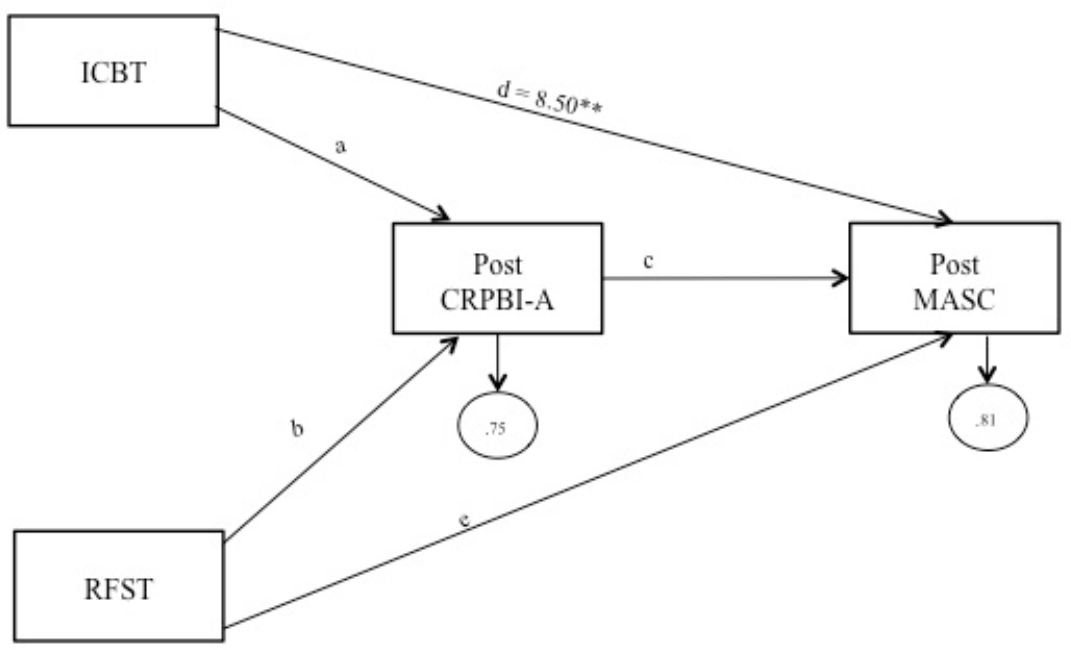

Note. RLST (Parent Relationship Training) is the reference group. ICBT $=$ Individual Cognitive Behavior Treatment. RFST $=$ Reinforcement Skills Training. CRPBI-A $=$ Child Report of the Parenting Behavior Inventory-Acceptance. MASC $=$ Multidimensional Anxiety Scale for Children. $\because=p<.01$ 
Figure 12a. CRPBI-PC MASC Model with ICBT as Reference Group

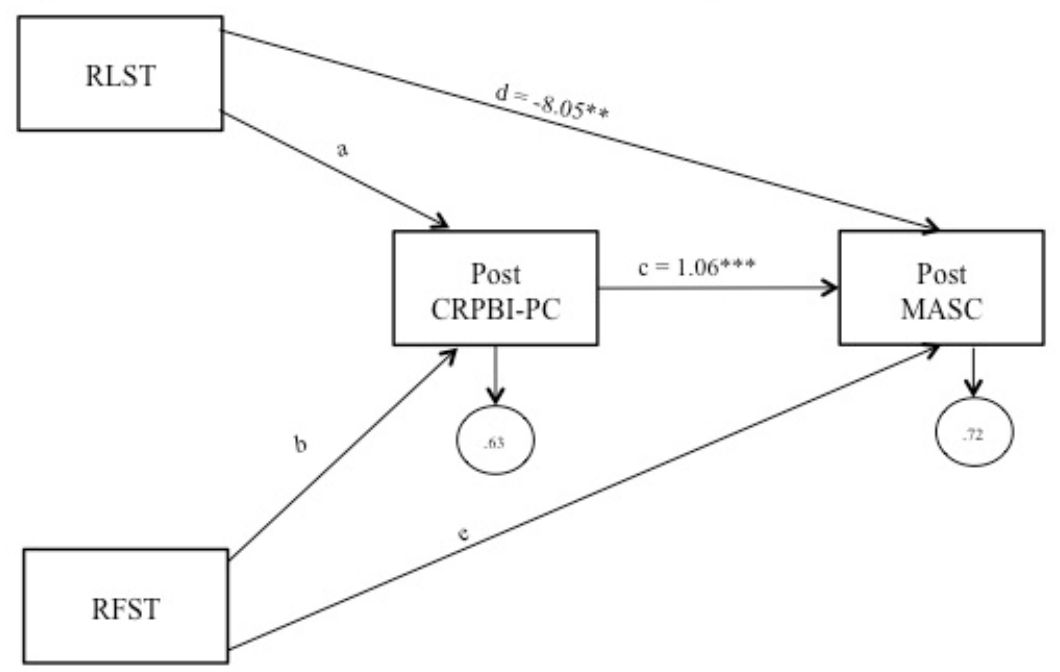

Note. ICBT (Individual Cognitive Behavior Treatment) is the reference group. RLST $=$ Parent Relationship Training. RFST $=$ Reinforcement Skills Training. CRPBI-PC $=$ Child Report of the Parenting Behavior Inventory-Psychological Control. MASC $=$ Multidimensional Anxiety Scale for Children. ${ }^{\cdots *}=p<.001{ }^{*+}=p<.01$ 
Figure 12b. CRPBI-PC MASC Model with RLST as Reference Group

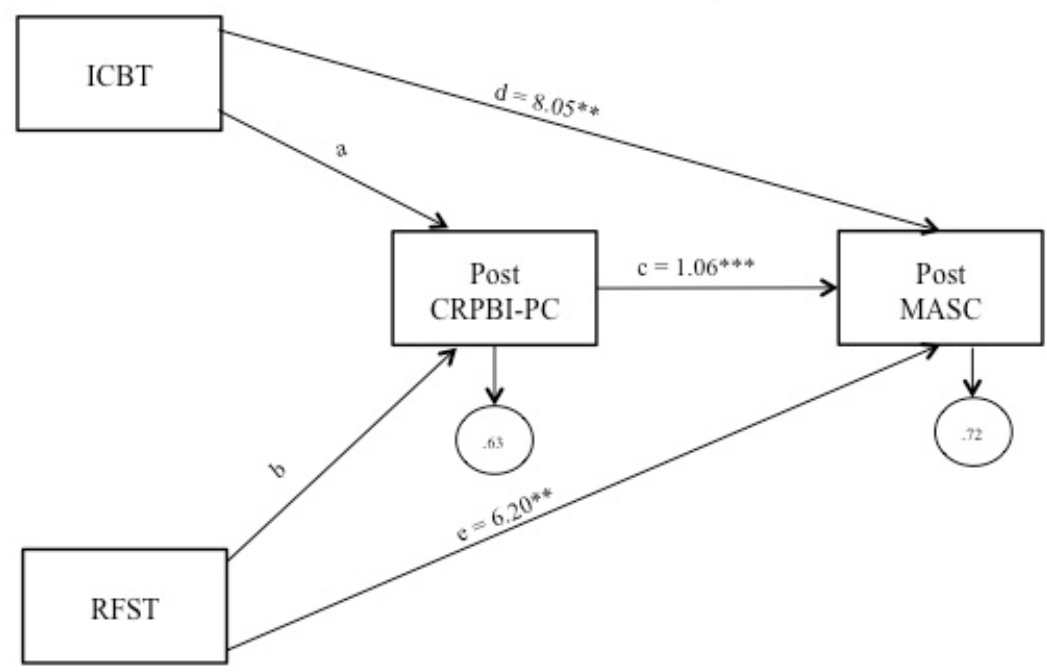

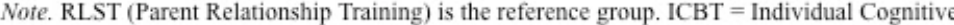
Behavior Treatment. RFST $=$ Reinforcement Skills Training. CRPBI-PC $=$ Child Report of the Parenting Behavior Inventory-Psychological Control. MASC $=$ Multidimensional Anxiety Scale for Children. ${ }^{\cdots *}=p<.001{ }^{*+}=p<.01$ 
Figure 13a. CDQ-PR RCMAS-P Model with ICBT as Reference Group

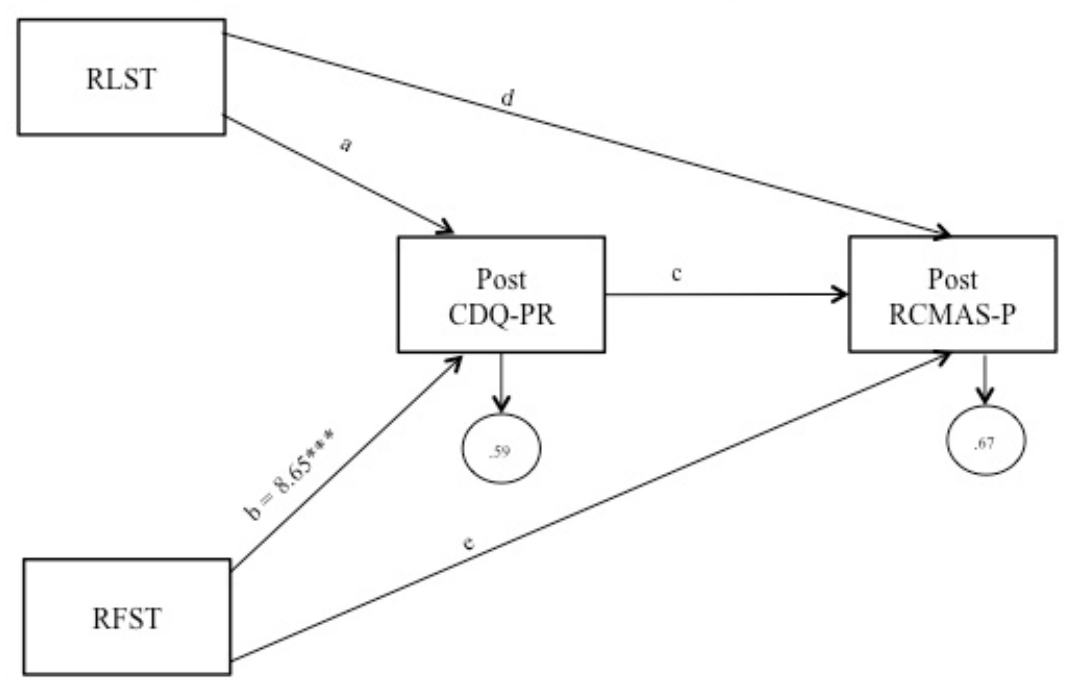

Note. ICBT (Individual Cognitive Behavior Treatment) is the reference group. RLST $=$ Parent Relationship Training. RFST $=$ Reinforcement Skills Training. CDQ-PR $=$ Parent Report of the Child Development Questionnaire-Positive Reinforcement. RCMAS-P = Revised Children's Manifest Anxiety Scale-Parent Version. ${ }^{+* *}=p<.001$ 
Figure 13b. CDQ-PR RCMAS-P Model with RLST as Reference Group

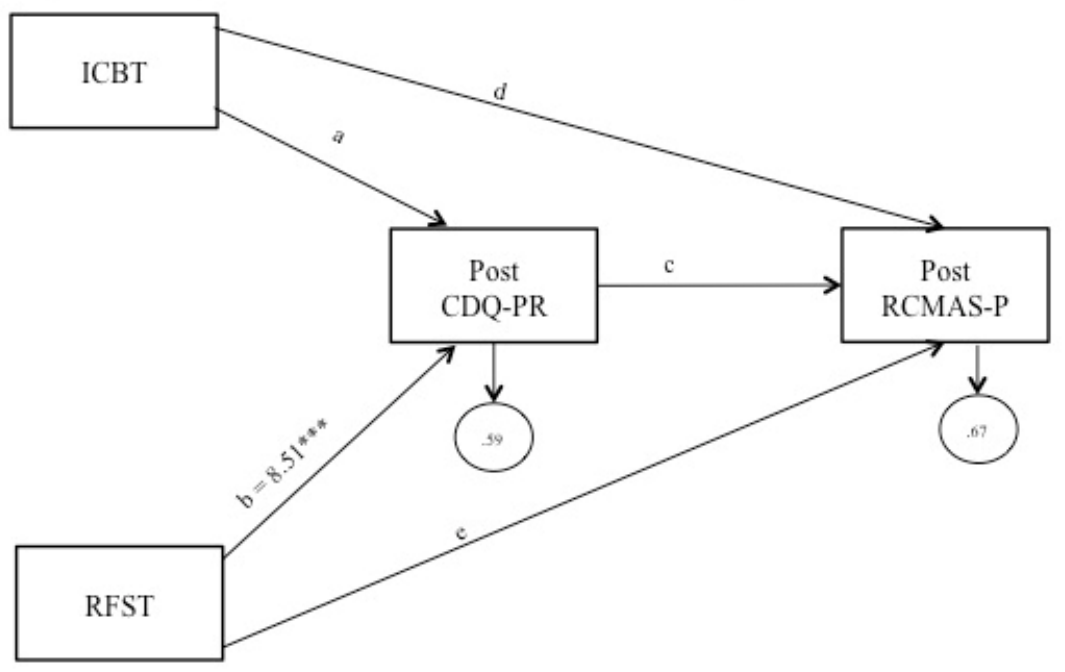

Note. RLST (Parent Relationship Training) is the reference group. ICBT = Individual Cognitive Behavior Treatment. RFST $=$ Reinforcement Skills Training. $C D Q-P R=$ Parent Report of the Child Development Questionnaire-Positive Reinforcement. RCMAS-P $=$ Revised Children's Manifest Anxiety Scale-Parent Version. ${ }^{* * *}=p<.001$ 
Figure 14a. CDQ-NR RCMAS-P Model with ICBT as Reference Group

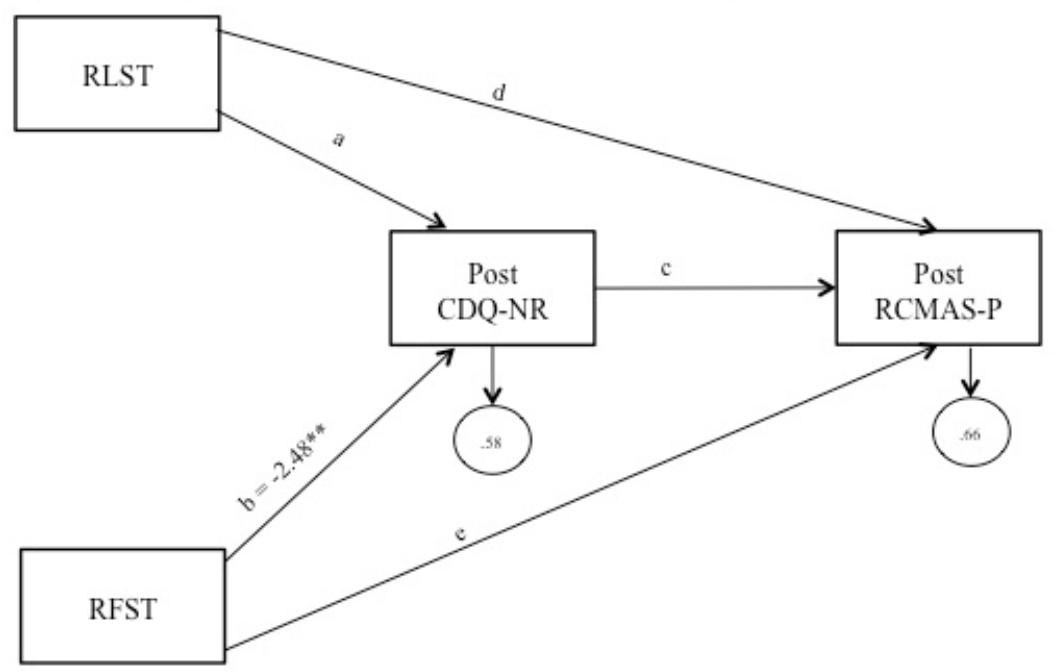

Note. ICBT (Individual Cognitive Behavior Treatment) is the reference group. RLST $=$ Parent Relationship Training. RFST $=$ Reinforcement Skills Training. CDQ-NR $=$ Parent Report of the Child Development Questionnaire-Negative Reinforcement. RCMAS-P = Revised Children's Manifest Anxiety Scale-Parent Version. ${ }^{+* *}=p<.001$ 
Figure 14b. CDQ-NR RCMAS-P Model with RLST as Reference Group

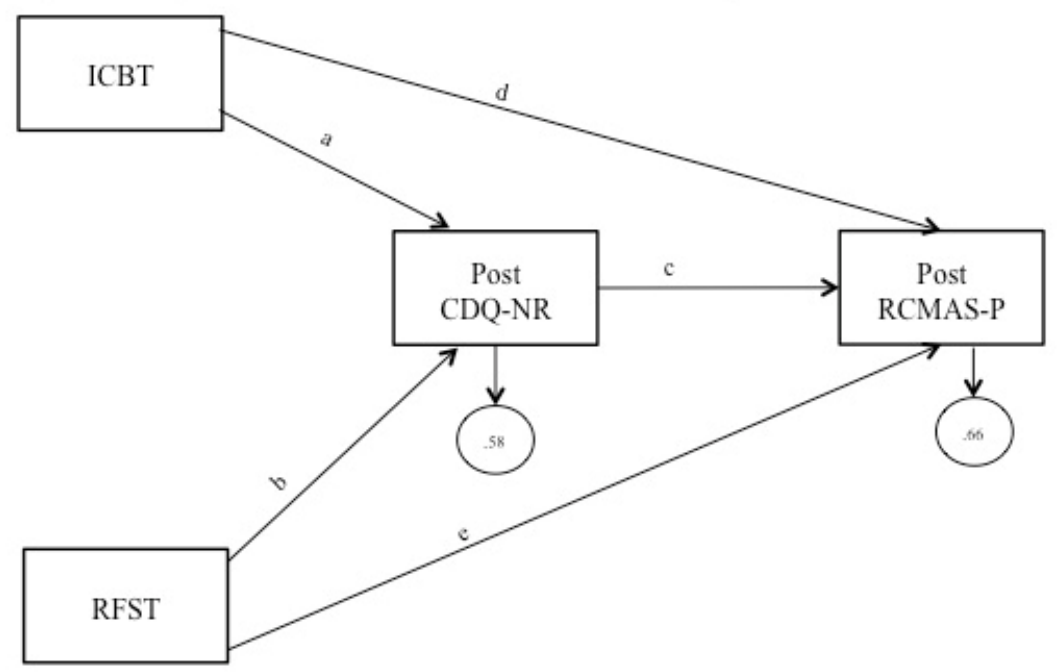

Note. RLST (Parent Relationship Training) is the reference group. ICBT = Individual Cognitive Behavior Treatment. RFST $=$ Reinforcement Skills Training. CDQ-NR = Parent Report of the Child Development Questionnaire-Negative Reinforcement. RCMAS-P = Revised Children's Manifest Anxiety Scale-Parent Version. 
Figure 15a. PRPBI-A RCMAS-P Model with ICBT as Reference Group

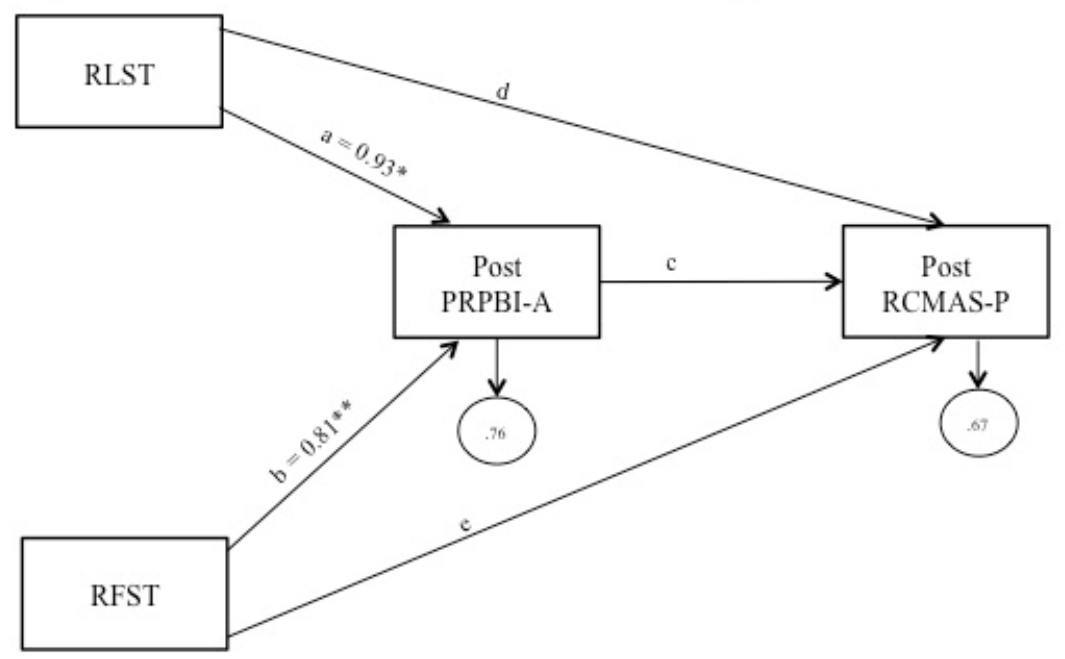

Note. ICBT (Individual Cognitive Behavior Treatment) is the reference group. $\mathrm{RLST}=\mathrm{Parent}$ Relationship Training. RFST = Reinforcement Skills Training. PRPBI-A = Parent Report of the Parenting Behavior Inventory-Acceptance. RCMAS-P = Revised Children's Manifest Anxiety ScaleParent Version. ${ }^{\circ}=p<.01 .^{*}=p<.05$ 
Figure 15b. PPRBI-A RCMAS-P Model with RLST as Reference Group

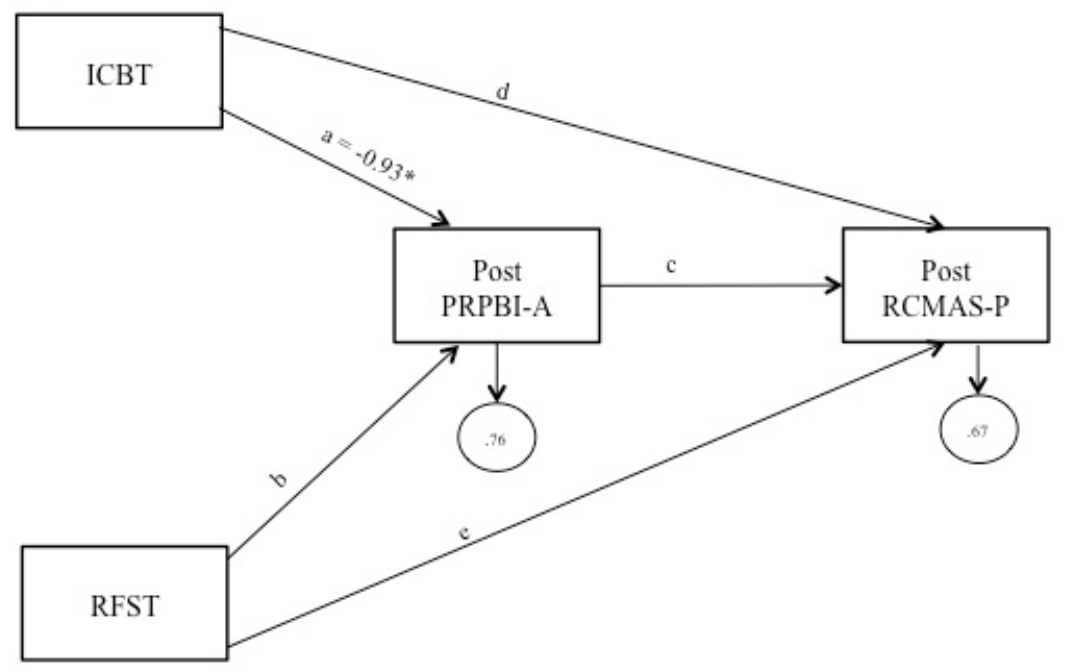

Note. RLST (Parent Relationship Training) is the reference group. ICBT = Individual Cognitive Behavior Treatment. RFST $=$ Reinforcement Skills Training. PRPBI-A = Parent Report of the Parenting Behavior Inventory-Acceptance. RCMAS-P = Revised Children's Manifest Anxiety ScaleParent Version. ${ }^{\circ}=p<.01 .{ }^{*}=p<.05$ 
Figure 16a. PRPBI-PC RCMAS-P Model with ICBT as Reference Group

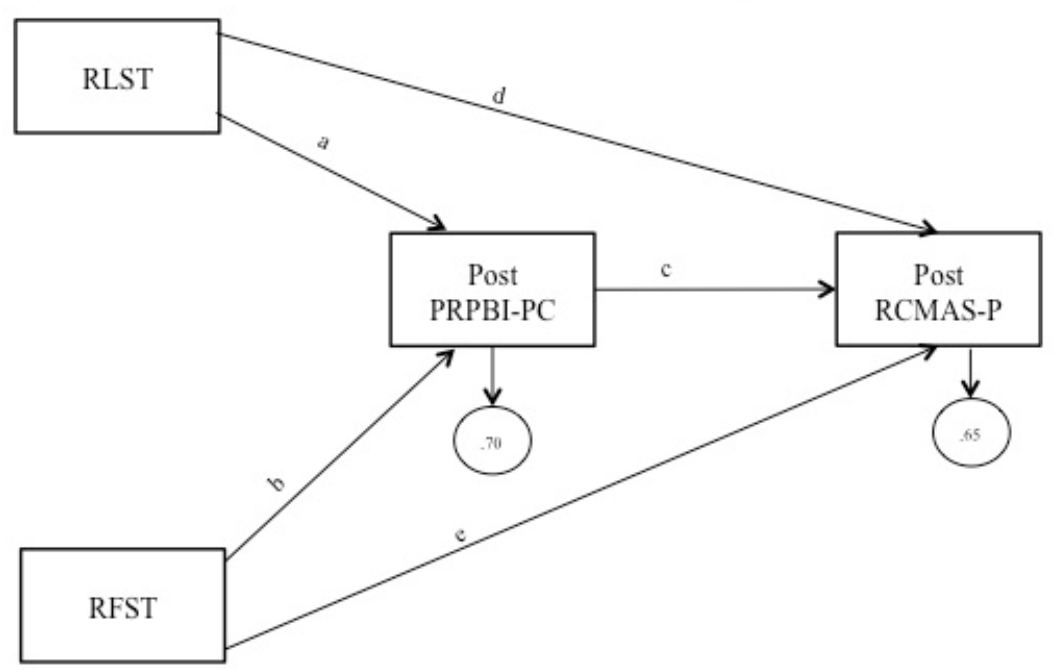

Note. ICBT (Individual Cognitive Behavior Treatment) is the reference group. RLST $=$ Parent Relationship Training. RFST $=$ Reinforcement Skills Training. PRPBI-PC $=$ Parent Report of the Parenting Behavior Inventory-Psychological Control. RCMAS-P = Revised Children's Manifest Anxiety Scale-Parent Version. 
Figure $16 b$. PRPBI-PC RCMAS-P Model with RLST as Reference Group

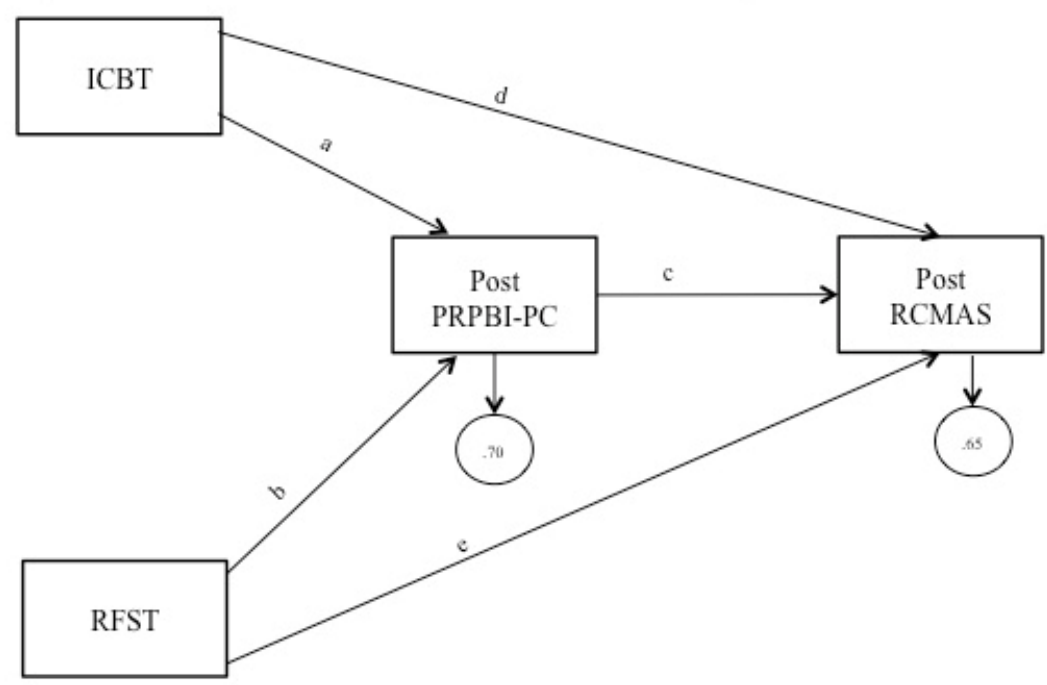

Note. RLST (Parent Relationship Training) is the reference group. ICBT = Individual Cognitive Behavior Treatment. RFST $=$ Reinforcement Skills Training. PRPBI-MA = Parent Report of the Parenting Behavior Inventory-Psychological Control. RCMAS-P = Revised Children's Manifest Anxiety Scale-Parent Version. 
VITA

\section{ILEANA HERNANDEZ}

Born, Gran Canaria, Spain

1998-2008

B.A., Psychology \& Women's Studies

Florida International University

Miami, Florida

2009-2012

M.S., Psychology

Florida International University

Miami, Florida

2012-2014

Ph.D., Psychology

Florida International University

Miami, Florida

\section{PUBLICATIONS AND PRESENTATIONS}

del Busto, C.T., Nichols-Lopez, K., Hernandez, I., Pettit, J.W., \& Silverman, W.K. (revise and resubmit). Referral source patterns for anxiety concerns in a clinically referred sample of Hispanic-Latino children: The role of parental sociocultural and psychopathological factors and child phenomenology.

Hernandez, I., Marin, C.E., Rey, Y., del Busto, C.T., Pettit, J., \& Silverman, W.K. (in preparation). The mediation effects of maternal psychological control on the relation between maternal acculturation and youth anxiety.

del Busto, C.T., Marin, C.E., Hernandez, I., Rey, Y., \& Silverman, W.K. (in preparation). Comparison of Standard- and Culturally-Adapted CBT for Selective Mutism: Two Case Studies.

del Busto, C.T., Rey, Y., Marin, C. E., Hernandez, I., Silverman, W. K., \& Pettit, J. W. (2013, November). Selective Mutism and Social Phobia: A first at look the cultural context in a clinic referred sample of anxious Hispanic children. Poster presented at the annual conference of the Association for Behavioral and Cognitive Therapies, Nashville, TN.

Marin, C. E., Rey, Y., Pienkowski, M., Hernandez, I., Dahan, J., \& Silverman, W. K. (2013, April). Parenting behaviors as mediators of the relation between maternal anxiety and youth anxiety. In R. Carter (Chair), Contextual influences in childhood anxiety. Symposium presented at the biennial convention of the Society for Research in Child Development, Seattle, WA. 
Marin, C. E., Rey, Y., Motoca, L., Pienkowski, M., Dahan, J., Hernandez, I., del Busto, C.T., \& Silverman, W.K. (2013, March). Directionality of peer influence on childhood anxiety treatment outcome. Symposium presented at the annual Anxiety and Depression Conference, Chicago, IL.

Motoca, L. M., Hernandez, I., Pienkowski, M., Dahan, J., \& Silverman, W. K. (2012, April). Using behavior observation tasks to assess parenting behaviors in a clinic referred sample of anxious children and adolescents. In Fox, J. K. (Chair), Early intervention of internalizing disorders: The current state of family-based approaches. Symposium presented at the annual conference of the Anxiety Disorders Association of America, Arlington, VA.

del Busto, C.T., Hernandez, I., \& Silverman, W. K. (2011, November). Examining culture as it relates to the clinical presentation of anxiety-disordered youth by referral source. Poster presented at the annual conference of the Association for Behavioral and Cognitive Therapies, Toronto, Canada.

Motoca, L. M., Hernandez, I., Pienkowski, M., Dahan, J., \& Silverman, W. K. (2011, November). Using behavioral observation tasks to directly assess parenting behaviors in a clinic referred sample of children and adolescents. Poster presented at the annual conference of the Association for Behavioral and Cognitive Therapies, Toronto, Canada.

Hernandez, I., Marin, C. E., \& Silverman, W. K. (2011, August). Maternal psychological control as a mediator of maternal acculturation and youth anxiety in a sample of Hispanic-Latino youth. Poster presented at the annual conference of the American Psychological Association, Washington, D.C.

Marin, C. E., Hernandez, I., Rey, Y., Nichols-Lopez, K., \& Silverman, W. K. (2008, November). Maternal psychological control and acculturation in relation to anxiety symptoms in Hispanic-Latino youth. Poster presented at the Association for Behavioral and Cognitive Therapies Convention, Orlando, FL.

Pienkowski, M., Gray. C., Hernandez, I., Sangiovanni, P., Alonso, A., Carter, R., \& Silverman,W.K. (2008, March). Overdue for a reconceptualization of the test anxiety construct in elementary schools: A new approach to identifying children at risk for anxiety disorders. Poster presented at the Anxiety Disorders Association of America Convention, Savannah, GA. 